\title{
2. Kontrolle, „Säuberung“ und wirtschaftliche mainmise
}

\subsection{Organisation des Theater- und Filmbetriebs}

Während der dreißiger Jahre hatte der französische Staat kaum in die Organisation der Filmbranche und noch weniger in jene des Theaterbetriebes eingegriffen. So existierten beispielsweise in beiden Bereichen keine übergeordneten Berufsorganisationen ${ }^{250}$. Insbesondere die französische Filmindustrie befand sich gleichsam in einem Zustand der Anarchie. Sie war weder wie in den westlichen Demokratien, den USA und England, selbständig zu einer eigenen Reglementierung gelangt, noch war ihr wie in Deutschland, Italien und der Sowjetunion eine Organisation staatlich auferlegt worden ${ }^{251}$. Diese Situation änderte sich während der Okkupation, die zu grundlegenden Eingriffen des französischen Staates in den Bereichen der Wirtschaft, des sozialen und auch des kulturellen Lebens führte ${ }^{252}$. Neben einem mehr oder weniger stark ausgeprägten Ordnungswillen der deutschen Dienststellen waren hierfür hauptsächlich zwei Faktoren verantwortlich: Zum einen machte die wirtschaftliche Ausbeutung des Landes durch die Besatzungsmacht sowie die damit verbundene Knappheit an Materialien und Rohstoffen eine verstärkte Organisation notwendig, zum anderen war diese Politik Teil der Ideologie des autoritären Vichy-Regimes. Nach der Devise „Arbeit, Familie, Vaterland“, verfolgte dieses eine Révolution nationale, eine nationale wie soziale Erneuerung des französischen Staates. Wichtige Funktionsträger um Pétain waren Militärs und Technokraten, die zumeist aus den Reihen der rechtsextremem Action Française stammten ${ }^{253}$.

Wenige Monate nach Beginn der Besatzung traf die Vichy-Regierung die ersten Maßnahmen zu einer neuen korporativen Organisation sämtlicher Industrie- und Handelszweige, mit der sie die Position der größeren Unternehmen und der Arbeitgeber konsolidieren wollte. Durch das Gesetz vom 16. August 1940 (Loi concernant l'organisation provisoire de la production industrielle) griff der Staat wesentlich in die Angelegenheiten der französischen Wirtschaft ein. In sämtlichen Branchen, also auch in der Filmindustrie, sollten in Zukunft Berufsorganisationen, die Comités d'organisation, gebildet werden, an deren Führung die Vertreter der wichtigsten Firmen der je-

250 BerTin-MAGHIT, Le Cinéma sous l'Occupation, S. 18f. AdDED, Le Théâtre, S. 141. 251 BerTin-Maghit, Le Cinéma sous l'Occupation, S. 18.

252 Henri Rousso, L'impact du régime sur la société: ses dimensions et ses limites, in: AZEMA, BEDARIDA, Vichy, S. 573-600.

253 Ibid. S. 577; zu Vichy und der Révolution nationale siehe Olivier WIEvIORKA, Vichy 1940-1944, Paris 1997; Olivier WORMSER, Les Origines doctrinales de la Révolution nationale (Vichy 10 juillet 1940 - 31 mars 1941, Paris 1971; GuILlON, La philosophie politique, in: AZEMA, BEDARIDA, Vichy, S. 167-183; Gérard BRUN, Technocrates et technocratie en France, 1918-1945, Paris 1985; siehe auch die Studie von PAXTON, La France de Vichy; ebenso die Untersuchun von COINTET-LABROUSSE, Vichy et le fascisme. 
weiligen Wirtschaftszweige zu beteiligen waren ${ }^{254}$. Dieses Gesetz war zunächst Anlaß einer ersten Machtdemonstration von seiten der Besatzungsmacht. Da die Vichy-Regierung trotz der Demarkationslinie die Verwaltungseinheit und somit die juristische Einheit des Landes aufrechterhalten wollte, verzichtete sie generell darauf, etwa nur für die unbesetzte Zone eine offizielle Gesetzgebung zu verabschieden. Stattdessen nahm sie in Kauf, daß der MBF sämtliche Gesetze kontrollierte; diese besaßen in beiden Zonen Gültigkeit. Strittig war jedoch zunächst der Zeitpunkt der Kontrolle. Der Miltärbefehlshaber bestand darauf, daß ihm die Gesetze bereits vor ihrer Publikation im Journal Officiel (J.O.) vorgelegt würden. Das Vorhaben der französischen Regierung, das obige Gesetz vom 16. August erst anschließend dem MBF zu übermitteln, scheiterte an einem Ultimatum desselben. Der MBF kontrollierte nun faktisch die französische Gesetzgebung für beide Zonen 255 .

Sowohl im Bereich des Theaters als auch in dem des Films gingen die ersten Initiativen zu einer Organisation zunächst von deutscher Seite aus. Bereits im Juli 1940 wurden auf Initiative Diedrichs, dem Leiter des Referats Film der Propaganda Abteilung, für die ZO zunächst sechs korporative Gruppierungen gebildet. An deren Spitze standen Vertreter der jeweiligen Zweige, wie etwa des Filmvertriebs und der filmtechnischen Industrie. Diese Persönlichkeiten waren zumeist bereits während der dreißiger Jahre mit der deutschen Filmindustrie in Kontakt gewesen und dienten nun gleichsam als Mittelsmänner zwischen den einzelnen Groupements und den Untergruppen des Referats Film ${ }^{256}$. Beispielsweise leiteten sie die Anträge auf Wiedereröffnung von Filmvertriebsfirmen und Filmtheatern an das Referat weiter 257 . Eine französische Studie zur Lage der Filmindustrie im September 1940 bezweifelt die Unabhängigkeit der Vertreter dieser Groupements und empfiehlt dringend, von seiten der Vichy-Regierung auf eine eigene Neuorganisation der Filmbranche zu drängen, um den deutschen Einfluß in diesem Bereich einzudämmen. Diese Studie verwies zudem neben der Bedeutung des Filmes als Propagandainstrument erneut ausführlich auf die Mängel der französischen Filmindustrie während der dreißiger Jahre hin und betonte die Wichtigkeit einer Neuordnung 258 .

254 Michel Margairaz, L'État et la décision économique, in: AzÉMA, BÉDarida,Vichy, S. 329-344; zudem wurden die Gewerkschaften aufgelöst und mit der Charte du travail im Oktober 1941 ein offizieller, staatlicher Syndikalismus ins Leben gerufen.

255 BARUCH, Servir, S. $71 \mathrm{f}$.

256 Zur Organisation der französischen Filmbranche siehe BERTIN-MaGHIT, Le Cinéma sous l'Occupation, S. 34-69; auch allg. LÉGLISE, Histoire, Bd. 2; zu den Vertretern der Groupements gehörten André Debrie als Vertreter der filmtechnischen Industrie, Adolphe Trichet für die Filmtheaterbesitzer, Jean Bachelet für die techniciens d'art, Jean Galland für die Schauspieler, M. Caval für den Filmvertrieb (BERTIN-MAGHIT, Le Cinéma sous l'Occupation, S. 291.).

257 AN, AJ40 1001, Prop.Abt., Tätigkeitsbericht, 7. 10.-13. 10. 1940.

258 Siehe die umfangreiche Studie zur Situation des französischen Kinos im September 
Erst nach langen Verhandlungen mit Diedrich gelang es den Vertretern der Vichy-Regierung, die Groupements corporatifs durch eine andere Organisation zu ersetzen. Mit einer Verordnung vom 2. Dezember 1940 wurde schließlich das bereits erwähnte COIC, das Comité d'organisation de l'industrie cinématographique, gegründet, welches die Angehörigen sämtlicher Professionen im Bereich des Filmes organisierte ${ }^{259}$. Zu den Hauptaufgaben des COIC gehörten die Reorganisation und Reglementierung der Branche sowie deren „moralische Gesundung“. Außerdem sollte die Wiederaufnahme der Filmproduktion sichergestellt werden. Seine Kompetenzen erstreckten sich auf ganz Frankreich, was das Streben Vichys nach der Aufrechterhaltung eines einheitlichen französischen Filmmarktes zum Ausdruck brachte. Innerhalb des COIC waren die verschiedenen Berufsgruppen durch zwanzig Repräsentanten in einer Commission consultative vertreten. Die Rolle dieser Kommission war in der Praxis jedoch ausgesprochen gering und in der Folge vermochten die Vertreter der Berufsgruppen kaum Einfluß auf die Politik des COIC zu nehmen. Geführt wurde die Berufsorganisation von einem mehrköpfigen Comité de direction, an dessen Spitze der Leiter des COIC stand. Auf Diedrichs Wunsch hin wurden die von ihm ins Leben gerufenen Groupements corporatifs in den COIC in Form von mehreren Groupements d'exécution integriert. Diese sollten in ihrem jeweiligen Sektor die Ausführung der vom COIC getroffenen Maßnahmen überwachen und dem COIC über Probleme innerhalb der Branche zu berichten. Um die $\mathrm{Zu}$ stimmung Diedrichs zur Bildung des COIC zu verstärken, übernahm es zudem alle Repräsentanten der alten Groupements.

Weder die Vertreter der Commission consultative noch die Posten innerhalb des Comité de direction wurden von den Angehörigen der einzelnen Professionen gewählt, was deutlich macht, wie wenig es sich hier tatsächlich um eine unabhängige Berufsorganisation handelte. Alle Persönlichkeiten wurden vom Regierungsbeauftragten für Filmfragen in Paris, dem Leiter des Service du cinéma, vorgeschlagen und für ihre Posten von dem für Information zuständigen Minister besetzt. Der Service du Cinéma unterstand direkt dem Secrétariat général à l'Information, dem Generalsekretariat für Information in Vichy, das im Frühjahr 1941 zum Secrétariat de l'Information et de la Propagande wurde. Zu Beginn der Besatzung wurde Jean-Louis Tixier-Vignancour als Secrétaire général adjoint à l'Information mit den Bereichen Film und Rundfunk betraut ${ }^{260}$. In seinen Kompetenzbereich fielen nun Auf-

1940 mit einem Rückblick auf die dreißiger Jahre: AN, F60 1487, S.E.R.C., Paveau an de Brinon, DGTO, Reprise de l'industrie cinématographique en France, Etude, Paris, 5. 9.1940.

${ }^{259} \mathrm{Zu}$ Aufbau und Aufgaben des COIC siehe auch die ausführliche Aufstellung in BAMA, RW35 224, Prop.Abt., Ref.Film, Tätigkeitsbericht, 10. 10.-17. 10. 1941.

260 Der noch junge Jurist hatte während der dreißiger Jahre mit rechtsextremistischen Bewegungen sympathisiert. Er war ein Freund Jacques Doriots und wurde in Vichy 
gaben, die während der dreißiger Jahre von sieben verschiedenen Ministerien wahrgenommen worden waren, was erheblich zum Scheitern der vorherigen Reorganisationsversuche beigetragen hatte.

Der Leiter des Service du cinéma sollte als Vetreter der Vichy-Regierung in Paris bei den Verhandlungen über die französische Filmwirtschaft wichtigster Ansprechpartner für die Besatzungsmacht sein. Zudem war seine Nominierung ein Versuch der Regierung, die eigenen Interessen im Filmbereich effektiver wahrzunehmen, zumal ein Großteil der wichtigsten Akteure der Filmbranche auch weiterhin in der französischen Hauptstadt lebte. Pierre Laval, Pétains Stellvertreter, betraute zunächst Guy de Carmoy mit dem Posten des Leiters des Service du cinéma. De Carmoy hatte während der dreißiger Jahre eine Studie zur Reorganisation der französischen Filmbranche erstellt und unter seinen Reformvorschlägen hatte sich bereits zu diesem Zeitpunkt die Gründung einer dem COIC entsprechenden Berufsorganisation befunden ${ }^{261}$. Als Leiter des Service du cinéma kam ihm generell eher eine planende Funktion zu. Vor allem hatte er den Standpunkt der Regierung zu vertreten und gegenüber den Entscheidungen des COIC besaß er ein Vetorecht. Das COIC wiederum war als ausführendes Organ gedacht und eigentlich eine reine Berufsorganisation. Allerdings waren die Kompetenzen zwischen beiden Stellen nicht eindeutig abgegrenzt. Das COIC war durch den Service du cinéma eng mit dem Staat verbunden. Diese Konstellation machte, so Bertin-Maghit, aus dem Filmwesen eine Art öffentlichen Dienst, den das VichyRegime zur Verbreitung seiner Ideen und somit als Propagandainstrument, nutzen wollte. Aus diesem Grunde war die Regierung besonders daran interessiert, den Filmbetrieb zu organisieren und ihn unter staatliche Kontrolle zu bringen. So förderte Vichy in der Folge beispielsweise propagandistische Spiel- und Kurzfilme, die films d'intérêt national ${ }^{262}$. Außerdem war Vichy an einer möglichst guten Reputation des französischen Filmes interessiert.

Daß die Einflußnahme der deutschen Dienststellen auf die Besetzung verantwortlicher Positionen innerhalb der französischen Filmorganisation auch indirekt geschehen konnte, zeigt das Beispiel Raoul Ploquins. Im Sommer 1940 hatte de Carmoy ihn als Leiter des COIC vorgeschlagen. De Carmoy erinnert sich an die Gründe hierfür:

Raoul Ploquin offrait l'avantage d'avoir longtemps travaillé avec l'industrie allemande, et par conséquent il avait une connaissance de l'allemand très supérieure a la mienne. Il avait été à Berlin où il avait travaillé dans l'industrie du film. Il était donc connu des per-

Vertreter von dessen Parti populaire français (PPF); siehe Bertin-MAGHIT, Le Cinéma sous l'Occupation, S. 35.

${ }^{261}$ AN, F 60 303, Présidence du Conseil, Conseil national économique, l'industrie cinématographique, Conclusions adoptées par le Conseil national économique dans sa session du 17. 7. 1936 et rapport presenté par M. de Carmoy, inspecteur des finances. 262 Bertin-Maghit, Le Cinéma sous l'Occupation, S. 60, 134-143; siehe auch die Untersuchung von GARÇON, De Blum. 
sonnalités allemandes du cinéma et son nom a été accepté par la Propaganda Abteilung ${ }^{263}$.

Ploquin war in den dreißiger Jahren in Berlin bei der Ufa für deutsch-französische Koproduktionen zuständig gewesen und besaß gute Kontakte zur deutschen Filmindustrie ${ }^{264}$. So erschien er als ideale Besetzung für die Leitung des COIC, denn immerhin war dieses laufend auf die Zusammenarbeit mit dem MBF, also dem Referat Film der Propaganda Abteilung, angewiesen. Für sämtliche Gesetzesvorlagen oder Maßnahmen war die Zustimmung des MBF notwendig. In der Praxis stimmte Ploquin, wie die Tätigkeitsberichte des Referats Film zeigen, in der Regel sämtliche Schritte vorher mit diesem $a b$, um ein nachträgliches Veto von deutscher Seite zu vermeiden. Einmal wöchentlich fand er sich zu Besprechungen mit Greven, Diedrich und manchmal auch mit Vertretern der deutschen Filmverleihfirmen Ufa/ACE und Tobis beim Referat Film ein; auch de Carmoy und später dessen Nachfolger Louis-Émile Galey waren hier anwesend. Im Frühjahr 1942 trat Ploquin schließlich zurück, da sich sein Verhältnis zu Greven mehr und mehr verschlechtert hatte. Ab Mai 1942 wurde das COIC von einem Comité directeur, bestehend aus drei Mitgliedern, geführt: Es waren André Debrie, Marcel Achard und Roger Richebé265.

Die Besatzungsmacht ließ während der ersten Verhandlungen über die Reorganisation des Filmbetriebes, die verzögerte Wiederaufnahme der Filmproduktion und über die Gründung einer deutsch-französischen Wochenschau keinen Zweifel daran, wie stark ihr Interesse an einer Ausnutzung und Kontrolle der französischen Filmindustrie war. Angesichts der von deutscher Seite so deutlich vertretenen Interessen, versuchten de Carmoy und TixierVignancour, die Interessen der französischen Regierung soweit als möglich durch einen Kollaborationskurs zu wahren. So berichtete das Referat Film beispielsweise im November 1940 über Verhandlungen Diedrichs mit de Carmoy, es herrsche nun auf beiden Seiten Einigkeit darüber, daß die Herstellung einer gemeinsamen Wochenschau zweckmäßig sei. Weiter hieß es: „Rein stimmungsmäßig trat in dieser Verhandlung auf französischer Seite ein besonders lebhafter Geist deutsch-französischer Verständigung zugunsten einer für beide Länder fruchtbaren Zusammenarbeit hervor" 266 . Diese von Tixier-Vignancour und de Carmoy verfolgte Politik stieß unter anderem auch auf Kritik von französischer Seite. Ein scharfer Kritiker war beispielsweise Charles Delacommune, seit Oktober 1940 Leiter des Service cinémato-

263 Interview mit Guy de Carmoy am 1.7.1992 in Fontainebleau.

264 Siehe Kapitel I. 1. dieser Arbeit; zu Ploquins Tätigkeit im COIC siehe auch BAB, 49.02-9126, Jean LAFFrAY, Où en est l'organisation du cinéma?, in: L'Euvre, 22. 1. 1941.

265 Siehe dazu BerTin-Maghit, Le Cinéma sous l'Occupation, S. 51, 57f. Albert Debrie hatte den schon nach kurzer Zeit aus gesundheitlichen Gründen demissionierten Albert Trarieux ersetzt.

266 AN, AJ40 1001, Prop.Abt., Tätigkeitsbericht, 28. 10.-3. 11. 1940. 
graphique d'État, der die Aktivitäten der unterschiedlichen Ministerien auf dem Gebiet der Herstellung von Propagandafilmen und in anderen Bereichen koordinieren sollte. Delacommune warf de Carmoy vor, er verkaufe den französischen Film an die Deutschen, führte seine Kritik sogar in einem Vermerk aus und äußerte sie gegenüber Dritten, was Tixier-Vignancour ihm in einem Schreiben besonders vorwar ${ }^{267}$. Weiter erhob beispielsweise im Frühjahr 1941 der Verwaltungschef der Centrale Catholique du Cinéma et de la Radio (CCCR) in Paris, L. Jacquemin, in einem allerdings generell sehr tendenziösen Schreiben den Vorwurf, Tixier-Vignancour und de Carmoy hätten einen starken Aufkauf der französischen Filmindustrie durch die Deutschen unterstützt. Jacquemin empörte sich weiter darüber, sie hätten ihm in einer Besprechung Diedrich als den „Reorganisator der französischen Filmindustrie" 268 vorgestellt. Hintergrund für diese Kritik waren allerdings vor allem Unstimmigkeiten zwischen der CCCR und den staatlichen Vertretern der Filmbranche über die Wiedereröffnung der katholischen Salles familiales, die allein sogenannte moralisch gesunde Filme zeigen sollten. Letztere wollten den streng moralischen Einfluß der Kirche auf den französischen Film unter Hinweis auf die künstlerische Freiheit und die Qualität desselben möglichst gering halten. Jacquemin warf ihnen jedoch vor, sie seien Diener Lavals ${ }^{269}$, würden die Arbeit des CCCR behindern und somit Verrat an dem Werk Pétains zu einer „moralischen Gesundung" Frankreichs begehen. Offenbar hatte de Carmoy zeitweise die angeblich fehlende Zustimmung des Referats Film als Argument gegen die Wiedereröffnung der katholischen Filmtheater vorgeschoben. Jacquemin empörte sich daraufhin, die Schwierigkeiten für den CCCR rührten eher von französischer Seite her und nicht von der Besatzungsmacht. Zudem brüstete er sich damit, er habe mit zur Entlassung von Tixier-Vignancour beigetragen ${ }^{270}$.

Tatsächlich erfuhr das Informationsministerium zu Beginn des Jahres 1941 einen Umbruch. Laval, der in Vichy einen stärkeren Kollaborationskurs als viele seiner Kollegen verfolgte, wurde aufgrund von Pétains Mißtrauen am 13. Dezember 1940 seiner Ämter enthoben und festgenommen ${ }^{271}$. TixierVignancour blieb auch danach zunächst noch als einer der wenigen im Informationsministerium auf seinem Posten, den er erst im Januar 1941 verlor. Als

267 AN, F60 1019, Présidence du Conseil, radiodiffusion, livre et cinéma, TixierVignancour an Delacommune, 27. 12. 1940.

268 Ibid. CCR, L. Jacquemin an Direction du cinéma, Vichy, Rapport moral sur l'Action des Allemands dans le cinéma français, et qu'il ne peuvent réaliser qu'avec la complicité gratuite ou onéreuse du personnel du Service du cinéma et du COIC, ohne Datum (etwa Mai 1941).

269 Ibid. CCR, Paris, L. Jacquemin an Direction du cinéma, Vichy, Histoire chronologique de démêles de la CCR avec la direction du cinéma à Vichy, le Commissariat et le COIC à Paris, 17. 5. 1941.

270 Ibid.

271 Im Frühjahr 1942 kehrte Laval jedoch in die Regierung zurück; siehe bei DuROSELLE, L'abîme, S. 429-436. 
schließlich Admiral Darlan Anfang Februar 1941 zu Pétains Stellvertreter ernannt wurde und das Außen-, Innen- und Informationsministerium übernahm, bewirkte dies auch einige Monate später die Entlassung Guy de Carmoys $^{272}$. So informierte de Carmoy im April 1941 Diedrich darüber, er werde sein Amt gemäß einer Entscheidung Admiral Darlans niederlegen. Diedrich berichtete, er habe von Raoul Ploquin, dem Leiter des COIC, erfahren, daß hierfür auch de Carmoys zu nachgiebige Haltung in der Frage einer rein französischen bzw. deutsch-französischen Wochenschau verantwortlich gewesen sei273.

Anfang Januar 1941 wurde Paul Marion zum Generalsekretär für Information und Propaganda ernannt, als Nachfolger de Carmoys wählte er im September 1941 Louis-Émile Galey, während der dreißiger Jahre ein Anhänger der extremen Linken, der mit dem Waffenstillstand zum Pétainisten geworden war. Aus dem Service du cinéma wurde nun die Direction générale du cinéma und Galeys Position war weit einflußreicher als die seines Vorgängers ${ }^{274}$. Vor Galeys Ernennung nahm die Propaganda Abteilung hierzu Stellung und der MBF stimmte zu; im Oktober machte Galey schließlich seinen Antrittsbesuch bei Diedrich ${ }^{275}$. Einen Monat vorher hatte auch die Deutsche Botschaft an Fernand de Brinon, den Generalbeauftragten der französischen Regierung im besetzten Gebiet, geschrieben, sie würde es begrüßen, wenn Galey die Nachfolge de Carmoys antreten würde, da er für diesen Posten als besonders geeignet erscheine ${ }^{276}$.

Die Besatzungsmacht hatte vor allem deswegen ein Interesse an der Gründung der französischen Berufsorganisationen, weil dadurch die eigenen Dienststellen entlastet werden konnten. Als Beispiel wäre hier die Carte d'identité professionelle (CIP) zu nennen, die im Oktober 1940 vom COIC eingeführt wurde. Ohne diese Arbeitserlaubnis durfte offiziell niemand in der Filmbranche tätig sein. Neben ihrer generellen Kontrollfunktion kann sie vor allem als ein Mittel zur Exklusion von Juden und Freimaurern gesehen werden 277 . Zudem war es für die Besatzer auf diese Weise möglich, unpopu-

\section{Bertin-Maghit, Le Cinéma sous l'Occupation, S. 48.}

273 BA-MA, RW4 v.218, Prop.Abt., Tätigkeitsbericht, 7. 4.-14. 4. 1941; gemeint waren hier die Verhandlungen über eine französische bzw. eine gemeinsame deutsch-französische Wochenschau; siehe dazu Kapitel III. 2.2. dieser Arbeit.

274 BERTIN-MAghit, Le Cinéma sous l'Occupation, S. 56f. Im Oktober 1941 wurde Galey zum Commissaire général du gouvernement pour le cinéma.

275 BA-MA, RW35 224, Prop.Abt., Ref.Film, Tätigkeitsbericht, 17. 10.-24. 10.1941.

276 AN, F60 1481, DBP, Dr. Lierau an de Brinon, DGTO, 22. 9. 1941; allerdings schrieb die Botschaft irrtümlich, Galey solle de Carmoys Nachfolger an der Spitze des COIC werden.

277 Unter anderem wurde durch dieses Gesetz das bisher übliche doppelte Filmprogramm, also das Vorführen von jeweils zwei abendfüllenden Spielfilmen pro Vorstellung, abgeschafft; in den dreißiger Jahren soll das doppelte Filmprogramm mit für die wirtschaftliche Krise der französischen Filmindustrie verantwortlich gewesen sein. Auf die CIP wird im Rahmen der Ausführungen zur „Säuberung“ des kulturellen Lebens noch näher einzugehen sein. 
läre Maßnahmen durch französische Stellen durchführen zu lassen. Das COIC war beispielsweise zuständig für die Zuteilung der in der Filmindustrie benötigten Rohstoffe und Materialien wie Kohle, Chemikalien, Rohfilm sowie Elektrizität, die vom MBF kontingentiert und im Laufe der Besatzungszeit immer knapper wurden. Trotzdem kann diese Berufsorganisation nicht als ein reines Instrument der deutschen Besatzer angesehen werden, zumal Vichy über den Service du cinéma bzw. die Direction générale du cinéma ebenfalls starken Einfluß auf das COIC hatte ${ }^{278}$.

Während das COIC relativ schnell ins Leben gerufen worden war, ließ sich Vichy mit einer Berufsorganisation im Bereich des Theaters weit mehr Zeit; erst ab dem Sommer 1941 begann man, die Bildung eines Comité d'organisation des entreprises de spectacle (COES) zu planen ${ }^{279}$. Dies war unter anderem darin begründet, daß das Theater nicht wie der Film als Industrie angesehen wurde und das Gesetz vom 16. August 1940 zur Gründung von Berufsorganisationen hatte sich schließlich auf die französische Industrie bezogen. Ein anderer Grund lag auch darin, daß Vichy, wie Serge Added herausgearbeitet hat, generell relativ wenig Interesse an einer Reglementierung im Bereich des Theaters hatte ${ }^{280}$. Immerhin wurde das Theater nicht wie der Film als bevorzugtes Propagandainstrument gesehen. Dieses teilweise Desinteresse Vichys war ein Grund dafür, daß hier bei der Bildung von Berufsorganisationen die Einmischung von deutscher Seite zumindest zu Beginn der Besatzungszeit weit größer war als im Bereich des Filmes. Gleich zu Beginn der Okkupation wurden „auf deutsches Bestreben "281 hin die Association des directeurs de théâtres de Paris (ADTP), in den Akten auch Theaterdirektorenverband genannt, und die Association des directeurs de tournée (ADT; Tourneeleiterverband) im Herbst 1940 gegründet ${ }^{282}$. Leiter des ADT war Raoul Audier; der ADTP wurde von Oktober 1940 bis zum April 1941 von Robert Trébor geleitet, es folgte ein sogenanntes Triumvirat bestehend aus Charles Dullin, Gaston Baty und Pierre Renoir, welches offiziell im November 1941 seine Demission einreichte, praktisch aber noch bis zur Gründung des COES im Amt blieb ${ }^{283}$. Das Hauptmotiv der Besatzer für die Gründung von $\mathrm{ADT}$ und $\mathrm{ADTP}$ war die bereits erwähnte Entlastung der deutschen Dienststellen; immerhin war das Theaterreferat nur mit einem Referenten

278 BeRTIN-Maghit, Le Cinéma sous l'Occupation, S. 60.

279 Zur Organisation des Theaterbetriebes siehe grundlegend ADDED, Le Théâtre, S. 139-225.

280 ADDED, Le Théâtre, S. 30-94.

281 AN, AJ40 1001-7, Prop.Abt., Gr.Kult.Th., Tätigkeitsbericht, März 1943.

282 Zum ADTP siehe ADDED, Le Théâtre, S. 141-161; Added konstatiert: „L'ADTP n'était pas un organisme d'État, aucune loi ne contraignait les directeurs. En fait, derrière cette astreinte, se profilait le pouvoir allemand et, par conséquent, une dépendance de l'ADTP envers lui" (Ibid. S. 142).

283 Ibid. S. 150-161. Carcopino, der Minister des Ministère de l'Éducation nationale, hatte die drei gebeten, mit ihrem Weggang bis zur Gründung einer neuen Berufsorganisation, dem COES, zu warten. 
und einigen Helfern besetzt. Man hatte nun in den Leitern dieser Verbände konkrete Ansprechpartner und mußte sich nicht in jeder Angelegenheit etwa an die einzelnen Theaterdirektoren wenden. Abgesehen davon, daß wie im Bereich des Filmes auch hier fast sämtliche Schritte der Berufsverbände vorher mit dem Theaterreferat abgestimmt wurden, waren die Besatzer unter anderem darauf bedacht, unliebsame Theaterdirektoren im Zweifelsfalle vom ADTP ausschließen zu können ${ }^{284}$.

Offenbar war das Pariser Theaterreferat mit seiner Einflußnahme auf die Bildung von Berufsorganisationen nach Ansicht des RMVP über das Ziel hinausgeschossen, denn im September 1941 wurde es von der Berliner Abteilung Theater zu weniger Einmischung ermahnt, da es nicht Aufgabe der deutschen Seite sein dürfe, „den Franzosen zu einer analog im Reich aufgebauten Theatergesetzgebung zu verhelfen" 285 . Die Aufmerksamkeit der Besatzungsmacht müsse sich darauf beschränken, „keine Opposition gegen die deutschen Gesichtspunkte aufkommen zu lassen“ und Einfluß auf die Besetzung der leitenden Stellen zu nehmen. Die Posten sollten Personen erhalten, mit denen eine gute Zusammenarbeit möglich sei. Dies sollte dem Theaterreferat die Kontrolle des Theaterbetriebs erleichtern. Wie sehr die deutschen Funktionsträger von ihrer Organisationsfähigkeit überzeugt waren, wird in einem Bericht des Theaterreferenten Frank vom Februar 1942 deutlich:

Die Franzosen, zunächst überrumpelt und in dem Zustand gelähmter Willenskraft der ordnenden Hilfe nicht abgeneigt, fingen an, aus der deutschen Organisationsfähigkeit Vorteile zu ziehen. Sie sahen im Deutschen den Herkules, der dazu dienen sollte, ihren Augiasstall auszuräumen. Die Anträge, die Besuche auf der Dienststelle häuften sich, die Staffel wurde als eine Art „Mädchen für alles“ in Anspruch genommen. Da es indessen nicht unsere Aufgabe sein konnte, Organisation und Ordnung nach deutschem Muster frei Haus zu liefern (Nationalsozialismus ist kein Exportartikel), ging das Referat dazu über, sich von der funktionellen Mitwirkung vorsichtig zurückzuziehen und nach dem Grundsatz „divide et impera" eine nach Maßgabe der deutschen Interessen beobachtende, beratende und kontrollierende Haltung einzunehmen ${ }^{286}$.

Der Widerstreit dieser beiden Aspekte, nämlich des Wunsches nach Entlastung einerseits und der Angst vor einer allzu guten Organisation des Theaterbetriebes andererseits spiegelt sich auch in dem langwierigen Entstehungsprozeß des COES wieder.

284 AN, AJ40 1002-3, Prop.St., Gr.Kult.Th., „Bemerkungen zu dem Entwurf: Genossenschaft der Direktoren der Pariser Theater", November 1940. Darin heißt es unter anderem: „Die deutsche Besatzungsmacht behält sich hierbei vor, ihr nicht genehme Genossenschaftsmitglieder auszuschließen, oder Direktoren, die neu zutreten wollen, den Zutritt zur Genossenschaft zu versagen, falls die Betreffenden nicht den Voraussetzungen der kulturpolitischen Bestrebungen der deutschen Besatzungsmacht entsprechen $[\ldots . . .]^{\text {“. }}$.

285 AN, AJ40 1001-7, Prop.St., Gr.Kult.Th., Aktennotiz über eine Besprechung mit den Vorgesetzten Dr. Schlösser und Dr. Lang (RMVP, Berlin) in Paris, 25. 9. 1941.

286 Ibid. ohne Titel, 3. 2. 1942. 
Seit dem Sommer 1941 plante Vichy diesen Berufsverband, der erst im April 1942 gegründet wurde und sämtliche Professionen im Bereich des Theaters organisierte ${ }^{287}$. Die verzögerte Gründung des COES war unter anderem auch darin begründet, daß Theaterreferent Baumann Einspruch erhoben hatte. Die Gründe hierfür erschienen dessen Nachfolger Frank als undurchsichtig. Jener berichtet in einer Aktennotiz vom Oktober 1941, angeblich habe Fernand de Brinon den Referenten Baumann um eine Unterredung bezüglich des Theatergesetzes zur Bildung des COES gebeten. Aus unerfindlichen Gründen habe diese jedoch niemals stattgefunden. Frank betont ferner, als allgemeine Richtlinie sei vom RMVP nun festgelegt worden, der französischen Seite solle bei der Abfassung des Theatergesetzes grundsätzlich freie Hand gelassen werden ${ }^{288}$. In einem Bericht Franks von Ende Oktober 1941 wird deutlich, daß das Theaterreferat die Bildung des COES grundsätzlich befürwortete, gleichzeitig aber keine zu gute Organisation des Theaterbetriebes wollte:

Es ist nicht unsere Aufgabe, den Franzosen zu einer der Handhabung im Reich angeglichenen administrativen Ordnung zu verhelfen. Andererseits haben wir ein Interesse daran, daß die Franzosen von sich aus zu einer Organisation finden, die den deutschen Dienststellen die Ausübung ihrer Tätigkeit erleichtert ${ }^{289}$.

Gruppenleiter Lucht teilte im Dezember 1941 der Abteilung Film des RMVP mit, das Theaterreferat sei gemeinsam mit dem französischen Ministerium darum bemüht, ein Theatergesetz zur Bildung des COES in die Wege zu leiten; in jedem Falle dürfte also das Interesse an der Gründung einer solchen Organisation trotz aller Zweifel überwogen haben 290 . Obgleich das Theaterreferat auf die Bildung des COES möglichst keinen Einfluß etwa nach dem Vorbild der im Dritten Reich existierenden Berufsverbände nehmen sollte, forderte es beim RMVP in Berlin „propagandistisches Material über den Aufbau der deutschen Kulturorganisationen, die Künstleraltenhilfe usw."291 an. Das RMVP betonte, das Theaterreferat dürfe in bezug auf die Gründung

${ }^{287}$ Zum COES siehe grundlegend ADDED, Le Thêatre, S. 163-192. An dieser Stelle ist anzumerken, daß im April 1942 die Famille professionelle du spectacle (FPS) gegründet wurde. Diesem Dachverband waren COES und COIC beigetreten; für die Zukunft war auch die Aufnahme anderer Verbände etwa aus den Bereichen Sport und Musik geplant. Während COES und COIC vorwiegend ökonomische und technische Fragen bearbeiten sollten, kam der FPS die Aufgabe einer Regelung sozialer Belange zu. Auf diese Organisation soll im folgenden nicht näher eingegangen werden, da die Arbeit der FPS als relativ unbedeutend und ineffektiv angesehen werden kann. Siehe dazu ADDED, Le Théâtre, S. 193-201. Added konstatiert: „Ayant brassé, en un peu plus d'un an, beaucoup d'énergie et quelques deniers publics, la FPS n'eut finalement aucune prise sur la réalitéc (Ibid. S. 199 f.).

288 AN, AJ40 1001-7, Prop.St., Gr.Kult.Th., Aktennotiz, 18. 10. 1941.

${ }^{289}$ Ibid. Tätigkeitsbericht, 10. 10.-31. 10. 1941.

290 AN, AJ40 1002-2, Prop.St., Gr.Kult.Th., Schreiben Gruppenleiter Lucht an Lang, RMVP, 11.12.1941.

291 AN, AJ40 1001-7, Prop.St., Gr.Kult.Th., Aktennotiz, Betr.: Telefongespräch mit Herrn Dr. Lang, 8. 11. 1941. 
des COES grundsätzlich frei agieren. Es ist fraglich, inwieweit nun diese $\mathrm{Ma}$ terialien oder allgemein deutsche Änderungsvorschläge für eine angeblich bessere Berufsorganisation tatsächlich in das Theatergesetz zur Bildung des COES mit einbezogen wurden. In einem Bericht des Theaterreferats heißt es lediglich allgemein über den deutschen Einfluß auf das Theatergesetz: „Bei allen diesbezüglichen Aussprachen war bisher seitens der Franzosen ein groBes Interesse für den deutschen Standpunkt und eine loyale Behandlung unserer Anregungen zu beobachten"292. Hieraus läßt sich allerdings nicht etwa schließen, die deutsche Einflußnahme sei sehr groß gewesen. Das Theaterreferat war vor allem darauf bedacht, seine Wünsche in bezug auf die Besetzung der führenden Positionen innerhalb des COES durchzusetzen.

Die Leitung des COES sollte nach dem Vorschlag Jérôme Carcopinos, dem Minister des zuständigen Ministère de l'Éducation nationale, durch einen sogenannten Sechs-Männer-Ausschuß geleitet werden. Dessen Leiter sollte Jacques Rouché, der 80jährige Direktor der Pariser Oper sein. Gegen Rouché meldete das Theaterreferat in einer Unterredung mit Louis Hautecœur, dem Leiter des für Theaterangelegenheiten zuständigen Secrétariat général des Beaux-Arts, Bedenken an. Es wollte auf dieser Position einen jüngeren Mann sehen ${ }^{293}$. Außerdem hatte Minister Carcopino die Liste mit den vorgeschlagenen Personen entgegen der ursprünglichen Abmachung mit dem Referat nicht abgesprochen, bevor sie dort zur Prüfung offiziell eingereicht wurde. In einem Bericht des Referats heißt es empört, Carcopino habe „eigenmächtig eine selbständige Auswahl getroffen“294. Es beschwerte sich darüber, daß die Namen der vorgeschlagenen Personen der Propaganda Staffel teilweise völlig unbekannt waren, während die Männer, mit denen das Theaterreferat bisher über die ADTP zusammengearbeitet habe, in dieser Liste kaum berücksichtigt waren. Für die Leitung des COES hatte Carcopino neben dem umstrittenen Rouché auch Gaston Baty, Eugène Bigot, René Chauvet, Paul Derval und Sacha Guitry vorgeschlagen ${ }^{295}$. Der Letztgenannte erregte ebenfalls den Unwillen des Referats. Der Grund hierfür lag in den zeitweisen Problemen Guitrys, seine arische Abstammung nachzuweisen. Das Theaterreferat bat bei der Abteilung Theater des RMVP telefonisch um eine Stellungnahme zu Rouché und Guitry. In einer Aktennotiz heißt es allerdings zur Position Berlins, es könne nicht im Interesse der Besatzungsmacht liegen, den Franzosen zu einer „zuverlässigen Standesorganisation nach deutschem Muster“296 zu verhelfen: „Infolgedessen legen wir keinen Wert darauf, daß starke Persönlichkeiten in Fragen der Organisation zum

292 Ibid. Tätigkeitsbericht, 31. 10.-14. 11. 1941.

293 Ibid. Aktennotiz, Betr.: Französisches Theatergesetz, 18. 10. 1941; zu Struktur und Leitung der Direction générale des Beaux-Arts, die erst 1941 zum Sécretariat général des Beaux-Arts wurde, siehe Joubert, S. 46-51.

294 AN, AJ40 1001-7, Prop.St., Gr.Kult.Th., Tätigkeitsbericht, 27. 12. 1941-12. 1. 1942.

295 Ibid. Aktennotiz, Betr.: COES, 19. 1. 1942.

296 Ibid. Aktennotiz, Betr.: Telefonat mit Dr. Lang, 22. 1. 1942. 
Ansatz kommen, vielmehr sind uns die unfähigsten Männer am meisten willkommen"297. Das RMVP sah in dem 80jährigen Rouché deshalb anders als das Theaterreferat der Staffel keine Gefahr. Letzteres blieb für dessen Ablehnung und betonte, er sei trotz seines hohen Alters ernst zu nehmen. Wenig später teilte es Carcopino mit, Rouché werde offiziell abgelehnt, gegen Guitry bestünden jedoch keine Bedenken ${ }^{298}$. Schließlich wurde René Rocher im April 1942 zum Leiter ernannt. Die Diskussion um die Leitung des COES zeigt, daß dieses sich bereits in seiner Gründungsphase zumindest zum Teil dem Zugriff des deutschen Einflusses zu entziehen vermochte. Minister Carcopino hatte bei seinen Personalvorschlägen in den Augen des Theaterreferats zu selbständig gehandelt. Zwar war die Nominierung Rouchés verhindert worden, doch war die deutsche Seite mit Carcopinos Entscheidung letztlich nicht ganz zufrieden. Im März 1942, kurz vor der Gründung des COES, berichtete das Theaterreferat, auch in französischen Theaterkreisen sei die Auswahl der Personen zu dessen Leitung umstritten. Persönlichkeiten, die sich seit Beginn der Besatzungszeit um eine gute Zusammenarbeit mit den Deutschen bemüht hätten, fühlten sich nun zurückgesetzt. Weil sie an der Spitze des COES nicht berücksichtigt seien, vermuteten sie „nicht mit Unrecht hierin eine bewußte Revanche für ihr deutschfreundliches Verhalten“299. Zudem war der Zuständigkeitsbereich des COES nicht genau abgegrenzt und das zukünftige Führungskomitee hatte mit den Leitern der vorhandenen Berufsorganisationen ADTP und ADT noch keine Verbindung aufgenommen ${ }^{300}$. Die Namensliste Carcopinos wurde bis auf Rouché vom Theaterreferat letztlich akzeptiert. In der Folge gelang es dem COES noch einige Male, sich dem Willen des Theaterreferats zu widersetzen. Grundsätzlich schwankte die Haltung des Referats auch weiterhin zwischen leichter Behinderung und Unterstützung der Maßnahmen des COES. Letzteres verhalf generell diesem Verband, der seinen Sitz übrigens in Paris hatte, gegenüber der Regierung in Vichy zu einer relativen Autonomie, wie Added herausgearbeitet hat ${ }^{301}$.

In den Akten des Theaterreferats lassen sich etliche Hinweise auf eine gute Zusammenarbeit der deutschen Behörden mit dem COES finden. Rittmei-

297 Ibid.

298 Ibid. Aktennotiz, Betr.: COES, 19. 1. 1942; Bleistiftnotiz vom 24. 1. 1942.

299 Ibid. Tätigkeitsbericht, 27. 2.-12. 3. 1942. Zwischen ADTP/ADT und dem COES existierten etliche Spannungen und Kompetenzgerangel, die zugunsten des COES endeten. Im Juni 1943 trat der ADTP dem COES schließlich bei (Ibid. Prop.Abt., Gr.Kult.Th., Tätigkeitsbericht, 30. 6. 1943). Das Theaterreferat hatte sich in diese Streitigkeiten kaum eingemischt. In einem Bericht vom März 1943 heißt es dazu: „Zu einer endgültigen Bereinigung der schwebenden Fragen kam es indessen noch nicht, da dem Referat wohl an einem gut funktionierenden Apparat in Sachen der Zensur und Verwaltung gelegen ist, nicht aber an einer straffen Organisation nach deutschem Muster" (Ibid. Prop.Abt., Gr.Kult.Th., Tätigkeitsbericht, März 1943).

300 Ibid. Prop.St., Gr.Kult.Th., Tätigkeitsbericht vom 27. 2.-12. 3. 1942.

301 ADDED, Le Thêâtre, S. 190. 
ster von Heyden-Linden lobte Ende August 1941, dieser Verband entwickele sich mehr und mehr zu einer tatkräftigen Vereinigung, ähnlich einer Reichstheaterkammer. Allerdings stand dieses Lob im Gegensatz zur Position des RMVP, das gerade so eine Organisation hatte verhindern wollen ${ }^{302}$. Im Dezember desselben Jahres beklagte sich das Theaterreferat generell über eine mangelnde Bereitschaft zur Kollaboration in Theaterkreisen, betonte jedoch, daß vor allem die Zusammenarbeit mit dem COES zufriedenstellend sei303. Die Zuteilung der vom MBF kontingentierten Rohstoffe und Materialien gehörte zu den Aufgaben des Verbandes. Die deutschen Dienststellen ließen derartig unliebsame Maßnahmen vorzugsweise direkt von den französischen Berufsverbänden durchsetzen, obgleich das COES sich zeitweise gegen diese unbequeme Rolle wehrte. Im Mai 1943 berichtete das Theaterreferat über die sich mehr und mehr verschlechternde Elektrizitätslage und fügte hinzu: „Der Versuch, die Verantwortung für unangenehme Maßnahmen (Relève, Stromkontingentierung usw.) der Propaganda-Abteilung Frankreich zuzuschieben, wurde dadurch unterdrückt, daß alle offiziellen Verlautbarungen des COES in Zukunft zur Zensur vorgelegt werden müssen"304. Eine weitere Aufgabe des COES bestand in der Ausgabe der Arbeitsgenehmigungen, der Cartes professionelles. Anders als im Bereich des Filmes, wurde für das Theater diese Arbeitsgenehmigung erst relativ spät, im März 1943, eingeführt. Die Initiative hierzu war von Lucht, dem Leiter der Gruppe Kultur ausgegangen, der auf der Einführung der Arbeitsgenehmigungen im Zusammenhang mit dem verstärkten Abzug französischer Zwangsarbeiter nach Deutschland bestand ${ }^{305}$. Anders als die CIP im Bereich des Filmes wurden diese Karten beim Theater nicht vorwiegend als Mittel zum Ausschluß von Juden, Freimaurern und politischen Gegnern eingesetzt.

Mit der Einflußnahme der deutschen Dienststellen auf die Organisation des Film- und Theaterbetriebes gleich zu Beginn der Besatzungszeit sollte eine Entlastung der deutschen Funktionsträger sowie eine bessere Kontrolle der französischen kulturellen Aktivität erreicht werden. Außerdem wurden sofort nach der Besetzung des Landes Maßnahmen zur "Säuberung“, d.h. zum Ausschluß von jüdischen Künstlern, Freimaurern und politischen Gegnern vom kulturellen Leben eingeleitet. So betonten beispielsweise deutsche Zeitungsartikel im Zusammenhang mit Berichten über die Neuordnung der französischen Filmindustrie immer auch gleichzeitig die rigorose Ausschaltung des sogenannten jüdischen Einflusses in diesem Bereich ${ }^{306}$. Besonders

302 AN, AJ40 1001-7, Prop.St., Gr.Kult.Th., Tätigkeitsbericht, 31. 8. 1942, Rittmeister von Heyden-Linden.

${ }^{303}$ Ibid. Prop.Abt., Tätigkeitsbericht, 30. 12. 1942.

304 Ibid. Tätigkeitsbericht, Frank, 26. 5. 1943.

305 Siehe ADDED, Le Théâtre, S. 185-189.

306 BAB, 49.02-9126, Frankreichs Filmindustrie, Ausschaltung jüdischen Einflusses Umfassende Organisationsmaßnahmen - Deutsch-französische Zusammenarbeit, in: Nachrichten für Außenhandel, 1. 10. 1942; ibid. Die Lage der französischen Filmindu- 
betroffen von der „Säuberung" waren die Juden, weshalb die Maßnahmen zur Arisierung im Vordergrund der folgenden Ausführungen zu diesem Themenkomplex stehen. Im Bereich des Filmes ging damit häufig der Ankauf von Filmtheatern und Filmstudios einher, die ehemals in jüdischem Besitz gewesen waren; sie sollten die Grundlage für die deutsche Filmexportpolitik nach Frankreich bilden. Freilich wurden solche sogenannten Investitionen von den Deutschen zu günstigen Konditionen getätigt. Die Situation der Besatzung und des Krieges nutzten die Besatzer zu einer wirtschaftlichen mainmise, zu einer teilweisen Inbesitznahme, Beherrschung und Ausnutzung der französischen Filmindustrie.

\subsection{Zur Arisierung von Bübne und Leinwand}

Jeder Jude, der in Europa wirkt, ist eine Gefahr für die europäische Kultur. Wenn man mir den Vorwurf machen würde, daß ich aus dieser Stadt, die einst die europäische Metropole des Judentums gewesen ist, Zehntausende von Juden ins östliche Ghetto abgeschoben habe, muß ich antworten: Ich sehe darin einen aktiven Beitrag zur europäischen Kultur ${ }^{307}$. (Baldur von Schirach, 15. 9. 1942)

In Deutschland propagierten die Nationalsozialisten unter anderem immer wieder den Vorwurf, die so zahlreichen jüdischen Kulturschaffenden wären schuld an einem kulturellen Leben, das von ökonomischen Interessen dominiert würde, wobei die Kultur allmählich zur Ware verkommen sei ${ }^{308}$. Ähnliches wurde während der Okkupation auch in Frankreich verbreitet, wo wie in anderen Ländern ein Antisemitismus auch schon vorher existiert hatte und ganz besonders in den dreißiger Jahren mit der wachsenden Anzahl jüdischer Emigranten sowie nach der französischen Niederlage von 1940 wieder neu aufgekommen war. Gleichwohl richtete sich dieser vorwiegend gegen ausländische Juden und unterschied sich in seiner Form von dem radikalen Rassismus der Nationalsozialisten. Es handelte sich hier eher um eine extreme Xenophobie gekennzeichnet durch eine allgemeine Angst vor sogenannter Überfremdung ${ }^{309}$. Die wohl bekannteste anti-jüdische Schrift der Okkupa-

strie, in: Westdeutscher Beobachter, 10. 9. 1942; ibid. Der Neuaufbau der französischen Filmwirtschaft, in: Frankfurter Zeitung, 18. 7. 1942.

307 Rede des Wiener Reichsstatthalters Baldur von Schirach am 15. 9. 1942; hier zit. $\mathrm{n}$. WULF, Theater und Film, S. 7. Zu Schirachs Kunstauffassung und kulturpolitischen Vorstellungen siehe bei MATHIEU, Kunstauffassungen, S. 244-261.

308 Siehe dazu WULF, Theater und Film, S. 255-277, 429-436. Jutta KuHLmanN schrieb in ihrem Artikel „Das war jüdisches Theater“, in: Die Bühne, 1943, S. 244: „Es ist eine, angesichts der jüdischen Mentalität durchaus erklärliche Tatsache, daß der Jude wohl kaum in einer Kunstgattung so festen Fuß fassen konnte, wie beim Theater und später beim Film. Mit seiner starken Intellektualität und kalten Berechnung erkannte er hier schon früh ein weites Wirkungsfeld für seine finanzielle Unternehmungs- und Ausbeutungsgabe und zugleich für seine politischen Machenschaften" (zit. n. WULF, Theater und Film, S. 259).

309 Siehe dazu PaXton, Marrus, Vichy et le juifs, S. 35-78; die Untersuchung von Ralph SCHOR, L'Antisémitisme en France pendant les années trente, Brüssel 1992; spe- 
tion, „Les Décombres“ (1942), stammt von Lucien Rebatet alias François Vinneuil. Derselbe Autor veröffentlichte 1941 das Buch „Les Tribus du cinéma et du théâtre". Rebatet zeichnet darin das Bild eines französischen Theater- und Filmbetriebes, der in der Vergangenheit vollständig von Juden, genauer gesagt von einer invasion juive ${ }^{310}$, beherrscht worden sei; diese, so wird behauptet, hätten aus dem kulturellen Leben enormen wirtschaftlichen Profit gezogen. Sowohl finanziell als auch geistig hätten sie die Franzosen bestohlen: „Quand vous n'avez rien à vous faire voler, il s'en prend à votre cervelle“311. Rebatet beschwert sich ferner, die Juden wollten sich angesichts der neuen Situation der Besatzung nun nicht einmal geschlagen geben:

Les Juifs du cinéma, à l'heure où j'achève ce petit tableau de leur espèce, ont l'audace et l'inconscience de ne pas s'avouer encore battus. Quelques-uns, à l'aide de passeports truqués, ont eu le front de regagner Paris, de s'afficher dans les coulisses, d'organiser mêmes des spectacles de théâtre. La plupart ont pris leurs quartiers sur la Côte d'Azur. Tandis que les Parisiens se serrent le ventre, ces pirates festoient au soleil avec leur butin. Ils se prélassent dans les plus belles villas ${ }^{312}$.

Rebatet ist der Ansicht, der französischen Film müsse ebenso wie das Theater von allen Juden befreit werden und konstatiert abschließend: „Quoi qu'il arrive, la France est perdue pour les Juifs “313. Abgesehen von der seit 1940 sowohl von der Besatzungsmacht und als auch der Vichy-Regierung betriebene Exklusion von Juden beinhaltete die Politik der „Säuberung“ des kulturellen Lebens auch einen Ausschluß von Freimaurern ${ }^{314}$ und politischen Gegnern, vor allem Kommunisten ${ }^{315}$.

Schon kurz nach Beginn der Besatzungszeit wurden sowohl vom MBF als auch von der Vichy-Regierung erste Maßnahmen zur Arisierung eingeleitet $^{316}$. Noch vor der ersten Verordnung des MBF ergriff hier Vichy unter-

ziell zur Publikation anti-jüdischer Schriften im Bereich des Filmes während der dreiBiger Jahre siehe ThalmanN, La Mise au pas, S. 150; Thalmann zitiert unter anderem den Regisseur Jacques Feyder, der 1938 in einem Interview mit Ciné-France sagte: „Les envahisseurs juifs ont mis la main sur le cinéma français" (Ibid.).

${ }^{310}$ Lucien REBATET, Les Tribus du cinéma et du théâtre, Paris 1941, S. 9.

311 Ibid. S. 79.

312 Ibid. S. 94.

313 Ibid. S. 124.

${ }^{314}$ In den Freimaurern sah Hitler eine Art Handlanger der Juden. 1925 schrieb er in "Mein Kampf“ zum „Werdegang des Judentums": „Zur Stärkung seiner politischen Sicherheit versucht er, die rassischen und staatsbürgerlichen Schranken einzureißen, die ihn zunächst noch auf Schritt und Tritt beengen. Er kämpft zu diesem Z wecke mit aller ihm eigenen Zähigkeit für die religiöse Toleranz - und hat in der ihm vollständig verfallenen Freimaurerei ein vorzügliches Instrument zur Verflechtung wie aber auch zur Durchschiebung seiner Ziele. Die Kreise der Regierenden sowie die höheren Schichten des politischen und wirtschaftlichen Bürgertums gelangen durch maurerische Fäden in seine Schlingen, ohne daß sie es auch nur zu ahnen brauchen" (Ibid. S. 345).

${ }^{315}$ Zur „Säuberung“, vor allem zur Arisierung im Bereich von Film und Theater siehe insbesondere Thalmann, La Mise au pas, S. 145-153; BerTin-Maghit, Le Cinéma sous l'Occupation, S. 70-75; ADDED, Le Théâtre, S. 71-76.

${ }^{316}$ Zur Politik der Besatzungsmacht sowie der Vichy-Regierung im Bereich der Arisie- 
schiedliche gesetzliche Maßnahmen, die sich zum Teil direkt oder auch indirekt gegen Juden richteten. $\mathrm{Zu}$ dem vorher häufig angeführten Argument, die Besatzer hätten Vichy gleichsam zu einer anti-jüdischen Gesetzgebung gezwungen, konstatierten Marrus und Paxton in ihrem Standardwerk zu Beginn der achtziger Jahre, jedwede Idee eines einfachen Diktats der Deutschen in diesem Bereich könne ausgeschlossen werden ${ }^{317}$. Die Haltung Vichys war unter anderem in der Vorstellung begründet, die Niederlage von 1940 sei auch eine Folge „Dekadenz" der Dritten Republik sowie eines Komplotts von Juden, Ausländern, Freimaurern und Kommunisten. Eine sogenannte Gesundung des Landes durch die Révolution nationale machte demnach einen Ausschluß dieser Vertreter eines sogenannten Anti-Frankreich notwendig 318 .

Nach der Verordnung des MBF über „Maßnahmen gegen Juden“ vom 27. September 1940 und dem von Vichy am 3. Oktober 1940 erlassenen Gesetz „Loi portant statut des juifs“ galt in Frankreich jede Person als Jude, die der jüdischen Konfession angehörte bzw. angehört hatte oder von mehr als zwei jüdischen Großelternteilen abstammte ${ }^{319}$. Juden wurden in der Verordnung des MBF aufgefordert, sich bis zum 20. Oktober 1940 bei den Unterpräfekturen des jeweiligen Arrondissements zu melden, denn in Frankreich war die Bevölkerung bisher nicht getrennt nach ihrer Religion registriert worden. Das von Vichy erlassene Gesetz vom 3. Oktober schloß die Juden von der Ausübung öffentlicher Ämter und einer Reihe weiterer Tätigkeiten aus; darunter befanden sich auch Berufe im Bereich von Film und Theater. Außerdem mußten nach einer Verordnung des MBF alle sogenannte jüdische Unternehmen, also auch Filmfirmen oder Theater, bei den Präfekturen ge-

rung siehe grundlegend Paxton, Marrus, Vichy et les juifs; Serge KLARsfeld, VichyAuschwitz: le rôle de Vichy dans la solution finale. 2 Bde. Paris 1983 und 1985; zum Verhalten der französischen Polizei in diesem Bereich siehe KASTEN, Gute Franzosen, S. 95-104, 166-175.

317 Paxton, Marrus, Vichy et les juifs, S. 19, siehe auch S. $17 \mathrm{f}$.

318 Siehe zusamenfassend Denis PESCHANSKI, Exclusion, persécution, répression, in: AzÉma, Bédarida, Vichy, S. 209-234; auch Denis Peschanski, Vichy 1940-1944, Contrôle et exclusion, Brüssel 1997.

319 BA-MA, RWD 19/1 (1940-41), Verordnung über Maßnahmen gegen Juden vom 27. 9. 1940, in: VOBIF (Verordnungsblatt des Militärbefehlshabers in Frankreich), 30. 9. 1940; auch BA-MA, RWD 19/1 (1942-44), Siebente Verordnung über Maßnahmen gegen Juden vom 24. 3. 1942, in: VOBIF, 15. 4. 1942; „Loi portant statut des juifs“, 3. 10. 1940, in: JO (Journal Officiel), 18. 10. 1940, auch abgedruckt in: PAXTON, MARRUS, Vichy et les juifs, S. 399 f. Eine kommentierte Edition der Gesetze der Vichy-Regierung liefert das Buch von Dominique RÉmY, Les Lois de Vichy. Actes dits "lois" de l'autorité de fait se prétendant "gouvernement de l'État français“, Paris 1992; insbesondere zur antisemitischen Gesetzgebung siehe: Le Statut des juifs de Vichy. Documentation, hg. und bearbeitet von Serge KLARSFELD, Les Fils et Filles de déportés Juifs de France (FFDJF), Paris 1990. Zu den Verordnungen des MBF siehe Philippe HérACLÈs, La Loi nazie en France, Paris 1974. 
meldet werden ${ }^{320}$. Ein weiteres französisches Gesetz vom 4. Oktober 1940 sah die Möglichkeit vor, ausländische Juden in Lagern zu internieren. Dieses Gesetz bildete die Grundlage für die Errichtung von Lagern auch in der ZNO, in denen die französische Regierung seit 1940 ausländische, oft aus Deutschland geflohene Emigranten, internierte und seit dem Frühjahr/Sommer 1942 an das nationalsozialistische Deutschland zur Deportation auslieferte $^{321}$.

Die ersten Maßnahmen zur Arisierung des Theaterlebens unternahm die Propaganda Staffel Paris offenbar bereits vor Inkraftsetzung der oben genannten Gesetze gegen Juden. So schreibt das Theaterreferat in einem Bericht vom Oktober 1940, bei etwa 20 Bühnen sei bei der Wiedereröffnung den Theaterdirektoren die „Säuberung“ der Theater zur Bedingung gemacht worden:

Anfangs widerstrebend und zum Teil unwillig fügten sich die Theaterleiter, paßten sich jedoch der neugeschaffenen Lage nach dem Erscheinen des Erlasses durch den Chef der Militärverwaltung vom 27.9.40 bereitwillig an, und nachdem in Vichy der Judenstatus erschien, sind unsere bisherigen Maßnahmen anerkannt und auf das bereitwilligste durchgeführt worden ${ }^{322}$.

Diese Maßnahmen würden jedoch dadurch erschwert, daß eine sogenannte rassische Trennung in diesem Lande nicht bestanden habe. Viele Juden hätten sich mit Hilfe von Taufscheinen zu Katholiken gemacht, was eine Prüfung durch die deutschen Dienststellen erschwere. Außerdem sei die katholische Kirche auch in der aktuellen Situation gerne dazu bereit, Taufscheine auszustellen. Auf Verlangen des Beweises einer katholischen Abstammung, seien dem Theaterreferat in vielen Fällen neue Taufscheine, die aus unterschiedlichen Gegenden stammten und aktuell datiert waren, vorgelegt worden. Weiter heißt es: „Den Franzosen ist nur die einfachste Formulierung des Zwecks, mit der eine Judenausschaltung befolgt wird, begreiflich; wenn man ihnen den Anspruch auf das Vorrecht eines französischen Bewerbers vor den Juden vorhält ${ }^{* 323}$. Trotzdem betonte das Theaterreferat, daß zu diesem Zeitpunkt 27 Pariser Theater unter sogenannter judenfreier Führung waren, wobei zu Beginn der Besatzungszeit angeblich etwa 80 Prozent der Theater jüdische Besitzer gehabt hatten. Die Direktoren mußten dem Theaterreferat eine schriftliche Erklärung zukommen lassen, nach der sie erklärten, keine Juden im Sinne der Verordnung vom 27. 9. $1940 \mathrm{zu}$ sein; andernfalls waren sie ge-

320 BA-MA, RWD 19/1, Zweite Verordnung über Maßnahmen gegen Juden, 18. 10. 1940, VOBIF, 20. 10.1940.

$321 \mathrm{Zu}$ den Lagern siehe Anne Grynberg, Les camps de la honte, Paris 1991.

322 AN, AJ40 1001-7, Prop.St., Tätigkeitsbericht der Gruppe IV: Kultur, Arbeitsgebiet Theater, ohne Datum. Aus dem Text geht hervor, daß der ADTP, der am 5. 10.1940 gegründet wurde, zu dem Zeitpunkt noch in Planung war. Ferner wird ein Erlaß der Militärverwaltung vom 27.9. 1940 erwähnt. Dem Inhalt nach ist der Bericht also vermutlich zwischen dem 27. 9. und dem 5. 10. 1940 verfaßt worden.

323 Ibid. 
zwungen, das Theater an einen kommissarischen Verwalter zu übergeben und zu verkaufen ${ }^{324}$. Im August 1941, so Thalmann, war die Arisierung des Theaterlebens weitgehend abgeschlossen ${ }^{325}$. Später wurden die Theaterdirektoren dazu verpflichtet, monatlich einen Fragebogen des Referats ausfüllen. Darin mußte auch die Frage beantwortet werden, ob sich unter den Mitarbeitern des jeweiligen Theaters Juden befänden ${ }^{326}$.

Unterstützt wurden die Maßnahmen zur Arisierung unter anderem auch durch Hinweise von französischer Seite. In dem oben erwähnten Bericht vom Oktober 1940 heißt es: „Durch Denunziationen, die in galantesten Nebenbemerkungen eingeflochten werden, geben die Franzosen gern Hinweise auf noch getarnt beschäftigte Juden, Anzeigen mit voller Verantwortung sind selten“"327. SS-Sturmbannführer Helmut Knochen, Beauftragter des Chefs der Sipo-SD in Paris, sandte an die Propaganda Staffel Paris im November 1940 in deutscher Übersetzung einen anonymen französischen Brief über „das Wirken gewisser Juden, Halbjuden und Freimaurer im französischen Theater oder Kabarett ${ }^{* 328}$. Dessen Autor gab an, durch einen anti-jüdischen Artikel im Paris Soir inspiriert worden zu sein ${ }^{329}$. Er begann mit den Worten:

es ist ein Franzose, der Ihnen schreibt. Ein nationaler Franzose. Der von jeher die Juden und Maurer verabscheut. [...] Und doch gibt es Tatsachen, die Euch entgehen, weil Ihr nicht alles wissen könnt. Namentlich in der Welt der Schauspiele, die doch ihre große Bedeutung hat, wegen der dort zur Zeit gegen Euch betriebenen Propaganda der Maurer und Juden, die Ihr habt durchgehen lassen ohne es zu wissen 330 .

Allein 23 Namen von angeblich jüdischen bzw. freimaurerischen Schauspielern, Sängern und Theaterdirektoren finden sich in diesem Brief. Grundsätzlich wurden die Maßnahmen zur Arisierung zum Teil über die französische Berufsorganisation, das COIC, umgesetzt. Im Dezember 1940 versandte die-

324 AN, AJ40 1002-3, Prop.St., Gr. Kult.Th., Brief vom 14. 10. 1940 von Herrn Trébor, des Direktors der ADTP (Association des directeurs de théatres de Paris) an Theaterreferenten Baumann.

325 Thalmann, La Mise au pas, S. 146. Thalmann konstatiert an anderer Stelle folgendes: „Dans la pratique, hormis les opérations de prestige de l'ambassade l'influence de l'occupant se limite presque exclusivement à la ,déjudaison' de la scène et à la censure " (Ibid. S. 180f.).

326 Siehe AN, AJ40 1003-1.

327 AN, AJ40 1001-7, Prop.St., Tätigkeitsbericht der Gruppe IV: Kultur, Arbeitsgebiet Theater, ohne Datum. (Oktober 1940)

328 AN, AJ40 1004-1, Schreiben vom 8. 11. 1940 des Beauftragten des Chefs der SipoSD für Belgien und Frankreich, Dienststelle Paris, SS- Sturmbannführer Dr. Knochen, an die Propaganda Staffel Paris.

329 Der Artikel im Paris Soir vom 16. 10. 1940 trug nach einer Übersetzung des SipoSD den Titel „Laßt uns die Parasiten vernichten“; darin hieß es: „Die Judenfrage steht allen anderem voran. Mit ihr die Frage der Freimaurerei. Gibt es da keine Abhilfe so werden sie weiterhin frei ihr seit Jahrhunderten bestehendes Schmarotzertum ausüben können" (Ibid.).

330 AN, AJ40 1004-1, Prop.St., Gr.Kult.Th., deutsche Übersetzung eines französischen Briefes von "Lambert" an "den Herrn Direktor der Nationalsozialistischen Partei“, ohne Datum. (Oktober/November 1940) 
ses ein Rundschreiben an Produktions- und Distributionsfirmen, in welchem man die Mitglieder der Profession daran erinnerte, daß gemäß dem von $\mathrm{V}_{1-}$ chy erlassenen Gesetz vom 3. Oktober 1940 Juden fast sämtliche Berufe im Bereich des Filmes nicht mehr ausführen dürften. Da ebenso wie im Bereich des Theaters nicht immer bekannt war, ob es sich etwa bei den Filmtheatern und Filmstudios um sogenannten jüdischen Besitz handelte, setzten die deutschen Dienststellen auch hier auf Hinweise. So notierte das Referat Film im Juni 1941, häufig hätte es durch anonyme Anzeigen von Firmen erfahren, die als arisch gegolten hatten, obwohl sie Juden gehörten. Weiter heißt es dort: „Die rege und wertvolle Mitarbeit des Comité d'Organisation in dieser Frage läßt erkennen, daß man sich auch in den führenden französischen Kreisen entschlossen hat, das Judentum aus dem Filmwesen nunmehr völlig auszuschalten" ${ }^{331}$. Kooperationsbereitschaft leistete das COIC auch bei der Exklusion von Juden durch die Einführung der CIP, der Carte d'identité professionelle im November 1940. Diese Arbeitserlaubnis war Voraussetzung für jede berufliche Tätigkeit im Bereich des Filmes ${ }^{332}$. Das COIC, bei dem sie beantragt werden mußte, vergab die CIP grundsätzlich nur an sogenannte Arier und ging somit sogar weiter als das Gesetz vom 3. Oktober, das nur einen Teil der Professionen im Bereich des Filmes für Juden ausgeschlossen hatte ${ }^{333}$. Der Grund hierfür wird wohl darin zu suchen sein, daß der MBF einer Arbeitserlaubnis für die jeweilige Person noch vor Ausgabe der CIP zustimmen mußte.

Offenbar wurde diese Kontrolle mitunter vom COIC umgangen, denn in Berichten des Referats Film vom August/September 1941 wird die Klage laut, das COIC habe die Karte auch dann ausgeteilt, wenn noch keine Arbeitsgenehmigung vom MBF vorgelegen habe. Außerdem mußte das Referat bei wiederholten Kontrollen feststellen, daß Produktionsfirmen auch Arbeiter einstellten, die keine CIP vorweisen konnten. Kurzzeitig durfte daraufhin die Berufsorganisation keine Karten mehr ausgeben und sämtliche Personen, die im Besitz einer CIP waren, wurden überprüft. Für die Zukunft drohte das Referat jedem Arbeiter, der ohne CIP beschäftigt wurde, Bestrafung und Arbeitsentzug an, einzelnen Firmen wurde mit Schließung gedroht. Im Oktober sandte das Referat ein Rundschreiben an sämtliche Produktionsfirmen, um sie an die herrschenden Bestimmungen zu erinnern ${ }^{334}$. Diese Kontrolle war trotzdem nicht immer wirksam, vor allem dann nicht, wenn es sich beispielsweise bei der Produktion von Filmen um Statisten handelte, die Juden

331 BA-MA, RW35 221, Prop.Abt., Ref.Film, Tätigkeitsbericht, 5. 6.-11. 6. 1941. Zu anonymen Denunziationen siehe auch den Tätigkeitsbericht vom 11.4.-16. 4. 1941 (BA-MA, RW35 220).

332 Siehe BA-MA, RWD 19/1, Verordnung über die Betätigung auf dem Gebiet des Filmwesens, 26. 11. 1940, VOBIF, 7. 12. 1940.

333 BERTIN-MAGHIT, Le Cinéma sous l'Occupation, S. 71.

334 BA-MA, RW35 223, Prop.Abt., Ref.Film, Tätigkeitsberichte, 22. 8.-29. 8. 1941; 19. 9.-26. 9. 1941; 3. 10.-10. 10.1941. 
waren. So hat die Schauspielerin Simone Signoret davon berichtet, wie sie trotz ihres jüdischen Vaters, der im Londoner Exil lebte, unter falschem Namen unter anderem auch als Statistin in einigen Filmen mitwirken konnte, ohne im Besitz einer CIP zu sein ${ }^{335}$.

Filmbetriebe und Theater, deren jüdische Besitzer oder Pächter oft in die ZNO oder ins Ausland geflohen waren, mußten zunächst von französischen kommissarischen Verwaltern treuhänderisch geleitet werden. Diese waren ausschließlich den deutschen Dienststellen verantwortlich. In einem Bericht des Referats Film vom März 1941 heißt es, inzwischen würden etwa hundert Filmfirmen solchen Treuhändern unterstehen. In den Fällen, wo die Besitzer von sich aus die betreffende Firma an einen Arier verkaufen wollten, so das Referat Film, würden solche Verhandlungen gefördert. Im Falle der Weigerung sei der kommissarische Verwalter angewiesen worden, die Betriebe einfach dementsprechend zu verkaufen. Wenn im Rahmen der französischen Wirtschaft kein Bedarf am Fortbestand des betreffenden Unternehmens bestehe, solle sie geschlossen werden ${ }^{336}$.

Die Arisierung betraf aber nicht nur direkt Persönlichkeiten wie Theaterdirektoren oder Schauspieler. Nach den deutschen Zensurbestimmungen waren Theaterstücke und Filme von Autoren, die Juden, Freimaurer, politische Gegner oder Angehörige der Feindstaaten waren bzw. dafür gehalten wurden, verboten. Ältere französische Filme wurden im Zuge einer sogenannten Bereinigung des Filmmarktes von den Besatzern eingezogen. Außerdem mußten jüdische Schauspieler ebenso wie in das Ausland emigrierte, als angeblich deutschfeindlich bekannte, französische Künstler in der Presse totgeschwiegen werden.

Seit dem Sommer 1941 verschärfte sich der Prozeß des Ausschlusses, der Verfolgung und der Unterdrückung von Juden, Freimaurern und Kommunisten $^{337}$. Im März 1941 war das Commissariat général aux questions juives eingerichtet worden, das unter der Leitung von Xavier Vallat die Arisierungspolitik der Vichy-Regierung umsetzte. Gleichzeitig wurde der Polizeiapparat reformiert und unter anderem die Police aux questions juives gegründet $^{338}$. Vichy verfolgte damit eine Strategie, die die Souveränität des französischen Staates in bezug auf das gesamte französische Gebiet bekräftigen sollte; der Verwaltungs- und Polizeiapparat diente hier als wesentliches Instrument. Im Juni 1941 erließ die Vichy-Regierung ein zweites Statut des juifs, das die Verbote des ersten Statuts noch verstärkte. Gleichzeitig begannen die französischen Behörden im Süden des Landes mit einer Zählung der jüdischen Bevölkerung. Obersturmführer Theodor Dannecker, sogenannter

335 SignORET, Nostalgie, S. 59-70.

336 BA-MA, RW35 220, Prop.Abt., Ref.Film, Tätigkeitsbericht, 13. 3.-19. 3. 1941.

$337 \mathrm{Zu}$ der im folgenden überblickshaft dargelegten Entwicklung siehe den Aufsatz von PesChansKi, Exclusion.

338 Außerdem wurde der Service de police anticommuniste (SPAC) sowie eine Police des sociêtés secrètes ins Leben gerufen. 
Judensachbearbeiter bei der Sipo-SD in Paris, erreichte im August 1941 die Einrichtung eines Konzentrationslagers in Drancy, in der Nähe von Paris, das später gleichsam zum Durchgangslager für die Deportation der ausländischen und auch französischen Juden wurde. Auf deutschen Druck hin organisierten französische Behörden und Polizei in Paris am 14. Mai, am 20.23. August sowie am 12. Dezember 1941 die ersten drei rafles, die Massenverhaftungen von Juden. Bei der letzteren wurden auch französische Juden festgenommen. Die starke Beteiligung französischer Stellen an solchen Maßnahmen war ganz im Sinne der deutschen Dienststellen, die damit negative Reaktionen der französischen Bevölkerung verhindern wollten. Zudem war die Besatzungsmacht aufgrund des eigenen Personalmangels auf den umfangreichen Apparat der französischen Polizei und Verwaltung angewiesen. Zusammen mit den Kommunisten waren es wiederum die Juden, die als erste von den Geiselerschießungen - den sogenannten deutschen Sühnemaßnahmen für die Attentate auf einzelne deutsche Soldaten - betroffen wurden. So waren unter den 471 Geiseln, die von September 1941 bis Mai 1942 in Frankreich erschossen wurden, vor allem inhaftierte Kommunisten und Juden; bis zur Libération wurden insgesamt 725 französische Geiseln erschossen ${ }^{339}$.

Das Frühjahr 1942 markierte in Frankreich den Beginn der Maßnahmen zur sogenannten Endlösung der Judenfrage. Am 27. März 1942 verließ der erste convoi de déportation Frankreich in Richtung Auschwitz. Auf deutscher Seite erhielt die SS gegenüber dem MBF die Oberhand; im März 1942 wurde Carl Oberg zum Höheren SS- und Polizeiführer für Frankreich berufen. Er war dem MBF nur nominell unterstellt und hatte als persönlicher Vertreter Himmlers ein starke Position. Auf französischer Seite war Laval seit April zurückgekehrt und von Pétain in das neu geschaffene Amt des Regierungschefs mit Verantwortung für die Innen- und Außenpolitik berufen worden. Er kontrollierte fortan die Verhandlungen mit der Besatzungsmacht um die sogenannte Judenfrage. Überzeugt von einem zukünftigen Sieg der Deutschen unterstellte er diese ebenso wie seine allgemeine Politik der Prämisse der erhofften Verhandlungen mit Hitler, in denen er einen privilegierten Platz Frankreichs in einem "Europa neuer Ordnung" erreichen wollte. So stellte Laval auf Drängen der Besatzungsmacht den französischen Verwaltungs- und Polizeiapparat für die Maßnahmen zur Judenverfolgung in Frankreich zur Verfügung. Die Zusammenarbeit zwischen deutscher und französischer Polizei regelte das sogenannte Oberg-Bousquet-Abkommen vom August $1942^{340}$.

Vom kulturellen Leben ausgeschlossen wurden im Zuge dieser Entwicklung ab dem Sommer 1942 nicht nur die Juden, die in den Theatern oder in der Filmindustrie arbeiteten. Nach einer Verordnung des MBF vom 8. Juli

339 Peschanski, Exclusion, S. $220 \mathrm{f}$.

340 Siehe dazu KASTEN, Gute Franzosen, S. 69-73; René Bousquet war Secrétaire général à la police; zu seiner Person siehe allg. Jean-Pierre Husson, L'itinéraire d'un haut fonctionnaire: René Bousquet, in: AzÉMA, BÉDARIDA, Vichy, S. 287-301. 
1942 wurde allen Juden das Betreten von Theatern, Filmtheatern und anderen kulturellen Veranstaltungsorten verboten. In einem Telegramm von Otto Abetz an das Auswärtige Amt vom 5. Juni 1942 heißt es dazu:

Gleichzeitig mit der Einführung Judenkennzeichnung mit gelbem Stern am 7. Juni beabsichtigt höherer SS- und Polizeiführer und Militärbefehlshaber für Juden ein Verbot, Betreten öffentlicher Einrichtungen und Teilnahme an öffentlichen Veranstaltungen herauszugeben. Verordnung soll etwa folgendermaßen heißen:

1a) Juden ist der Besuch aller öffentlicher Einrichtungen wie Gaststätten, Lichtspieltheater, Theater, Konzerte, Varietés verboten.

b) Ausgenommen sind rein jüdische, besonders gekennzeichnete Betriebe, Veranstaltungen und Einrichtungen.

2. Juden ist jegliche Teilnahme an öffentlichen Veranstaltungen verboten ${ }^{341}$.

Im Sommer 1942 folgten umfangreiche Massenverhaftungen, die sich gegen Juden und Kommunisten richteten. So verhaftete allein am 16. und 17. Juli 1942 die städtische Polizei mehr als 13000 Juden in Paris. Rund 11000 andere, die noch in der ZNO lebten, wurden zwischen Mai und Oktober desselben Jahres inhaftiert. Gleichwohl konnten etwa drei Viertel der Juden in Frankreich den Deportationen entkommen ${ }^{342}$. Insgesamt wurden in Frankreich etwa 80000 Männer, Frauen und Kinder deportiert, davon sind weniger als 3000 später zurückgekehrt; rund 50000 waren ausländische Juden und allein 57 Prozent wurden im Jahr 1942 verhaftet und deportiert ${ }^{343}$.

Bei der Verfolgung von Schauspielern und anderen bekannten Persönlichkeiten des kulturellen Lebens spielte in den Augen der deutschen Dienststellen neben der tatsächlichen - oder auch nur vermuteten - jüdischen Abstammung auch eine Rolle, inwieweit sie das Interesse der französischen Öffentlichkeit auf sich zogen. So dienten beispielsweise die vom Referat Film erstellten Listen von „in Frankreich tätig gewesenen jüdischen Filmschaffenden ${ }^{344}$ sowie von sogenannten deutschfeindlichen "nichtjüdischen Filmschaffenden" vor allem dem Zweck, deren Nennung in der französischen Presse zu unterbinden. Dagegen hielt das Referat die Ausarbeitung solcher Listen für die Persönlichkeiten, die in der Filmindustrie wirtschaftlich oder organisatorisch tätig waren, nicht für notwendig: „An diesen Personen ist die Öffentlichkeit weniger interessiert, so daß insoweit nichts zu befürchten ist" 345 . Befürchtet wurde hier vor allem, eine Nennung der in den Augen der Besatzungsmacht unerwünschten und gleichzeitig sehr bekannten Künstler könne in der französischen Presse gleichsam als Schwäche und mangelnde Kontrolle der deutschen Dienststellen ausgelegt werden.

341 CDJC, LXXI-97; siehe auch Europa unterm Hakenkreuz, Bd. 3, S. 213, Dok. 114.

342 Peschanski, Exclusion, S. 226.

343 KLARSFELD, Vichy-Auschwitz, Bd. 2, S. 393 f.

344 BA-MA, RW 35 223, Prop.Abt., Ref. Film, Tätigkeitsbericht 5. 9.-12. 9. 1941; siehe im Anhang des Tätigkeitsberichts die Liste der nichtjüdischen Filmschaffenden und die Liste, der in Frankreich tätig gewesenen jüdischen Filmschaffenden.

345 Ibid. 
Aufgrund ihrer Präsenz innerhalb der französischen Öffentlichkeit liefen bekannte Schauspieler und Regisseure mitunter Gefahr, von den Maßnahmen zur Arisierung besonders betroffen zu sein. Auf die in der Presse geäußerten Vermutungen hin, sie seien Juden, beeilten sich beispielsweise der Regisseur Abel Gance, die Schauspielerin Viviane Romance sowie der Regisseur und Schauspieler Sacha Guitry, dieses durch die Vorlage eines Ariernachweises beim Referat Film zu entkräften ${ }^{346}$. Auch im Falle Maurice Lehmanns, Direktor des Thêâtre du Châtelet, war die in Presse und Öffentlichkeit geäuBerte Meinung, er sei Jude, nicht ohne Bedeutung. Die Deutsche Botschaft schrieb im Dezember 1941 über Lehmann, der während der Okkupation nur unter Schwierigkeiten zeitweise seinen Beruf ausüben konnte, dieser habe auch in früheren Jahren in Pariser Theaterkreisen als Jude gegolten. Als die jüdische Abstammung in diesem Milieu noch von Vorteil gewesen sei, habe Lehmann sich zum Judentum bekannt, was er nun allein aufgrund der veränderten Umstände nicht mehr getan habe ${ }^{347}$. Auch das Referat Theater der Propaganda Staffel Paris notierte im August 1942, Lehmann werde ,in der Öffentlichkeit als Jude angesehen" 348 . Außerdem hätten weitere Nachforschungen ergeben, daß Lehmanns Vater Jude sei und seine Mutter den Jungen erst im Alter von fünf Jahren getauft habe. Lehmann, der bisher als sogenannter Halbjude eingestuft worden sei, müsse in Zukunft jedwede öffentliche Tätigkeit untersagt werden.

Trotzdem konnte der Bekanntheitsgrad der Künstler auch ein Argument für eine zeitweise Vernachlässigung der anti-jüdischen Gesetzgebung sein. Auf einen Vorschlag des Referats Film hin sollte beispielsweise die Deutsche Botschaft im August 1941 bei der französischen Regierung erwirken, diese möge vier der nach den USA emigrierten Schauspieler und Regisseure dazu überreden, nach Frankreich zurückzukehren. Es handelte sich um Michèle Morgan, Jean Gabin, René Clair und Julien Duvivier. Die letztgenannten Regisseure waren mit Jüdinnen verheiratet, für die sie, so die Vermutung des Referats, im Falle einer Rückkehr freies Geleit verlangen würden. Offenbar zogen die deutschen Dienststellen diese Möglichkeit durchaus in Betracht. Die Maßnahmen zur Arisierung standen hier hinter den Motiven für diese übrigens erfolglose Rückholung französischer Künstler zurück. Das Referat Film wollte dadurch vor allem verhindern, daß die genannten Personen in

346 ThalmanN, La Mise au pas, S. 149; Romance und Gance kehrten aus der ZNO zurück, um dem Referat Film ihren Ariernachweis zu unterbreiten; zu Viviane Romance siehe BA-MA, RW35 222, Prop.Abt., Ref.Film, Tätigkeitsbericht, 29. 8.-5. 9. 1941.

347 AN, F60 1481, DBP, Schleier an de Brinon, DGTO, 6. 12. 1941.

348 AN, AJ40 1001, Prop.St., Gr.Kult.Th., Tätigkeitsbericht, 22. 8. 1941. Paradoxerweise mußte sich übrigens Lehmann nach der Libération innerhalb der französischen Presse gegen den Vorwurf wehren, er habe an den Pforten seines Theaters gleichsam für die deutschen Besucher Parade gestanden. Siehe dazu AN, F21 5129-3, Maurice Lehmann an den Leiter der Zeitung Front National, 9. 9. 1944. 
den USA bei der Produktion sogenannter amerikanischer Hetzfilme gegen das nationalsozialistische Deutschland mitwirkten ${ }^{349}$.

Welche Bedeutung der Presse und Öffentlichkeit bei der Arisierung des kulturellen Lebens mitunter zukommen konnte, wird insbesondere am Beispiel des renommierten Film- und Theaterschauspielers Harry Baur deutlich. Eine eingehendere Darstellung seines Falles ist lohnenswert, weil sich hier die Bedeutung allein der vermuteten jüdischen Herkunft bei der Verfolgung der Künstler durch die deutschen Behörden zeigt. Der französische Schauspieler hatte seit 1909 in etlichen Stummfilmen mitgewirkt, nach 1930 spielte er unter anderem in Filmen von Julien Duvivier, Jean Dréville, Maurice Tourneur, Abel Gance, Marcel L'Herbier und Robert Siodmak ${ }^{350}$. Am 30. Mai 1942 nahm die Sipo-SD ihn zusammen mit seiner Frau Rika Radifé fest und inhaftierte beide. Baur wurde ebenso wie seine Frau verdächtigt, Jude zu sein. Nach Vernehmungen und mehreren Monaten Einzelhaft, in denen er schwer erkrankte, wurde er schließlich am 19. September 1942 aus dem Prison du Cherche-Midi entlassen, weil ihm keine jüdische Abstammung nachgewiesen werden konnte ${ }^{351}$. Seine Frau erlangte nach 115 Tagen Haft wieder ihre Freiheit. Am 8. April 1943 starb Baur im Alter von 63 Jahren in seiner Pariser Wohnung - wahrscheinlich an den gesundheitlichen Folgen der Inhaftierung, von der er sich nicht wieder erholt hatte.

Die Verhaftung Harry Baurs, die Vernehmungen sowie die Umstände seines Todes haben bisher Anlaß zu etlichen Spekulationen gegeben. So findet sich in der Sekundärliteratur unter anderem die Notiz, Harry Baur sei 1943 von den Nationalsozialisten deportiert und umgebracht worden ${ }^{352}$. Weiterhin wurde beispielsweise vermutet, Baur sei zum Verhängnis geworden, daß er zu eng mit der Besatzungsmacht kollaboriert habe. Der Schauspieler wirkte 1941 in zwei Produktionen der deutschen Continental Films in Paris mit. Kurz vor seiner Verhaftung hatte er 1942 in Berlin auf Goebbels Wunsch hin die Hauptrolle in Hans Bertrams Musikfilm "Symphonie eines Lebens“ an der Seite von Henny Porten gespielt. Anläßlich der Vorbereitungen und Dreharbeiten zu diesem Film hatte sich Baur bereits seit Mitte September 1941 in Berlin aufgehalten. Laut Le Boterf waren vier weitere deutsche Filme

349 BA-MA, RW35 222, Prop.Abt., Ref.Film, Tätigkeitsbericht, 22. 8.-29. 8. 1941; vgl. Thalmann, La Mise au pas, S. 149.

350 Baur übernahm beispielsweise die Rolle des Beethoven in „Un grand amour de Beethoven " von Abel Gance (1936), 1937 spielte er Justin Mollenard in Siodmaks „Mollenard“, 1940 verkörperte er den Volpone in Maurice Tourneurs „Volpone“ nach Theater-Dialogen von Jules Romains und Stefan Zweig, die Adaption einer Komödie Ben Jonsons.

351 PA-AA, 1218, Kult 12 Nr. 4 II, DBP, Knothe an Staatssekretär Leopold Gutterer, RMVP, 13. 10. 1942.

352 Siehe Thomas ElSAESSER, Chacun au Monde a deux patries. Robert Siodmak und das Paris der 30er Jahre, in: BOCK, JACOBSEN, SCHÖNING, Hallo, S. 87; die folgenden Ausführungen über die diversen Thesen zu Baurs Verhaftung beruhen auf der Biographie von Hervé Le Boterf, Harry Baur, Paris 1995, S. 200-216, siehe auch S. 188-199. 
mit Harry Baur geplant und nach Drewniak bezeichnete die NS-Kritik diesen als „größten Schauspieler des französischen Films"353. Diese Zusammenarbeit in Verbindung mit Gerüchten über Baurs jüdische Herkunft soll anschließend den Unmut der Nationalsozialisten hervorgerufen haben. Angeblich soll sogar Goebbels nach Ende der Dreharbeiten in Berlin Baur vorgeschlagen haben sogenannter Volksdeutscher zu werden, zumal dieser Sohn elsässischer Eltern war. Dessen Ablehnung habe dann zu seiner Inhaftierung geführt. Eine weitere nicht belegte These - vertreten von Robert Aron beinhaltete die Mitgliedschaft Baurs in der Résistance ${ }^{354}$. Als gesichert gilt jedoch nur, daß er das Engagement seines Sohnes in der Résistance befürwortete; jener war bereits 1940 nach London geflohen und hatte sich der France Libre de Gaulles angeschlossen. Weitere Spekulationen zu Baurs Verhaftung besagten schließlich, ein eifersüchtiger Schauspieler habe diesen denunziert.

Goebbels hatte die Festnahme Baurs keineswegs persönlich initiiert. Der Propagandaminister war zunächst nicht einmal über die Hintergründe der Anschuldigungen gegen den Schauspieler informiert. So sandte er kurz nach dessen Inhaftierung, am Morgen des 1. Juni 1942, ein Telegramm an die Deutsche Botschaft, das diese an die Sipo-SD weiterleiten sollte. Goebbels betonte, er erfahre seit einigen Tagen vage Beschuldigungen gegen Baur und verlange nähere Auskunft darüber, insbesondere ob sicheres Beweismaterial vorliege und wer diese Anschuldigungen erhebe. Nur wenige Stunden später sandte Goebbels an die Botschaft ein weiteres Telegramm, in dem er der Sipo-SD für die Beantwortung seiner Fragen ein Ultimatum bis zum Mittag des darauffolgenden Tages setzte ${ }^{355}$. In seiner Antwort schrieb Oberg, die Verhaftung von Baur sei bereits vor dessen Rückkehr aus Berlin geplant gewesen und vor allem aus zwei Gründen erfolgt. Demnach hatte ein Zeuge ausgesagt, daß sich Baur für 400000 Francs den Nachweis seiner arischen Abstammung gekauft hätte. Abgesehen von weiteren belastenden Aussagen war der Schauspieler gerade zu diesem Zeitpunkt verhaftet worden, weil mit der Einführung des Judensterns im besetzten Gebiet laut Sipo-SD nun die Gefahr einer Flucht Baurs in die ZNO bestanden habe ${ }^{356}$.

Aus dem 29 Seiten umfassenden Abschlußbericht der Sipo-SD über den Fall Harry Baurs geht hervor, daß es nicht etwa einzelne Denunziationen wa-

353 LE BOTERF, Harry Baur, S. 196; für die deutsche Continental Films spielte Baur 1941 in Christian-Jaques "L'Assassinat du père Noël“ sowie in Maurice Tourneurs „Péchés de jeunesse“. Zu Baur siehe auch ThalmanN, La Mise au pas, S. 212; laut Thalmann wurde Baur von der Besatzungsmacht aus Angst vor einem Skandal wieder freigelassen, angeblich unter der Bedingung, die Kosten der mit ihm in Deutschland gedrehten Filme zurückzuerstatten. "Symphonie eines Lebens" war aber der erste in Deutschland gedrehte Film Baurs und wurde nach einer Verzögerung letztlich doch aufgeführt. Siehe bei DrEwNIAK, Der deutsche Film, S. 434.

354 ARON, Histoire, S. 231-233.

355 PA-AA, 1217, Kult 12 Nr. 4 I, Goebbels an Knothe, DBP, Fernschreiben Nr. 2243 u. $2260,1.6 .1942$.

356 Ibid. Sipo-SD, Oberg an Goebbels, Fernschreiben, 2. 6. 1942. 
ren, die zu seiner Verhaftung geführt hatten. Vielmehr liefert der Bericht eine Fülle von angeblichem Beweismaterial gegen den Schauspieler, das die deutschen Behörden lange vor seiner Verhaftung erhalten hatten. So sind dort beispielsweise zahlreiche Meldungen und Hinweise sogenannter Gewährs- oder Vertrauensmänner zu finden. Diese Hinweise waren, wie im folgenden zu zeigen sein wird, in Verbindung mit anderen Faktoren für das Vorgehen der Sipo-SD gegen Baur im Frühjahr 1942 verantwortlich ${ }^{357}$. Das RMVP hatte bereits während der dreißiger Jahre, im Februar 1936, bei der Deutschen Botschaft um Auskunft gebeten, ob Harry Baur Jude sei. Als Grund für diese Anfrage nannte das Ministerium den Golem-Film in Frankreich. Baur verkörperte in „Le Golem“ (1935) von Julien Duvivier den Herrscher Rudolf II. Der Film erzählt die im jüdischen Ghetto in Prag spielende Geschichte des Golem, eine durch den Rabbiner Loew aus Lehm geschaffene Kreatur, welche die Juden vor dem Despoten retten sollte, jedoch zu einem grausamen Monster wurde ${ }^{358}$. Das RMVP übersandte der Botschaft zudem einen Zeitungsausschnitt aus der Jüdischen Rundschau vom 11. Februar 1936, in dem Baur genannt war, und betonte, der Schauspieler werde ,immer wieder von jüdischen Kreisen als einer ihresgleichen in Anspruch genommen " 359 . Einen Monat später antwortete die Botschaft, sie habe aus Filmkreisen die Auskunft erhalten, Harry Baur sei jüdischer Herkunft ${ }^{360}$. Tatsächlich galt Baur unter den Pariser Künstlern und Intellektuellen während der dreißiger Jahre als jüdischer Schauspieler. Der gebürtige Pariser war allerdings nach eigenen Angaben Sproß einer katholischen Familie aus dem Elsaß ${ }^{361}$. Gleichwohl hatte Baur die Aussage, er sei Jude, während der dreißiger Jahre nicht ausdrücklich dementiert. Zudem trugen sein angeblich jüdisches Aussehen sowie einige seiner Filmrollen, in denen er Juden verkörperte, mit dazu bei, daß die Öffentlichkeit ihn für einen Juden hielt ${ }^{362}$. Die während der dreißiger Jahre in der Öffentlichkeit verbreitete Meinung, Baur sei Jude, sollte für diesen mit Beginn der deutschen Besatzung zu einem Problem werden.

357 PA-AA, 1218, Kult 12 Nr. 4 II, SD, Betrifft: Harry Baur, ohne Datum (September 1942).

358 Der Golem-Stoff war vorher in mehreren deutschen Stummfilmen verarbeitet worden: 1915 in Henrik Galeens „Der Golem“, 1917 in „Der Golem und die Tänzerin“ unter der Regie von Rochus Giese und Paul Wegener sowie 1920 in „Der Golem, wie er in die Welt kam" von Carl Boese und Paul Wegener; letzterer spiele in allen drei Filmen die Rolle des Golem.

359 PA-AA, DBP, 2283, V11, Bd. 7, RMVP an DBP, Betr.: Golem-Film in Frankreich, 27. 2. 1936.

360 Ibid. DBP, Kühn an RMVP, Betr.: Golem-Film in Frankreich, 19. 3. 1936.

361 Auch seine Witwe - selbst Jüdin - betonte später, daß Baur weder Jude noch Kommunist, sondern ein „alter Katholik“ gewesen sei; nach seinem Tode wurde der Schauspieler auf dem katholischen Friedhof Saint-Vincent de Montmartre begraben; siehe LE BOTERF, Harry Baur, S. 207.

362 LE BOTERF, Harry Baur, Prologue. Baur spielte 1930 den Juden David Golder in dem gleichnamigen Film von Julien Duvivier; 1931 spielte Baur in „Le Juif polonais“ von Jean Kremm den Mathias. 
Bei dem Vorgehen der Besatzungsmacht gegen Baur im Frühjahr 1942 spielte die die öffentliche Meinung bzw. die Angriffe der Presse gegen ihn eine wesentliche Rolle. Das hierzu gesammelte Material nahm in dem Bericht der Sipo-SD einen großen Raum ein. Bereits im Dezember 1940 beschuldigte vor allem die Kollaborationspresse Baur, Jude und Freimaurer zu sein. Die Anschuldigungen erschienen in Artikeln zur Wiedereröffnung des Théâtre du Gymnase, wo Harry Baur in Marcel Pagnols "Jazz" die Hauptrolle spielte und Regie führte. Laut Bericht der Sipo-SD wurden zudem Theaterplakate, die Baurs Auftreten ankündigten, mit der Aufschrift „Sale Juif“ versehen ${ }^{363}$. Obgleich die Direktorin des Theaters, Paule Rolle, ihn in Schutz nahm und die Journalisten sogar aufforderte, bei ihr deponierte Dokumente über die katholische Herkunft des Schauspielers einzusehen, blieb die Resonanz in der Presse weiterhin negativ ${ }^{364}$. Auch andere Versuche, den Schauspieler zu verteidigen, wendete die Presse in das Gegenteil. Die Zeitung La France an travail schrieb am 20. Dezember 1940, ihr sei von einer Verehrerin Baurs vorgeworfen worden, den größten tragischen Schauspieler Frankreichs an den Pranger gestellt zu haben. Diese Beschwerde nahm die Zeitung jedoch nur zum Anlaß, weiter zu betonen, daß Harry Baur Jude sei ${ }^{365}$. Der für seine kollaborationistische Haltung bekannte Kritiker Alain Laubreaux bezeichnete Baur in "Je suis partout" als sogenannten Neo-Arier. Nach Protesten des Schauspielers, die dieser mit Dokumenten über seine katholische Herkunft stützte, veröffentlichte Laubreaux zwar im November 1941 einen Artikel, der dies öffentlich bekräftigte, doch die Angriffe gegen Baur in der Presse waren damit nicht beendet ${ }^{366}$.

Die Berichte französischer Vertrauensmänner, die zur Verhaftung des Schauspielers geführt hatten, gingen bereits 1941 bei mehreren deutschen Dienststellen ein. Alle schienen Harry Baur eindeutig als Juden zu identifi-

363 PA-AA, 1218, Kult 12 Nr. 4 II, SD, Betrifft: Harry Baur, ohne Datum (September 1942. Die Zeitung Le Cri du peuple berichtete demnach am 17. Dezember 1940 über Harry Baur, man habe geglaubt, von nun an nur arischen Künstlern auf Pariser Bühnen applaudieren zu können. Über Baurs Herkunft schwebe jedoch ein Zweifel. Über sein jüdisches Aussehen hätten außerdem bereits jüdische Filmleute das beste Urteil getroffen, indem sie ihn für die Darstellung des David Golder ausgewählt hätten (Ibid.).

364 Ibid. Die Zeitung Le Cri du Peuple berichtete zwar am 28. Dezember über die Initiative der Direktorin, betonte jedoch gleichzeitig, Baur bemühe sich spät um eine Richtigstellung seiner Herkunft, nachdem er zehn Jahre lang - während die Juden das Theater und den Film beherrscht hätten - die Presse ungehindert über seine jüdische Herkunft schreiben lassen.

365 PA-AA, 1218, Kult 12 Nr. 4 II, SD, Betrifft: Harry Baur, ohne Datum (September 1942).

366 LE BOTERF, Harry Baur, S. 190; siehe PA-AA, 1218, Kult 12 Nr. 4 II, SD, Betrifft: Harry Baur, ohne Datum (September 1942): Am 13. April 1942 äußerte Au Pilori in einem Artikel über Baur erneut Zweifel über dessen Herkunft und die Echtheit der Dokumente, die bewiesen, daß Baur katholisch sei; Mitarbeiter der Zeitung hätten diese zwar eingesehen, doch werde Baur in einer Ausgabe des Univers Israélite von 1911 als Jude aufgeführt. 
zieren. So erklärte beispielsweise ein französischer Friseur namens Charles Guillaud der Propaganda Staffel, er habe Baur im Jahre 1936 in dem Friseursalon, in dem er arbeitete, sagen hören: „Wir jüdischen Artisten sind die besten der Welt ${ }^{\star 367}$. Bei einem späteren Verhör nach Baurs Verhaftung sagte er zudem aus, Baur habe diesen Ausruf zur Verteidigung der Juden getan, als in dem besagten Friseursalon unter mehreren Kunden eine Unterhaltung über die sogenannte Judenfrage entstanden sei. Die Geheime Feldpolizei berichtete am 4. März 1941 von einem französischen Vertrauensmann, der angab, Baur sei bekanntermaßen in den Kreisen jüdischer Künstler eindeutig als jüdischer Schauspieler anerkannt. Der Bericht wies ferner auf ein in der Presse veröffentlichtes Foto Baurs mit Heinrich George hin, das angeblich in der Bevölkerung große Beachtung fand und, so der Vertrauensmann, der Besatzungsmacht negativ ausgelegt worden sein soll, da es einen Juden zusammen mit einem deutschen Künstler zeigte ${ }^{368}$. Beide Schauspieler waren befreundet und laut Le Boterf soll George während der Inhaftierung Baurs versucht haben, diesem zu helfen ${ }^{369}$. Ein anderer Informant ging in seiner Mitteilung an die Sipo-SD am 7. Oktober 1941 auf die Anwesenheit Harry Baurs im Berliner Sportpalast während der Rede Hitlers anläßlich der Eröffnung des Winterhilfswerks 1941/42 ein. In der französischen Presse war am 5. Oktober ein Photo des Schauspielers, das ihn auf dieser Veranstaltung zeigte, erschienen, was die gaullistische Propaganda anschließend ausnutzte. Ferner berichtete er von einem Gerücht, Baur habe für seinen sogenannten Arier-Nachweis 400000 Francs gezahlt. Daß Baur Filme in Deutschland drehen würde, werde als Beweis für die Inkonsequenz der Besatzungsmacht gesehen, die Juden dann bevorzugte, wenn sie gut zahlten. Nach Meinung des Informanten schadete der Fall Baur der deutschen anti-jüdischen Propaganda ${ }^{370}$. Unter den Vertrauensmännern war auch ein Schauspieler, der oft mit Baur zusammengearbeitet hatte. Im Mai 1942 hatte ihm in einem Pariser Restaurant angeblich die Filmschauspielerin Monique Joyce erzählt, Baur habe ihr gegenüber während der Dreharbeiten zu „Péchés de Jeunesse" erwähnt, daß er sich für 400000 Francs falsche Geburtspapiere habe anfertigen lassen. Nun sei es ihm möglich, zu verbreiten, „daß er das Kind einer Nonne sei, die von einem Mönch vergewaltigt worden wäre“371. Nach Baurs Verhaftung bestätigte die Schauspielerin diese Darstellung während einer Vernehmung und fügte

367 PA-AA, 1218, Kult 12 Nr. 4 II, SD, Betrifft: Harry Baur, ohne Datum (September 1942).

368 Ibid.

369 LE BOTERF, Harry Baur, S. 211; George und Baur sollen sich bei den Dreharbeiten zu „Le Cap perdu“ (1931) von Ewald André Dupont kennengelernt haben. Das Foto der beiden war anläßlich des Theatergastspiels des Schillertheaters am 25. und 26. Februar 1941 in Paris gemacht worden. Das Ensemble führte an der Comédie-Française Schillers „Kabale und Liebe“ auf.

370 PA-AA, 1218, Kult 12 Nr. 4 II, SD, Betrifft: Harry Baur, ohne Datum (September 1942).

371 Ibid. 
hinzu, daß nach Ansicht vieler Künstler die Ehefrau von Baur eine türkische Jüdin sei. Die im Bericht der Sipo-SD aufgeführten Hinweise zu Baurs Person betrafen jedoch nicht nur seine angeblich jüdische Abstammung, sondern auch antideutsche Äußerungen des Schauspielers. Gemäß der Aussage eines Pariser Arztes soll Baur in einem Restaurant laut ausgerufen haben, er werde sämtliche Kollaborateure erschießen. Am 30. Mai 1942 - also am Tag seiner Verhaftung - soll er sogar während eines Essens folgendes gesagt haben: „Ich habe in Berlin mit verschiedenen Boche-Generälen gespeist, und sie haben mir erklärt, daß der Krieg für Deutschland verloren wäre "372. Seine Frau soll gemäß einer weiteren Zeugenaussage bei ihrer Ankunft auf dem Pariser Bahnhof nach der Rückkehr aus Berlin erklärt haben, die Deutschen könne man nur durch eine Blockade oder eine Hungersnot fertig machen.

Auch wenn man dem Bericht der Sipo-SD keinesfalls ohne Einschränkungen wird Glauben schenken dürfen, so liest sich dieser dennoch nahezu wie eine Verleumdungskampagne innerhalb der Kollaborations-Presse und Teilen der französischen Öffentlichkeit, unterstützt von den Berichten der Vertrauensmänner. Die Anfeindungen gegen Baur waren vielschichtig und hatten ihren Ursprung bereits in den dreißiger Jahren. Zum einen wurde dem angeblich jüdischen Baur vorgeworfen, mit den Deutschen zu kollaborieren, zum anderen soll er deutschfeindliche Aussagen gemacht haben. Die Besatzungsmacht sah sich ihrerseits dem Vorwurf ausgesetzt, sie arbeite in aller Öffentlichkeit mit einem jüdischen Schauspieler zusammen und sei in ihrer anti-jüdischen Haltung somit inkonsequent. Vermutlich war es auch diese mehrdeutige Persönlichkeit des Schauspielers - man hielt ihn für einen Juden, einen Kommunisten oder einen Kollaborateur - die dazu beitrug, daß der renommierte Schauspieler nach seinem Ableben und nach Ende des Krieges nahezu in Vergessenheit geriet ${ }^{373}$.

Aktueller Anlaß für die Verhaftung Baurs im Mai 1942, die vor allem im Kontext der Einführung des Judensterns in Frankreich im Juni 1942 zu sehen ist, war laut Bericht der Sipo-SD nicht allein das gegen ihn gesammelte Material, sondern auch die Befürchtungen der deutschen Dienststellen, es könne nach der Rückkehr Baurs aus Berlin zu negativen Reaktionen in deutschfreundlichen Kreisen der französischen Öffentlichkeit kommen. Baur hatte anläßlich der Dreharbeiten zu „Symphonie eines Lebens“ mehrere Monate in Berlin verbracht. Presseberichte über seine Rückkehr aus Berlin, wurden von den deutschen Dienststellen verhindert. Sipo-SD und Referat Film kamen nach seiner Verhaftung überein, die auf dem Markt befindlichen Filme mit Baur erst allmählich zurückzuziehen und die Aufführung neuer Filme zu unterbinden ${ }^{374}$. Baur wurde also auch seine enge Zusammenarbeit mit den Deutschen in Verbindung mit zahlreichen Gerüchten über seine jüdische

372 Ibid.

373 Le Boterf, Harry Baur, siehe den Prolog.

374 BA-MA, RW35 226, Prop.Abt., Gr.Film, Tätigkeitsbereicht, 13. 6. 1942. 
Herkunft zum Verhängnis. Ausschlaggebend für seine Verhaftung war die allgemeine Entwicklung in Frankreich hinsichtlich der Verschärfung der Maßnahmen zur Arisierung.

Über Baurs Verhalten während der Vernehmungen durch die Sipo-SD ist bisher viel spekuliert worden, zumal dieser im Anschluß nur wenig über die schmerzliche Erfahrung der Inhaftierung und der Verhöre sprach ${ }^{375}$. Die Sipo-SD bezeichnete den Schauspieler während des ersten Verhörs als „sehr

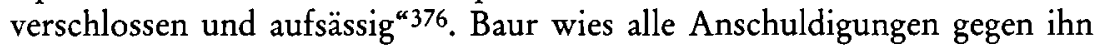
strikt zurück und weigerte sich zudem, auf die Vorwürfe gegen ihn einzugehen und sie zu erklären: „Die ihn belastenden Äußerungen von Franzosen, die ihn persönlich kannten, bezeichnete er rundweg als Lüge“"377. Nach einem ersten erfolglosen Verhör stellte die Sipo-SD weitere, intensive Nachforschungen an. Nach wie vor schien Harry Baur demnach aufgrund vieler Berichte als Jude zu gelten. Die Nachprüfungen ergaben zudem jedoch die Richtigkeit seiner katholischen Herkunft. Verhört wurden auch weitere sogenannte Zeugen, darunter der berühmte französische Filmschauspieler Muraire Raimu. Laut Bericht der Sipo-SD soll dieser auf Befragen erklärt haben, daß Harry Baur in Kreisen der Künstler als Jude angesehen werde. Zudem habe Raimu als Auskunftsperson die Schauspielerin Rosine Deréan angegeben, die ihm kürzlich erklärt habe, daß Baur sich nach den Dreharbeiten zu dem Film „Taras Bulba“"378 (1938) falsche Papiere besorgt habe, „um die Möglichkeit zu haben, diesen Film ungehindert in Deutschland erscheinen zu lassen"379. In einem Verhör bestätigte die Schauspielerin anschließend diese Aussage und gab an, sie habe davon wiederum durch Paulette Dorysse erfahren. Als die Sipo-SD diese verhörte, antwortete sie, sie habe ihrerseits die Geschichte um Harry Baurs Paßfälschung im Juni 1942 während einer "Gesellschaft, an der ausschließlich Filmschauspieler teilnahmen“, gehört. Harry Baur wurde somit auch Opfer von Gerüchten, die innerhalb der französischen Film- und Theaterwelt kursierten. Zudem fand sich in den Verhören der französischen Zeugen immer wieder die Aussage, daß Baur bereits während der dreißiger Jahre für einen Juden gehalten worden sei oder sich

375 LE BOTERF, Harry Baur, S. $212 \mathrm{f}$.

376 PA-AA, 1218, Kult 12 Nr. 4 II, SD, Betrifft: Harry Baur, ohne Datum (September 1942).

377 Ibid. In dem Verhör übernahm Baur die Verantwortung für die Fälschung seines Familienbuches hinsichtlich des Mädchennamens seiner Frau, er war von Rebecca Behar in Refka Böhör Beyar umgeändert worden. Er erklärte jedoch, daß er nicht wisse, wer diese vorgenommen habe. Seine Frau erklärte später während eines Verhörs, daß ihr Sohn, Cecil Baur, diese Änderung vorgenommen habe, weil ihm auf dem Sekretariat an der Universität in Paris vorgehalten worden war, seine Mutter sei Jüdin.

378 In der englischen Filmproduktion „The Rebel son“ bzw. „Taras Bulba“ von Adrian Brunel und Albert de Courville nach einer Geschichte von Nikolai Gogol spielte Baur den Kosackenanführer Taras Bulba.

379 PA-AA, 1218, Kult 12 Nr. 4 II, SD, Betrifft: Harry Baur, ohne Datum (September 1942). 
angeblich selbst als Juden bezeichnet habe. Entlastend waren für Baur die Vernehmungen seiner Frau und vor allem die seines Neffen Antoine Marcel Barincou. Die Sipo-SD betonte, daß er zur Klärung vieler Fragen beigetragen und zudem einen glaubwürdigen Eindruck gemacht habe. Die Argumente, die Baur in den Augen der Sipo-SD zu entlasten schienen, zielten gleichsam auf eine Art Unzurechnungsfähigkeit seiner Person ab. So betonte Barincou, sein Onkel sei als Schauspieler sehr begabt, doch benehme er sich in Alltagsfragen wie ein Kind: „Er versteht vom praktischen Leben absolut nichts“380. Barincou zeigte sich über das belastende Material nicht verwundert, weil es vor dem Krieg in dessen beruflichem Interesse gelegen hatte als Jude zu erscheinen: „Ohne dies wäre es ihm unmöglich gewesen, eine so glänzende Karriere zu machen"381. Obwohl Baur zunächst alle Vorwürfe gegen ihn abgestritten hatte, änderte sich dieses Verhalten im Verlaufe der offenbar zermürbenden Verhöre. Nach einer „energischen Zurechtweisung und Vorhaltung " 382 , daß der Tatbestand der Sipo-SD bekannt sei, gab Baur zu, daß sein Sohn den Vor- und Nachnamen seiner Frau in dem Familienbuch gefälscht habe. Auf die Aufforderung, eine abschließende Erklärung abzugeben, soll Baur angeblich spontan ausgesagt haben, er sehe ein, daß die deutschen Polizeibehörden angesichts der Fülle an Belastungsmaterial das Recht und die Pflicht zu einer Untersuchung seines Falles gehabt hätten. Angesichts der harten Haftbedingungen ist freilich undenkbar, daß Baur tatsächlich dieser Ansicht war. Vielmehr zeigt sich hier, daß die Inhaftierung ihre Auswirkungen auf den Widerstandswillen und den Allgemeinzustand des Schauspielers zeigte. Laut Le Boterf erlaubte man Baur während der gesamten Zeit seiner Haft nicht, seine Kleidung zu wechseln. Sein Gesundheitszustand litt besonders stark, weil ihm Medikamente, die er dringend brauchte, vorenthalten wurden. Zudem saß er in Einzelhaft und durfte keinerlei Besuch erhalten ${ }^{383}$. Vor diesem Hintergrund sind auch die folgenden Sätze zu sehen, die zu seiner angeblichen Abschlußerklärung gehörten:

Ich weiß, daß ich von Seiten meiner Landsleute als Jude betrachtet und verleumdet worden bin. Ich bin sogar beschimpft und bedroht worden. Anläßlich der Schließung des Theaters Gymnase habe ich tagtäglich anonyme Briefe und Drohbriefe erhalten, in denen ich als Jude bezeichnet wurde. Ich habe auch zahlreiche Telefonanrufe erhalten, in denen ich als Jude beschimpft worden bin. Die gegen mich geführte Hetze erreichte nach meiner Rückkehr aus Berlin den Höhepunkt.[...] Bei meiner Ankunft im Gefäng-

380 Ibid.

${ }^{381}$ Ibid. Die Überzeugung der Öffentlichkeit, daß er Jude sei, führte Barincou vor allem auf den Namen Baurs zurück, der nicht sehr französisch klinge und in jüdischen Lexika zu finden sei, außerdem auf dessen Beziehungen zu Baron Rothschild sowie einflußreichen Juden aus dem Bereich des Theaters.

382 Ibid.

383 LE BOTERF, Harry Baur, S. 200-216. 
nis hörte ich, wie man vor meiner Zelle sagte: „Endlich haben sie ihn erwischt, den Juden aus der rue des Rosiers" 384 !

Damit sollte in dem Bericht der Eindruck betont werden, schuld an der Inhaftierung Baurs sei vor allem die französische Öffentlichkeit, die ihn als Juden bezeichnet und zum Teil beschimpft habe. Vollkommen unglaubhaft wirkt allerdings auch die abschließende Erklärung Baurs, er sei den deutschen Behörden dankbar, seinen Fall geklärt zu haben. Aus dem Bericht der Sipo-SD geht hervor, daß die Vorwürfe gegen Baur zwar nicht vollkommen entkräftet werden konnten, aber auch keine Beweise etwa für eine jüdische Herkunft erbracht werden konnten. Angeblich wurde Baur deswegen wieder freigelassen; hier ist jedoch der schlechte Gesundheitszustand Baurs anzuführen, der nach seiner Entlassung nicht wieder gesundete und seine Wohnung nicht mehr verließ. Seine Frau, deren jüdische Abstammung die SipoSD als erwiesen ansah, blieb nach ihrer Entlassung unbehelligt. Baur, der am 8. April 1943 vermutlich an den Folgen seiner Haft verstarb, sollte die Uraufführung seines letzten Filmes, der "Symphonie eines Lebens“, am 21. April 1943 in Berlin nicht mehr erleben. Goebbels hatte sich kurz nach der Entlassung Baurs vorbehalten, über die Zulassung dieses Filmes in Deutschland erst nach Einsichtnahme des Abschlußberichtes der Sipo-SD zu entscheiden $^{385}$. Ende Dezember 1942 hatte der Propagandaminister schließlich angeordnet, das Spielverbot Harry Baurs aufzuheben und diesen für die Continental-Films vertraglich zu verpflichten, damit keine andere Produktionsfirma ihn verpflichten konnte. Er wollte Baur unbedingt vertraglich binden „ohne Rücksicht darauf, ob und wann er verwendet werden kann"386. Die Entscheidung, ob Baur jemals wieder in einem Film spielen sollte, behielt er sich persönlich vor. Goebbels wollte damit jegliche weitere schauspielerische Aktivität Baurs allein bestimmen. Der hochrangige französische Schauspieler sollte für die deutsche Continental reserviert werden und nicht der französischen Filmproduktion, die als Konkurrenz gesehen wurde, von Nutzen sein.

Die Verhaftung Baurs bewirkte auf Seiten der deutschen Dienststellen in der Folge eine größere Vorsicht, wenn es darum ging, französische Schauspieler etwa für die Zwecke deutscher Kulturpropaganda einzuspannen. So mußten diese insbesondere vor offiziellen Reisen nach Deutschland nun bei der Sipo-SD einen Arier-Nachweis erbringen, unabhängig davon, ob sie dies bereits beim Referat Film der Propaganda Abteilung getan hatten. Davon betroffen waren im Juni 1942 der Schauspieler Sacha Guitry und seine Frau, die Ende Juni auf Goebbels Wunsch hin nach Berlin eingeladen werden sollten. Die Sipo-SD teilte dem Referat Film mit, aufgrund der Ermittlungen über

384 PA-AA, 1218, Kult 12 Nr. 4 II, SD, Betrifft: Harry Baur, ohne Datum (September 1942).

385 Ibid. DBP, Knothe an AA, 11. 12. 1942.

386 Ibid. DBP, Knothe an Greven, Continental-Films, 28. 12. 1942. 
dessen angeblich jüdische Abstammung solle von einer Einladung Guitrys nach Berlin erst einmal abgesehen werden, bis sein Fall geklärt sei ${ }^{387}$.

Auch bei kritischer Betrachtung des Berichtes der Sipo-SD über die Untersuchung des Falles Harry Baurs kann davon ausgegangen werden, daß die Diskussionen und Anschuldigungen innerhalb der französischen Presse und Öffentlichkeit sowie die Denunziationen für das Vorgehen der deutschen Behörden gegen diesen bekannten Schauspieler eine entscheidende Rolle gespielt haben. Der Bekanntheitsgrad Baurs und seine Tätigkeit für den deutschen Film führten einerseits zeitweise dazu, daß er wegen der Gerüchte um seine Abstammung nicht behelligt wurde, andererseits waren gerade diese Aspekte letztlich für seine Verhaftung ausschlaggebend. Baur wurde entlassen, obgleich die Sipo-SD weiterhin der Überzeugung war, er sei Jude, nur könne ihm dies nicht nachgewiesen werden. Da Goebbels auch nach dessen Freilassung noch auf die Arbeitskraft Baurs spekulierte, zeigt sich hier, daß trotz der rasseideologischen Gesichtspunkte in den Augen des Propagandaministers die Bedeutung Baurs für die deutschen Filminteressen im Vordergrund stand. Das Zusammenspiel rasseideologischer, wirtschaftlicher und propagandistischer Interessen der Besatzungsmacht kennzeichnet auch die Politik der wirtschaftlichen Inbesitznahme und Ausbeutung der französischen Filmindustrie.

\subsection{Wirtschaftliche Inbesitznabme der französischen Filmindustrie}

Die dargelegten Maßnahmen zur sogenannten Säuberung des kulturellen Lebens gingen im Bereich des Filmes einher mit einer Politik der wirtschaftlichen Inbesitznahme. Der Zusammenhang insbesondere zwischen aryanisation und wirtschaftlicher mainmise ist von der Besatzungsmacht gegenüber dem französischen Wirtschafts- und Finanzministerium immer wieder verneint worden. Arisierung bedeute nicht, daß die betreffenden Firmen in deutsche Hände fielen. Dennoch war sich die französische Seite dieser Verbindung sehr wohl bewußt ${ }^{388}$. Die Besatzungsmacht kaufte vor allem die kommissarisch verwalteten Filmtheater, die zuvor Juden gehört hatten. Nicht selten liefen diese Geschäfte über französische Strohmänner. Einige Filmtheater wurden als sogenannte Soldatentheater beschlagnahmt ${ }^{389}$. Das

387 BA-MA, RW35 226, Prop.Abt., Gr.Film, Tätigkeitsbericht, 13. 6. 1942; zu den intensiven Vorgesprächen Diedrichs mit Guitry siehe ibid. Tätigkeitsberichte, 9. 5. 1942, 23. 5. 1942, 1.6. 1942. Die Einladung Guitrys ist im Kontext der vorangegangenen Reise französischer Schauspieler nach Berlin vom 18.-31. März 1942 zu sehen, die wie andere Reisen französischer Künstler und Intellektuellen nach Deutschland zu einem positiven Bild des nationalsozialistischen Deutschland in Frankreich hatte beitragen sollen.

388 Siehe beispielsweise AN, F37 2, Ministère de l'Économie nationale et des Finances, de Montalembert, Note, Réunion des affaires juives du 30 octobre 1942, 2.11. 1942.

389 Siehe dazu vor allem DREWNIAK, Der deutsche Film, S. 723-734 und BERTIN-MAGHIT, Le Cinéma sous l'Occupation, S. 21-33 sowie den veröffentlichten Bericht der 
französische Wirtschafts- und Finanzministerium berichtete von einem weiteren Vorgehen: In einigen Fällen hätten sich die Interessenten auch direkt an die Besitzer gewandt und diesen für die Filmtheater einen überhöhten Preis angeboten. Dies hätte den Erwerb der Theater durch französische Firmen völlig unmöglich gemacht ${ }^{390}$. Im Gegensatz dazu erwarb die Besatzungsmacht in Paris kein einziges Theater. Zwar hatte es von seiten des Pariser Theaterreferats Initiativen dazu gegeben, weil man hoffte, auf diese Weise vermehrt deutsche Werke in den angekauften Theatern spielen zu können, doch wurden solche Pläne nie verwirklicht. Die Gründe hierfür gehen aus den Akten des Referats nicht hervor. Es ist aber wahrscheinlich, daß der finanzielle Aufwand deswegen vom RMVP gescheut wurde, weil das propagandistische Interesse am Theater allgemein geringer war als am Film ${ }^{391}$. Das Theaterreferat betrieb allerdings das beschlagnahmte Théâtre des ChampsElysées mit seinen Bühnen Studio und Comédie ${ }^{392}$. Ferner mußten in den Pariser Theatern auch einzelne Plätze für die Angehörigen der Besatzungsbehörden reserviert werden. Für KDF-Veranstaltungen beschlagnahmte die Besatzungsmacht häufig das Théâtre National du Palais de Chaillot ${ }^{393}$.

Nach Goebbels Vorstellungen sollte der deutsche Film in der Zukunft den europäischen Markt vollständig beherrschen, wofür die Voraussetzungen schon während des Krieges geschaffen werden sollten. Die politische und militärische Situation wollte der Propagandaminister ausnutzen, um den deutschen Film auch über den Krieg hinaus in Frankreich zu etablieren. Vor allem in dem Ankauf von Filmtheatern sah er langfristig die einzige Möglichkeit, deutsche Filme in französische Lichtspieltheater zu bringen, da man somit auf die Kooperationsbereitschaft französischer Besitzer nicht angewiesen war ${ }^{394}$. Bei dem Erwerb von Filmtheatern verbanden sich also propagandistische, ökonomische und rasseideologische Interessen miteinander. Der Ankauf und Betrieb der Filmtheater gehörte zu den Aufgaben Alfred Grevens. Hierfür stellte die seit 1937 zum großen Teil verstaatlichte deutsche Filmin-

Commission Consultative des Dommages et des Réparations, CCDR, L'Emprise Allemande sur la Pensée Française, Paris 1947 (in BDIC einsehbar). Siehe auch KREIMEIER, Die Ufa-Story, S. 394; EHRLICH, Cinema of Paradox, S. 43-46.

390 AN, F37 2, Ministère de l'Économie nationale et des Finances, DGRE, J. Terray, Note, Affaire Cinéma, 25. 4. 1941.

391 Siehe AN, AJ40 1001-7, Prop.St. u. Abt., Gr.Kult.Th., Tätigkeitsberichte, 30. 1.6. 2. 1942; 30. 12. 1942; April 1943; 26. 5. 1943; Aktennotiz über die Besprechungen am 19., 20. und 21. 3. 1942 in Berlin mit den Herren Ministerialdirektor Dr. Schlösser, Dr. Lang und Herrn Bollert von der Auslandsabteilung RMVP, Paris, den 28. März 1942; Aktennotiz, 16. 4. 1942.

392 Ibid. Bericht über den Monat April 1943.

393 Siehe dazu beispielsweise zahlreiche Beschwerde-Briefe des Direktors des Théâtre National du Palais de Chaillot, Pierre Aldebert, an das Secrétariat des Beaux-Arts im Ministère de l'Éducation nationale, AN, F21/5272. Der Aspekt der Beschlagnahmungen zu KDF-Zwecken wird im folgenden nicht berücksichtigt werden.

394 Siehe beispielsweise Goebbels Rede vor den Filmschaffenden am 28. 2. 1942 in Berlin, abgedruckt in: ALBRECHT, Nationalsozialistische Filmpolitik, Dokument 6, S. 486. 
dustrie ganz erhebliche Geldbeträge zur Verfügung. In der Aufzeichnung einer Sitzung des Wirtschaftsausschusses der Ufa am 28. Oktober 1941 heißt es: „Für die aus politischen Gründen erstrebte Interessennahme der reichsmittelbaren Filmwirtschaft an der französischen Produktion und den westeuropäischen Theaterparks hat die Ufa zunächst einen Betrag von 10 Millionen Reichsmark bereitgestell ${ }^{\alpha 395}$. Allein auf Frankreich entfielen davon 7 Millionen Reichsmark. 1,5 Millionen steuerte die Ufa zum Gründungskapital der Continental Films (3 Millionen) bei. Die restlichen 3 Millionen waren für ähnliche Geschäfte in Belgien und Holland bestimmt. In dem Protokoll wird weiter berichtet, die Terra Filmkunst $\mathrm{GmbH}$ werde demnächst 4 Millionen Reichsmark für derartige Investitionen bereitstellen. Verwaltet wurde dieses Geld von Max Winkler, dem Leiter der Cautio Treuhandgesellschaft $\mathrm{mbH}$, der es wiederum an Greven weiterleitete ${ }^{396}$. Aus einem Bericht über die Greven-Gesellschaften im Jahr 1943 geht hervor, daß Greven 14 Millionen Reichsmark erhalten hatte, wovon 1,5 Millionen für Belgien bestimmt waren ${ }^{397}$. Gleich zu Beginn der Besatzung hatte Greven im Herbst 1940 in Paris sämtliche Filmtheater der sogenannten Siritzky-Kette für die vergleichsweise geringe Summe von einer Million Reichsmark gekauft; neben etlichen Filmtheatern in der Provinz war darunter vor allem auch ein Teil der größten $\mathrm{Pa}$ riser Uraufführungstheater, der Salles d'éxclusivité. Offizieller Käufer war die von Greven gegründete Société de gestion et d'exploitation du cinéma (SOGEC) ${ }^{398}$. Gerade der Erwerb dieser Filmtheater war für die deutsche Filmpolitik im besetzten Frankreich von besonderer Bedeutung. Im September 1941 betonte das Referat Film, auf französischer Seite bestehe verständli-

395 Aufzeichnung von einer Sitzung des Wirtschaftsausschusses der Universum Film AG am 28. Oktober 1941 über das Eindringen in die westeuropäische Filmwirtschaft, abgedruckt in: NeSTLER, Europa unterm Hakenkreuz, Bd. 3, Dok. 75, S. 181. Siehe auch DREWNIAK, Der deutsche Film, S. 724; laut Drewniak soll das RMVP insgesamt im Jahre 194130 Millionen Reichsmark für den Erwerb von Filmtheatern in Frankreich und den Umbau von Filmtheatern in anderen, vom Reich annektierten Gebieten, ausgegeben haben.

${ }_{396}$ Aufzeichnung von einer Sitzung des Wirtschaftsausschusses der Universum Film AG am 28. Oktober 1941 über das Eindringen in die westeuropäische Filmwirtschaft, abgedruckt in: NESTLER, Europa unterm Hakenkreuz, Bd. 3, Dok. 75, S. 181. BA-KO, R109 III/34, Cautio an Greven, Continental, 17. 12. 1940; ibid. R109 I/2919, Cautio, Winkler an Regierungsrat Masserer, Reichswirtschaftsministerium, Abschrift, 28. 10. 1942.

397 BA-KO, R109 I/2025, Ufa, Vorläufiger Bericht zu dem Abschluß der Greven-Betriebe in Frankreich und Belgien für das Jahr 1943, 6. 6. 1944. Zusätzlich erhielt er 1,3 Millionen für Ankäufe in Holland; siehe auch KREIMEIER, Die Ufa-Story, S. 394.

398 DREWNIAK, Der deutsche Film, S. 725, siehe die Liste der angekauften Filmtheater in Paris bis zum November 1940; siehe auch CCDR, L'Emprise allemande, spectacles, S. 9; BERTIN-MAGHIT, Le Cinéma sous l'Occupation, S. 28-31. Zu den günstigen Konditionen dieser Ankäufe siehe BA-KO, R109 I/2025, Ufa, Vorläufiger Bericht zu dem Abschluß der Greven-Betriebe in Frankreich und Belgien für das Jahr 1943, 6. 6. 1944; darin heißt es: „Da Herr Greven schnell handelte, sind diese Theater in der Mehrzahl der Fälle überaus günstig erworben worden“. 
cherweise der Wunsch „für den Start französischer Filme der unabhängigen französischen Filmherstellung entsprechende Uraufführungstheater zu si-

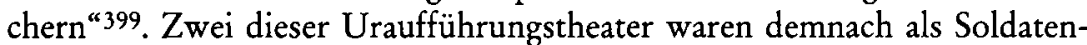
kinos beschlagnahmt worden, eine Reihe anderer ebenfalls in deutschem Besitz, während auch die Italiener für den Start italienischer Filme Interesse angemeldet hatten. Referatsleiter Diedrich war der Ansicht, bis zu einer späteren Freigabe der Soldatenkinos könnten eventuell zwei einfache Filmtheater zu Uraufführungstheatern gemacht werden ${ }^{400}$. Dieser Vorschlag dürfte allerdings nur ein schwacher Trost für die französischen Filmproduzenten gewesen sein, die ihre neuen Filme praktisch überhaupt nicht mehr en exclusivité auf den Markt bringen konnten.

Sicherlich war auch dies mit ein Grund dafür, daß die französischen Behörden versuchten, Greven an dem weiteren Ankauf von Filmtheatern zu hindern. Im Juni 1941 vermerkte das Referat Film, daß es Greven in einigen Fällen nicht gelungen war, Pariser Filmtheater zu erwerben, obwohl er auf die französischen Verhandlungspartner starken Druck ausgeübt hatte. Das Referat vermutete hier eine Verzögerungstaktik der französischen Kommissare, welche die Filmtheater vorläufig verwalteten. Aus sogenannten vertraulichen Äußerungen der Verwalter ging hervor, daß die Regierung in Vichy die Anweisung erteilt hatte, die Verkaufsverhandlungen um vier bis sechs Wochen zu verschleppen, falls die Käufer auftauchten, die nun allmählich als Strohmänner Grevens bekannt waren ${ }^{401}$. Als Gegenmaßnahme entsandte Major Schmidtke ein Schreiben an das COIC, in dem er daran erinnerte, daß die Eröffnung eines Filmtheaters der Genehmigung des Referats bedürfe. In Zukunft sollte die Erlaubnis nur dann erteilt werden, wenn die deutsche Dienststelle noch vor Abschluß der Verkaufsverträge über den Käufer informiert wurde. Jedes bereits in Betrieb befindliche Filmtheater sollte die Genehmigung verlieren, wenn das Referat vor dem Verkauf nicht unterrichtet worden ist. Filmtheater, die nach dem 23. Mai 1940 arisiert wurden, verloren die Genehmigung, falls sich der Verkauf als sogenanntes Scheingeschäft herausstellte. Schmidtke ermahnte das COIC, diese Bestimmungen möglichst schnell den Filmtheaterbesitzern bekannt zu machen. Außerdem wurde dieser Brief in Kopie sämtlichen Staffeln und Außenstellen zugesandt. In dem Anschreiben hierzu heißt es unter anderem: „Die Regelung des anliegenden Schreibens ist daher eine Kampfmaßnahme, die jedoch französischen Stellen und Filmtheater-Besitzern gegenüber nicht als solche bezeichnet werden darf" ${ }^{402}$. Auf diese Weise versuchte das Referat Film, den Verkauf von Filmtheatern an andere französische Käufer als die Strohmänner Grevens zu ver-

399 BA-MA, RW35 223, Prop.Abt., Ref.Film, Tätigkeitsbericht, 29. 8.-5. 9. 1941. Im Gegensatz zu der unabhängigen französischen Filmherstellung liefen die ContinentalFilme freilich ohne Probleme in den großen Uraufführungstheatern an.

400 Ibid.

401 BA-MA, RW35 221, Tätigkeitsbericht, 19. 6.-24. 6. 1941.

402 Ibid. 
hindern. Doch auch im Juli 1941 berichtete das Referat Film noch von Schwierigkeiten in Hinsicht auf Grevens Kaufpläne. Demnach wehrte sich die französische Seite gegen sogenannte Überfremdung, was laut Referat nicht für die Anzahl sondern die Bedeutung der von Greven angekauften Filmtheater zutraf. Deutsche Beteiligungen, an den Unternehmen ließen die französischen Verhandlungspartner eher zu, in einigen Fällen sogar Mehrheitsbeteiligungen. Dies reichte nach Ansicht des Referats Film aus, „weil hierdurch in jedem Falle die Führung des Theaters und besonders das Spielen deutscher Filme gewährleistet wird“403.

Die französische Seite war jedoch nur wenig überzeugt von dem Erfolg der eigenen Versuche, eine deutsche Inbesitznahme der französischen Filmindustrie zu verhindern. So befand das Wirtschafts- und Finanzministerium im September 1941 angesichts der Aktivitäten der SOGEC und der Continental: „Il est certain qu'à l'heure actuelle le secteur ,cinéma' est celui de toute l'économie française où la souveraineté française a pu être le moins bien sauvegardée" 404 . Bereits jetzt sei der Filmtheaterpark der SOGEC der wichtigste in Frankreich. In einem anderen Bericht des Ministeriums heißt es, die französische Filmwirtschaft befinde sich aufgrund der mainmise durch die Greven-Gesellschaften in einer schwierigen Situation. Das COIC und der Filmbeauftragte der Vichy-Regierung in Paris hätten zwar versucht, die von Greven anvisierten Filmtheater vorher durch französische Firmen ankaufen zu lassen, doch sei dies nicht gelungen. Es müßten möglichst schnell einige französische Firmen gegründet werden, welche mit der finanziellen Unterstützung des Staates diese Aufgabe übernehmen könnten. Diese Firmen müßten die Filmtheater, die noch übrig seien, oder eventuelle neue Filmtheater ankaufen ${ }^{405}$. Diese Gegenmaßnahmen hinderten Greven letztlich nicht daran, seinen Filmtheaterpark bis Ende 1942 weiter auszubauen. Zeitweise versuchte er sogar, Filmtheater in Algerien zu erwerben ${ }^{406}$ und kaufte weiterhin Filmtheater in Paris und Umgebung, seit dem Sommer 1941 auch in der unbesetzten Zone. Im April 1941 waren 23 Filmtheater im Besitz verschiedener Gesellschaften, hinter denen die SOGEC stand ${ }^{407}$. In einem Bericht der Ufa über „Ergebnis und Bilanz der französischen Theaterbetriebe $1942^{\text {“408 }}$ heißt es, der Erwerb von Filmtheatern durch Greven sei in Frankreich in die-

403 BA-MA, RW35 222, Tätigkeitsbericht, 18. 7.-25. 7. 1941.

404 AN, F37 66, Ministère de l'Économie nationale et des Finances, DGRE, Compte rendu hebdomadaire Nr. 22, 12. 9. 1941.

405 AN, F37 2, Ministère de l'Économie nationale et des Finances, DGRE, J. Terray, Note sur l'industrie du Cinéma, 11. 9. 1941. Zu weiteren Gegenmaßnahmen gegen den Ankauf der Filmtheater siehe auch ibid., J. Terray, Vermerke vom 19.6., 6. 9. und 8. 9. 1941.

406 AN, F37 66, Ministère de l'Économie nationale et des Finances, DGRE, Compte rendu hebdomadaire $\mathrm{Nr}$. 22, 12. 9. 1941.

407 Eine genaue Auflistung dieser Firmen liefert DrewnIAK, Der deutsche Film, S. 729. ${ }^{408}$ R109 I/2025, Ufa, Ergebnis und Bilanz der französischen Theaterbetriebe 1942, ohne Datum. 
sem Jahr zu einem Abschluß gekommen. Im Ergebnis standen der deutschen Filmwirtschaft 37 Filmtheater in Frankreich zur Verfügung, davon lagen allein 15 in Paris, die übrigen 22 Filmtheater waren auf weitere 10 Städte verteilt. Die in der ZNO gelegenen Filmtheater ließ Greven bis zur Besetzung ganz Frankreichs durch ein Büro in Marseille führen. Das Resümee der Ufa lautete: „Die deutsche Filmwirtschaft hat selbstverständlich die Theaterkette in Frankreich nicht aus wirtschaftlichem Selbstzweck durch Herrn Greven erwerben lassen, sondern um dem deutschen Film den gebührenden Einfluß in der französischen Filmwirtschaft zu verschaffen"409. Daß dieses Ziel jedoch noch keineswegs erreicht war, zeigen die in dem Bericht ebenfalls angeführten Einnahmen durch deutsche Filme, die weit hinter denen der französischen lagen, worauf in den Ausführungen zur deutschen Filmexportpolitik noch näher eingegangen werden soll 140.1942 wurden nahezu alle angekauften Theater von der SOGEC allein übernommen ${ }^{411}$. Grevens Imperium umfaßte von filmtechnischen Firmen einmal abgesehen, mit der Continental, den Exklusivrechten für Ateliers und dem umfangreichen Filmtheaterpark alle wichtigen Branchen der Filmindustrie ${ }^{412}$.

Auch im Bereich der filmtechnischen Industrie kann von einer mainmise allemande gesprochen werden. Zuständig war hierfür seit dem 15. Oktober 1940 in Zusammenarbeit mit dem Referat Film Dr. Hofer als Deutscher Beauftragter für die filmtechnischen Betriebe im besetzten französischen $\mathrm{Ge}$ biet. Neben der Zuteilung von Rohstoffen war dieser auch für die Überwachung von 87 französischen Betrieben - beispielsweise von Geräteherstellern und Rohfilmproduzenten - zuständig. Die Firmen erhielten von ihm grundsätzlich nur dann eine Produktionserlaubnis, wenn sie deutsche Fertigungsaufträge für Rüstungsgüter akzeptierten, Aktienanteile an deutsche Firmen verkauften oder aber filmtechnische Geräte für die deutsche Filmindustrie produzierten ${ }^{413}$. In seinem Jahresbericht Ende 1941 betont Hofer, daß es ihm in allen Fällen gelungen ist, für die filmischen Unternehmungen der Propaganda Abteilung, des OKW/WPr und vieler anderer Stellen im Deutschen

409 Ibid.

410 Siehe Kapitel III. 2.1. der vorliegenden Untersuchung.

411 R109 I/2025, SOGEC, Gewinn- und Verlustrechnung per 31. Dezember 1942; siehe Anlage 2, die Aufstellung der Theater und Theaterergebnisse 1942.

412 Einen Uberblick zu den Greven-Gesellschaften siehe in BA-KO, R109 I/2029, Greven, Vorläufiger Abschlußbericht, Lehnamühle in Thüringen, 30. 12. 1944; ibid. R109 I/2721, Ufa, Verzeichnis des Treugutes zum Stande vom 15.1. 1944; demnach hielt Greven als Treuhänder einen Anteil von 199980000 Francs des Stammkapitals der Continental, seine Mitarbeiter Bauermeister und von Eicke hielten jeweils 10000 Francs; insgesamt waren es 200000000 Francs; ein französischer Rechtsanwalt namens Dairaines hielt treuhänderisch im Auftrag Grevens ein Stammkapitel von 13420000 Francs für vier weitere Gesellschaften, darunter die SOGEC mit 570000 Francs. Hinzu kamen unter anderem beispielsweise noch Aktien-, Obligationen- und Forderungsmajoritäten der Cineac S.A. in Athen; insgesamt belief sich das Treugut Grevens auf 250556653,40 Francs.

${ }^{413}$ Bertin-Maghit, Le Cinéma sous l'Occupation, S. 32. 
Reich die notwendigen technischen Mittel von Frankreich aus bereitzustellen: "Der deutschen Filmindustrie, einschließlich der Filmvorhaben der Wehrmachtsteile, entstand gegenüber den Normalverhältnissen in Frankreich, im abgelaufenen Jahr ein Vorteil von insgesamt etwa 20 Millionen Franken, im Vergleich zur entsprechenden französischen Industrie“414. Hauptzweck von Hofers Tätigkeit war vor allem die Koordinierung und Kontrolle einer größtmöglichen wirtschaftlichen Ausnutzung der französischen filmtechnischen Industrie zugunsten der deutschen Filmindustrie, die im Laufe des Krieges mehr und mehr mit der Herstellung von Rüstungsgütern beschäftigt war. So wurden erst in den Jahren 1943 und 1944 vermehrt technische Einrichtungen für die deutsche Filmindustrie in Frankreich erworben oder beschlagnahmt. Hierfür richtete man eine Außenstelle der Berliner Filmtechnischen Zentralstelle in Paris ein ${ }^{415}$. Hofer formulierte seine Aufgaben folgendermaßen:

- Bereitstellung der notwendigen Rohfilmmengen und Chemikalien für den deutschen und französischen Bedarf, insbesondere während des kommenden Winters [...]

- Begünstigung der deutschen Filmunternehmen in Paris in der Beschaffung von filmtechnischen Geräten zum Zweck der Propaganda in Frankreich [...]

- Ausrichtung der bisher stark nach Amerika orientierten Filmtechnik auf deutsche Vorbilder und Anbahnungen dauerhafter, guter Beziehungen.

Alle diese Aufgaben sind bereits in Angriff genommen ${ }^{416}$.

Tatsächlich können die von Hofer genannten Aufgaben als wesentliche Grundsätze der in diesem Bereich verfolgten Politik der Besatzungsmacht gesehen werden. Wie sich die sogenannte Bereitstellung von Rohfilm für den deutschen bzw. französischen Bedarf in der Praxis gestaltete, zeigt eine Aufstellung Hofers vom Oktober 1941. Sein Ziel war es, den Mangel an Rohfilm in Deutschland bestmöglich zu beheben. Hofer legte in dieser Auflistung die Rohfilmproduktion der französischen Firma Kodak-Pathé so fest, daß im kommenden Jahr 3050000 Meter Rohfilm an deutsche Firmen ausgeliefert werden mußten. Lediglich 850000 Meter Rohfilm waren für den französischen Bedarf bestimmt ${ }^{417}$. Die Kontingentierung an Rohfilm begrenzte die Möglichkeiten der französischen Filmproduktion erheblich. Gegen Ende des

414 BA-MA, RW35 224, Prop.Abt., Ref.Film, Tätigkeitsbericht, 7.11.-14.11. 1941; Jahresmeldung des Deutschen Beauftragten für die filmtechnischen Betriebe im besetzten französischen Gebiet, Dr. Hofer.

415 DrewniaK, Der deutsche Film, S. 723. Zu dem Komplex der Beschlagnahmungen und Ankäufe im Bereich der filmtechnischen Industrie sowie zur Tätigkeit Hofers läßt sich in den Tätigkeitsberichten des Referats Film eine Fülle von Material finden. In den folgenden Ausführungen soll dieser Themenbereich jedoch nur überblicksartig umrissen werden, zumal es sich hier vor allem auch um die Durchsetzung wirtschaftlicher Interessen der Besatzungsmacht gehandelt hat.

${ }^{416}$ Jahresmeldung des Deutschen Beauftragten für die filmtechnischen Betriebe im besetzten französischen Gebiet, Dr. Hofer, abgedruckt in: BA-MA, RW35 224, Prop.Abt., Ref.Film, Tätigkeitsbericht, 7. 11.-14. 11. 1941.

417 Ibid. Tätigkeitsberichte, 17. 10.-24. 10. 1941; 13. 6.-20. 6. 1942. 
Jahres 1942 wurde ein Teil der Aufgaben Hofers von der Filmprüfstelle der Propaganda Abteilung übernommen, weil sein Posten aufgelöst wurde418.

Mit der von Hofer genannten Ausrichtung der filmtechnischen Ausrüstung französischer Ateliers auf deutsche Vorbilder, zielten die Besatzer langfristig auf eine wirtschaftliche Verflechtung von deutscher und französischer Filmindustrie ab, um letztere auch nach dem Kriege ökonomisch weiterhin beherrschen zu können. Kurzfristig hatte eine wirtschaftliche Kollaboration freilich den Zweck, die französische Filmindustrie zugunsten der deutschen ausnutzen zu können. In einem Bericht des Referats Film vom April 1941 werden unterschiedliche Filmstudios und Kopierwerke angeführt, die bereit waren, ihre meist amerikanischen Tonfilm-Aufnahme-Apparaturen durch deutsche zu ersetzen. Abschließend heißt es, mehrere französische Ateliers zeigten eine ernste Absicht, sich in Zukunft allein auf die deutsche Technik einzustellen. Diese Ateliers machten jedoch auch deutlich, daß sie im Gegenzug eine Bevorzugung erwarteten, wenn es um die Vergabe von Aufträgen deutscher Filmfirmen ging 419 . Die französischen Firmen, die in eine Umrüstung ihrer Anlagen einwilligten, waren demnach deshalb so kooperativ, weil sie sich von einer Zusammenarbeit mit deutschen Firmen in Zukunft Vorteile versprachen. Freilich entstand diese Kooperation nicht ohne $Z$ wang oder Druck durch die Besatzungsmacht. Immerhin hielt der MBF mit der Verteilung von Rohstoffen und der Kontingentierung von Elektrizität ganz erhebliche Druckmittel in der Hand, so daß ein Großteil der französischen Filmindustrie zu einer wirtschaftlichen Kollaboration bereit war ${ }^{420}$.

Die Kontingentierung von Rohstoffen und die Ausfuhrerlaubnis der in Frankreich hergestellten filmtechnischen Geräte wurden außerdem als Druckmittel benutzt, um eine Konzentration der Filmherstellung und deren vollständige Rückführung nach Paris zu erreichen; etliche ehemalige Pariser Filmproduzenten waren nach dem Einmarsch der deutschen Truppen in die ZNO geflüchtet und dort weiterhin tätig gewesen. Eine Politik der Konzentration der Filmproduktion in Paris sollte mit Hilfe des COIC verwirklicht werden. Im Oktober 1941 berichtete das Referat Film: „Es wird versucht über die zuständigen französischen Stellen eine Konzentration der Filmherstellungsunternehmen des unbesetzten Gebietes und deren Umsiedlung nach Paris herbeizuführen"421. Die Besatzungsmacht konnte dann über die Genehmigung der Produktionsfirmen in der ZNO auch diese umgesiedelten

418 BA-MA, RW35 227, Prop.Abt., Filmprüfstelle, Tätigkeitsbericht, 21. 11.-28. 11. 1942.

419 Ibid. RW35 220, Tätigkeitsbericht, 3. 4.-10. 4. 1941.

420 Siehe dazu BerTin-Maghit, Le Cinéma sous l'Occupation, S. 153-166; zum Verhalten der Vertreter der Industrie während der Okkupation siehe allg. bei BURRIN, La France, S. 233-266.

421 BA-MA, RW35 224, Prop.Abt., Ref.Film, Tätigkeitsbericht, 17. 10.-24. 10. 1941, Schreiben des Ref. Film, Prop. Abt., an RMVP vom 20. 10. 1941. Zu dieser Politik siehe auch die Tätigkeitsberichte, RW35 222, 8. 8.-15. 8. 1941; RW35 223, 22. 8.-29. 8. 1941; 3. 10.-10. 10. 1941 . 
Firmen kontrollieren. Zur Durchsetzung dieses Zieles sperrte das Referat Film die Ausfuhr filmtechnischen Geräts und die Lieferung von Rohfilm in das unbesetzte französische Gebiet ${ }^{422}$. Noch vor der Besetzung ganz Frankreichs im November 1941 wurde auf diese Weise von den Besatzern also versucht, auch die Filmwirtschaft der ZNO unter Kontrolle zu bringen ${ }^{423}$.

Neben der Kontingentierung von Rohstoffen und einer ökonomischen Kollaboration zugunsten der deutschen Filmindustrie war auch der sogenannte Abzug französischer Arbeitskräfte vor allem in den letzten beiden Kriegsjahren ausschlaggebend für die schwierige Lage der französischen Filmindustrie. Wie in sämtlichen anderen Branchen der Wirtschaft wurden auch in der Filmindustrie im Rahmen des Service du travail obligatoire (STO) insbesondere seit dem Frühjahr/Sommer 1942 mehr und mehr französische Arbeiter zum Arbeitseinsatz nach Deutschland zwangsverpflichtet. Oft wurden sie dort ebenfalls in der Filmindustrie eingesetzt. Teilweise mußten sogar ganze Filmfirmen in Frankreich geschlossen werden, einer Konzentration wurde auf diese Weise Vorschub geleistet, was eine bessere Kontrolle durch die Besatzer gewährleisten solltet24. Ende September 1942 entsandte das RMVP einen Mitarbeiter namens Dr. Keil nach Paris, welcher sich um die sogenannte Vermittlung französischer Arbeitskräfte für die deutsche Filmindustrie bemühen sollte; Keil hatte sogar vor, geschlossene Atelierbetriebe nach Deutschland gleichsam zu überführen. Die Filmprüfstelle war von diesem Vorhaben Keils keineswegs begeistert:

Es wurde in Übereinstimmung mit der Deutschen Botschaft dahin beschieden, daß mindestens aus militärischen Gründen ein unverzichtbares Interesse an der Aufrechterhaltung der französischen Produktion und der Versorgung der Filmtheater Frankreichs mit französischen Filmen besteht. Im Hinblick auf die Dauer des Krieges und die Besatzung gegebene Lage Frankreichs bleiben die Filmtheater Frankreichs eines der wichtigsten Mittel der Unterhaltung und Ablenkung des französischen Volkes ${ }^{425}$.

In dem Bericht heißt es weiter, man beabsichtige deshalb, nur kleinere Betriebe stillzulegen. Demnach setzten sich die deutschen Dienststellen in Paris für die Aufrechterhaltung der französischen Filmproduktion ein, während von Berlin aus vor allem die Interessen der deutschen Filmindustrie Vorrang hatten. Diese Beobachtung läßt sich auch für den seit Ende 1942 verstärkten Abzug von Rohfilm aus Frankreich bestätigen ${ }^{426}$. Im Oktober 1942 meldete die Filmprüfstelle trotzdem die Schließung von sieben weiteren filmtechnischen Firmen: „Durch diese Aktion werden wieder 250 hochqualifizierte

422 Ibid.

${ }^{423}$ Zur sukzessiven deutschen Kontrolle der Filmwirtschaft im gesamten französischen Gebiet siehe beispielsweise BA-MA, RW35 224, Prop.Abt., Ref.Film, Tätigkeitsberichte, 10. 10.-17. 10.1941; RW35 225, 18. 4.-25. 4. 1942.

${ }^{424}$ BA-MA, RW35 226, Prop.Abt., Gr.Film, Tätigkeitsberichte, 6. 6.-12. 6. 1942; 10.7. 1942. Zum STO siehe beispielsweise MICHEL, Paris allemand, S. 175-205.

425 BA-MA, RW35 227, Prop.Abt., Filmprüfstelle, Tätigkeitsbericht, 27. 9.-3. 10.1942. 426 BA-MA, RW35 226, Gr.Film, Tätigkeitsberichte, 1.6.-6.6.1942; RW35 227, Filmprüfstelle, 13.3.-20.3.1943. 
Fachkräfte für Arbeitseinsatz nach Deutschland frei werden. Die Zahl der stillgelegten Betriebe erhöht sich somit auf 20“427. Einen Monat später wird berichtet, in der darauffolgenden Woche würden etwa 300 französische Arbeiter aus filmtechnischen Betrieben nach Deutschland gesandt, da die „Durchkämmung der Studios und Kopieranstalten“428 nach Arbeitskräften weitere Fortschritte gemacht habe. Für den französischen Bedarf bleibe nur noch ein sogenannter Restarbeiterstamm von etwa 60 Prozent übrig. Dementsprechend werde die Filmproduktion in Frankreich in Zukunft stark gehemmt werden. Tatsächlich wurde unter diesen Umständen die Herstellung französischer Filme gegen Ende der Besatzungszeit praktisch lahmgelegt.

Der Theaterbetrieb dagegen, der allgemein weit weniger als die Filmindustrie von der Zuteilung etwa von Rohstoffen und Materialien abhängig war, konnte im besetzten Paris trotz der immer strikter werdenden Kontingentierung von Elektrizität weitgehend aufrechterhalten werden. Die Schauspielerin Colette Brossart erinnert sich:

Les théâtres n'ont jamais aussi bien marché à Paris. Quelques fois on était obligé de fermer, parce qu'on était contingenté en électricité. Il y avait des mois ou on avait le droit à tant de kilowatts d'électricité et on a été obligé de finir les représentations avec des bougies. Il y avait des théâtres qui pouvaient ouvrir leur plafond et on jouait à la lumière du jour. Puis, moi j'ai joué dans un thêâtre très riche, parce que c'était un théâtre qui était tenu par des gens qui avaient beaucoup collaboré avec les Allemands et qui avaient de l'argent. Alors, on avait des cyclistes qui pédalaient à côté de nous, pendant qu'on était sur scène, pour faire de la lumière. Quand la lumière baissait on disait: „Plus vite, pédalez plus vite!" C'était en pleine année 43 , les thêâtres riches avaient des cyclistes, les théâtres pauvres avait fait casser le toit et on jouait à la lumière du jour. On avait très froid. Rien n'était facile ${ }^{429}$.

Laut einem Bericht des Theaterreferats über den Monat Juni 1944 konnten zu diesem Zeitpunkt nur die Staatstheater wie die Comédie-Française, Odéon, Palais de Chaillot und die Pariser Oper die ohnehin schon kontingentierte Menge an Strom für tägliche Aufführungen erhalten; den privaten Theatern waren mit geringeren Zuteilungen an Elektrizität nur Aufführungen am Wochenende möglich. In dem genannten Bericht heißt es anerkennend: „Die große Begabung der Franzosen, Schwierigkeiten zu überwinden, macht sich in der Zunutzemachung des Tageslichts durch Spiegelreflexe für die Bühnenbeleuchtung bemerkbar; 12 Theater haben auf diese Weise die Möglichkeit, tägliche Aufführungen zu veranstalten" ${ }^{430}$. Gegen Ende der Besatzungszeit wurden außerdem etliche Pariser Lichtspielhäuser wegen des Mangels an Strom zu Theatern umfunktioniert, indem man die Dächer zum Teil offnete und bei Tageslicht dort Theater spielte, wo vorher Filme gezeigt worden waren. Im Juli 1944 schränkte der MBF die Zuteilungen an Elektrizität erneut ein, so daß fast nur noch am Tage Aufführungen stattfanden.

427 BA-MA, RW35 227, Filmprüfstelle, Tätigkeitsbericht, 10. 10.-17. 10. 1942

428 Ibid. Tätigkeitsbericht, 21. 11.-28. 11. 1942.

429 Interview mit Colette Brossart und Ehemann Robert Dhéry, 26. 4. 1992, Paris.

430 AN, AJ40 1001-7, Prop.Abt., Gr.Kult.Th., Bericht über den Monat Juni 1944. 
Nach Angaben des Theaterreferats spielten zu diesem Zeitpunkt von den 40 privaten Theatern noch 28; man versuche, diesen Mangel so gut als möglich mit Holzgasmotoren, Kerzen und Öllampen auszugleichen ${ }^{431}$. Freilich mangelte es beim Theater auch an Materialien zur Herstellung von Kostümen oder Bühnenbildern, doch behalf man sich dort unter anderem mit der Umänderung alter Dekorationen. Außerdem sollen Bühnenbilder mit schwarzen Tüchern gestaltet worden sein, welche die Theater regelmäßig von Bestattungsunternehmen anmieteten. So meint Colette Brossart zu den Theaterdekorationen der Okkupation:

C'était un peu du bricolage. C'est-à-dire qu'on prenait un vieux canapé d'une autre pièce, on mettait un autre tissu dessus et puis, c'était complètement bricolé. La Comédie-Française et l'Opéra avaient leur stock de vieux décors, mais les pièces nouvelles n'étaient pas riches du tout. Jean Anouilh quand il a monté Antigone à l'Atelier, les décors, c'étaient uniquement des rideaux noirs qu'on louait. D'ailleurs on jouait beaucoup dans des décors de rideaux noirs. C'était très à la mode, parce qu'on les louait aux entreprises de pompes funèbres. C'était une époque où les gens riches se faisaient enterrer en mettant pleins de rideaux noirs dans toute l'église, c'était très beau. La plus grande entreprise de pompes funèbres à Paris s'appelait Borniolles et c'est pour ça qu'on appelait ces rideaux noirs des Borniolles ${ }^{432}$.

In den vorangegangen Ausführungen ist deutlich geworden, daß die rasseideologisch begründete „Säuberung“ des kulturellen Lebens auch den $\mathrm{Ne}$ beneffekt einer gleichsam mühelosen Inbesitznahme von Teilen der französischen Filmindustrie durch die Besatzungsmacht hatte - trotz der Gegenmaßnahmen französischer Stellen. Alfred Greven betrieb mit Hilfe von Strohmännern und unter dem Deckmantel der SOGEC eine rigorose Ankaufspolitik, die wiederum das Referat Film der Propaganda Abteilung mit gezielten Maßnahmen zu flankieren wußte. Mit dem Filmtheaterpark der SOGEC und der unter bevorzugten Bedingungen arbeitenden Continental Films hielt Greven wesentliche Bereiche der französischen Filmwirtschaft in den Händen. Durch diese Politik sollte langfristig der Vertrieb deutscher Filme in Frankreich und somit deutsche Kulturpropaganda gewährleistet sein. Außerdem verfolgten die Besatzer kurzfristig durch den Abzug von Rohstoffen, Rohfilm, Filmgeräten und Arbeitskräften eine Ausnutzung der filmtechnischen Industrie zugunsten der deutschen. Tendenziell versuchten die deutschen Dienststellen vor Ort, eine zu starke Ausbeutung der französischen Filmindustrie dann zu verhindern, wenn sie die Aufrechterhaltung des Filmbetriebes gefährdet sahen. Von Berlin aus verfolgte das RMVP hier eine rücksichtslosere Politik, die vorwiegend an den Interessen der deutschen Filmwirtschaft ausgerichtet war. Langfristig wollte die Besatzungsmacht zudem eine wirtschaftliche Verflechtung der deutschen und französischen Filmindustrie erreichen, mit dem Ziel der langfristigen Ausnutzung, Kontrolle und Beherrschung der letzteren.

431 Ibid. Bericht über den Monat Juli 1944.

432 Interview mit Colette Brossart und Ehemann Robert Dhéry, 26. 4. 1992, Paris. 
Weniger beherrschen als vor allem kontrollieren wollten die Besatzer die französische kulturelle Aktivität. Eine wichtige Maßnahme stellte hier die Zensur dar. Eine Theater- und Filmzensur konnte im besetzten Paris grundsätzlich auf unterschiedlichen Ebenen stattfinden. So existierte beispielsweise eine Selbstzensur der Künstler, die ein Interesse daran hatten, daß ihr Filmentwurf oder Theaterstück produziert bzw. gespielt wurde und die mitunter ihr Manuskript schon den Umständen entsprechend verfaßten ${ }^{433}$. Ferner konnten französische Theaterdirektoren, Regisseure oder Filmproduzenten eine Art von Zensur ausüben, indem sie bestimmte Stoffe bevorzugten und andere aus ihrer Auswahl ausschlossen. Auch Zeitungskritiken oder allgemein die öffentliche Meinung konnten eine gewisse Zensurfunktion haben ${ }^{434}$. Auf diese Formen der Zensur soll im folgenden nicht näher eingegangen werden, da es für eine Darstellung deutscher Kulturpolitik sinnvoll ist, vor allem die Ebene der offiziellen, staatlichen Zensur zu untersuchen. Vor allem für die Besatzungsmacht war die Zensur ein wesentliches Kontrollinstrument der kulturellen Aktivität, doch bediente sich auch die französische Seite einer eigenen Zensur. In der Darstellung der französischen Zensur werden insbesondere Konflikte zwischen den deutschen Dienststellen einerseits und den französischen staatlichen und kirchlichen Institutionen andererseits von Interesse sein.

\subsection{Kontrolle und Marktbereinigung durch deutsche Zensoren}

Für die deutsche Film- und Theaterzensur im besetzten Gebiet war offiziell allein der MBF zuständig435; sie gehörte, von einer geringfügigen Ausnahme abgesehen, zu keinem Zeitpunkt der Besatzung zu den Aufgabenbereichen der Deutschen Botschaft ${ }^{436}$. Beim Theaterreferat wurden in einer Vorzensur, die Texte der Theaterstücke, die ein Direktor aufzuführen gedachte, in zwei Exemplaren ${ }^{437}$ eingereicht und von den Referenten überprüf $t^{438}$. Zensor war

433 Denis Peschanski, Une politique de la censure?, in: Rioux, La Vie culturelle, S. 79; GARÇON, De Blum, S. 169. Ein Beispiel für diese Selbstzensur siehe in den Memoiren von L'HERBIER, La Tête, S. 284.

434 Siehe dazu beispielsweise für den Bereich des Filmes die Ausführungen von GARÇON, De Blum, S. 40-42.

435 Nach der Verordnung über die Zulassung von Filmen zur öffentlichen Vorführung vom 9. September 1940, (Vobif Nr. 7, 16. 9. 1940) war allein der Militärbefehlshaber Frankreich für die Zulassung von Filmen im besetzten Gebiet zuständig; die Prüfung erstreckte sich ebenfalls auf das Reklamematerial zu den Filmen.

436 Eine Ausnahme bildete das Théâtre du Grand Palais, das zum Aufgabenbereich der Deutschen Botschaft gehörte und nicht der Zensur der Staffel unterlag; siehe AN, AJ40 1001-7, Prop.St., Gr.Kult.Th., Tätigkeitsbericht vom 31. 7. 1942.

437 Ibid. Tätigkeitsbericht der Gruppe IV: Kultur, Arbeitsgebiet Theater, ohne Datum. (vermutl. Oktober 1940)

438 Zur Theaterzensur siehe auch Ingrid GALSTER, Organisation et tâches de la censure théâtrale allemande à Paris sous l'Occupation, in: Actes du Colloque de Reims (1981), La Littérature française sous l'Occupation, Reims 1989, S. 253-265; DiES., Le Théâtre 
zunächst Referent Baumann, dann sein Nachfolger Frank und schließlich Goldmann. Für eine Person war der tägliche Arbeitsanfall sehr umfangreich. In einem Bericht vom Sommer 1942 heißt es, bei dreißig Pariser Theatern, Tourneen und sonstigen Aufführungen, ohne die Wiederaufnahmen einzurechnen, müßten monatlich durchschnittlich 50 Stücke, etwa zwei pro Tag, gelesen und geprüft werden ${ }^{439}$. In Anbetracht dieser Menge an Stücken, zu denen noch die Texte im Bereich Artistik und Musik hinzuzurechnen sind, ist es eher unwahrscheinlich, daß die Manuskripte abgesehen vom jeweiligen Referenten stets auch von dessen Vorgesetzten, dem Leiter der Gruppe Kultur, Leutnant Lucht, noch einmal überprüft wurden. Nur in Zweifelsfällen fertigte der Referent Berichte für Lucht oder Kommandeur Schmidtke an ${ }^{440}$. Seit Juni 1942 durften die Manuskripte nicht mehr direkt beim Theaterreferat, sondern nur noch über den COES eingereicht werden. Auf diese Weise sollte eine bessere Kontrolle gewährleistet werden, weil einige Theatergruppen Vorstellungen gegeben hatten, die nicht vorher zensiert worden waren $^{441}$. Die französische Berufsorganisation diente gleichsam als Filter, sollte die Arbeit der deutschen Dienststellen entlasten und gegebenenfalls als Sündenbock für deutsche Zensurbestimmungen fungieren.

Auch im Bereich des Filmes wurden die Anträge für die Herstellung von Filmen über die Berufsorganisation, das COIC, beim Referat Film eingereicht ${ }^{442}$. Jedem Antrag zur Filmherstellung mußte auch eine synopsis, d.h. ein Exposé zur Handlung des Films, beigefügt werden. In der Regel hatte der Filmproduzent also schon vor der Beantragung seines Vorhabens Geld investiert, während ein Theaterdirektor nur den Text des Stückes einzureichen hatte. Über die Zulassung zur Herstellung eines Filmes bestimmte dann die

de Jean-Paul Sartre devant ses premiers critiques, Tübingen/Paris, 1986, S. 72-86; ADDED, Le Théâtre, S. 98-101, 109, 125, 128; PESCHANSKI, Une politique, S. 63-69; THALMANN, La Mise au pas, S. 181.

439 AN, AJ40 1001-7, Prop.St., Gr.Kult.Th., Tätigkeit des Referats Theater, ohne Datum. (vermutl. Juli 1942) Im Juni 1943 heißt es, das Referat prüfe monatlich um die 60 Stücke. Etwa 10 Prozent würden „der Ablehnung verfallen“, außerdem seien im Monat etwa 50 Wohltätigkeitsveranstaltungen, Laien-Aufführungen und Konferenzen zu zensieren (AN, AJ40 1001-7, Prop.Abt., Gr.Kult., Aktennotiz für den Herrn Kommandeur, 12. 6.1943). In einem weiteren Bericht des Referats vom 6. 7. 1943 heißt es unter anderem, es gebe pro Woche etwa 3-4 Premieren in Paris.

440 Das Referat Artistik der Gruppe Kultur mußte sämtliche Texte der Sketche und Chansons der zahlreichen Pariser Cabarets und Varietés vorzensieren; es handelte sich hier um monatlich 750 Programme im Bereich der Artistik und 150 Programme in dem der Musik; siehe AN, AJ40 1001-7, Prop.Abt., Gr.Kult, Aktennotiz für den Herrn Kommandeur, 12.6.1943.

441 AN, AJ40 1001-7, Prop.St., Gr.Kult.Th., Tätigkeitsbericht vom 1.-30. 6. 1942.

442 Zur Filmzensur siehe BERTIN-MAGHIT, Le Cinéma sous l'Occupation, S. 90-103; Ehrlich, Cinema of Paradox, S. 153-157; Garçon, De Blum, S. 39-42; ThalmanN, La Mise aus pas, S. 187-191. Übrigens existierte ferner eine „inoffizielle“ Zensur des COIC, weil diese Berufsorganisation bei der Prüfung der Filmentwürfe über staatliche Subventionen entschied, doch soll hierauf nicht näher eingegangen werden (BERTINMAGHIT, Le Cinéma sous l'Occupation, S. 84). 
Untergruppe Filmherstellung und -verleih des Referats Film. Die Kriterien hierfür waren nicht nur inhaltlicher Art sondern das Filmvorhaben wurde insbesondere auch auf wirtschaftliche Aspekte hin geprüft. Ferner waren fast sämtliche Vorgänge der Herstellung des Filmes durch erneute Genehmigungen kontrollierbar ${ }^{443}$. So wollte das Referat Film die Herstellung des Filmes "Papa" nur dann genehmigen, wenn die betreffende Produktionsfirma, Les Films Fernand Rivers ihre Tochterfirma Les Moulins d'Or auflösen würde. Die von deutscher Seite verfolgte Politik einer Konzentration der französischen Filmunternehmen wurde hier mit Hilfe der Genehmigung zur Herstellung von Filmen durchgesetzt $t^{444}$. Die Filmprüfstelle zensierte schließlich den fertigen Film, den sie mit und ohne Schnitte zulassen oder auch gänzlich verbieten konnte ${ }^{445}$. Aus den Akten des Referats gehen die Namen der Zensoren der Filmprüfstelle nicht näher hervor; als Leiter der Filmprüfstelle wird zunächst Hauptmann Anton Koegl genannt, der am 15. Mai 1942 in die Propaganda Ersatzabteilung Potsdam versetzt wurde. Sein Nachfolger wurde Leutnant Dr. Derichsweiler ${ }^{446}$. Geprüft wurden aber nicht nur die neueren Filme, die während der Besatzungszeit gedreht wurden, sondern auch Filme der älteren Produktion. So hatte die Filmprüfstelle Ende Mai 1941 bereits insgesamt 4261 Filme zensiert, Anfang September waren es 4950, Mitte Oktober 5231, Ende Januar 19425918 und Anfang Februar 6047 Filme ${ }^{447}$. In Zweifelsfällen wurden sie Schmidtke oder Diedrich zur Entscheidung vorge-

${ }_{443}$ BA-MA, RW35 226, Prop.Abt., Gr.Film, Tätigkeitsbericht, 2. 5.-9. 5. 1942; siehe darin die Bedingungen für die Filmherstellung für die Produktion 1942-43. Beispielsweise mußte der Sitz der Produktionsfirma in Paris sein, gedreht werden durfte nur in den vom MBF genehmigten Ateliers; Außenaufnahmen bedurften einer speziellen Genehmigung und vierzehn Tage vor Drehbeginn mußte ein genauer Finanzierungsplan von der Gruppe Film genehmigt werden; erst dann wurde aus einer vorläufigen Genehmigung zur Herstellung eines Filmes eine endgültige. Ferner mußten sämtliche Mitwirkende des Filmes eine Arbeitsgenehmigung durch den MBF besitzen und jeder Verleihoder Verkaufsvertrag für den Film mußte vor dem Abschluß der Gruppe Film vorgelegt werden. Freilich bedurfte auch die Ausfuhr der Filme der Genehmigung der Propaganda Abteilung.

444 BA-MA, RW35 223, Tätigkeitsbericht, 19. 9.-26. 9. 1941.

445 Auf Initiative Diedrichs erging zur Sicherung einer ordnungsgemäßen Filmprüfung am 23. Oktober 1941 von Kommandeur Schmidtke ein Befehl, der genau festschrieb, welche Personen bei einer Filmprüfung anwesend sein durften; der Kommandeur mit Adjutant, Offiziere Z.B.V., Referatsleiter Aktivpropaganda, Staffelführer Paris, Zensuroffiziere der Filmprüfstelle, Vertreter der Deutschen Botschaft, Sekretärin der Filmprüfstelle, Referatsleiter Film und - oder Vertreter, Leiter der Untergruppe Herstellung und Verleih (BA-MA, RW35 224, Tätigkeitsbericht, 17. 10.-24. 10. 1941). Offiziere Z.B.V. bedeutet: Offiziere zur besonderen Verwendung.

446 BA-MA, RW35 226, Gr.Film, Tätigkeitsbericht, 15. 5.-23. 5. 1942.

447 In jedem Tätigkeitsbericht des Referats Film finden sich Angaben zur Anzahl der bisher zensierten Filme sowie der verbotenen und zugelassenen Filme. Bei den letzteren Angaben sind die Filme getrennt nach Nationalitäten und nach Spieldauer aufgeführt. Zu den im Text genannten Zahlen siehe folgende Tätigkeitsberichte 29. 8.5. 9. 1941; 12. 9.-19. 9. 1941; 10. 10.-17. 10. 1941; 7.11.-14. 11. 1941; 24. 1.-31. 1. 1942; 30. 1.-6. 2. 1942 (BA-MA, RW35 222-226). 
führt ${ }^{448}$. In den Akten des Referats läßt sich zumindest ein Beispiel für eine direkte Einmischung Goebbels finden. So wurde der italienische Film „Alkazar" auf dessen Wunsch im Mai 1942 für Frankreich verboten ${ }^{449}$.

Eine Nachzensur war im Bereich des Filmes im Gegensatz zu dem des Theaters nicht notwendig. Filme sind gleichsam in einmaliger Inszenierung auf Zelluloid gebannt und werden in der Regel vor der Vorführung in den Filmtheatern nicht mehr verändert. Trotzdem besuchten die Angehörigen des Referats Film, häufig sogar Diedrich selbst, die Filmvorstellungen, um die Reaktionen des Publikums, insbesondere auch auf die Wochenschau und die deutschen Filme, zu beobachten. Zur Kontrolle der Aufführungen von Theaterstücken besuchte der Theaterreferent regelmäßig Premieren oder Generalproben. Im Juni 1943 beklagte die Gruppe Kultur ihren Personalmangel und berichtete von Zensurverstößen in den Theatern, vor allem im Bereich der Artistik. Besonders Chansonniers, Komiker und Conferenciers unterlägen der „Verführung, aus der Situation heraus oder auf Zuruf vom Programm abzuweichen und aktuell zu polemisieren ${ }^{* 450}$. Zudem müsse allerdings auch bei ernsten Darbietungen immer damit gerechnet werden, „daß durch die Regie oder die Persönlichkeit des Künstlers Wirkungen entstehen, die bei der Textzensur nicht vorauszusehen waren " ${ }^{451}$. Bei drei bis vier Premieren pro Woche zuzüglich der Wiederaufnahmen war die sogenannte Gegenzensur für den Theaterreferenten allein ein kaum zu bewältigender Aufwand ${ }^{452}$. Deswegen wurden auch andere Angehörige der Staffel und der Abteilung zur Nachzensur eingesetzt ${ }^{453}$. In den Quellen lassen sich beispielsweise Hauptmann Dr. Schöneich und Prof. Dr. Blümel als Zensoren finden. In besonders strittigen Einzelfällen besuchte auch der Vorgesetzte Lucht einzelne Vorstellungen ${ }^{454}$.

448 BA-MA, RW35 222, Prop.Abt., Ref.Film, Tätigkeitsbericht 25.6.-1. 7.1941. Es ging hier um den französischen Film „Le Duel“, der einen religiösen Inhalt besaß. Der Film wurde schließlich nicht verboten.

449 BA-MA, RW35 226, Gr. Film, Tätigkeitsbericht, 15. 5.-23. 5. 1942.

450 AN, AJ40 1001-7, Prop.Abt., Gr.Kult., Aktennotiz für den Herrn Kommandeur, 12.6. 1943 .

451 Ibid.

452 Ibid. Bericht vom 6. 7. 1943.

453 Es lassen sich Hauptmann Dr. Schöneich und Prof. Dr. Blümel als Zensoren finden: AN, AJ40 1002-4a, Hauptmann Dr. Schöneich über die Premiere „Les Dieux de la nuit" am 7. 4. 1942 im Théâtre Hébertot, 8. 4. 1942; AN, AJ40 1002-7, Dr. Schöneich, Bericht über die Premiere des „Don Carlos“ im Odéon am 11. 4. 1942, 13. 4. 1942. Prof. Dr. Blümel war bei der Premiere des Stückes "La Machine à écrire" von Cocteau, im Théatre Hébertot; AN, AJ40 1002-4a, Prop.St., Gr.Kult.Th., Baumann, Aktennotiz vom 2. 5. 1941. Siehe auch AN, AJ40 1001-7, Prop.Abt., Gr.Kult., Aktennotiz für den Herrn Kommandeur, 12.6. 1943; darin wird ausdrücklich betont, jedes Referat (Musik, Artistik, Theater) sei nur mit einem Fachreferenten besetzt. Da Blümel und Schöneich auch nicht als Hilfskräfte in den Akten des Theaterreferats erwähnt sind, waren sie vermutlich keine ständigen Mitarbeiter dieses Referats.

454 Im Falle der Aufführung des Stückes „La Machine à écrire“ besuchte Lucht eine der 
Die französischen Berufsorganisationen filterten also sowohl die Filme als auch die Theaterstücke zunächst vor, die im Anschluß daran zweifach von deutscher Seite zensiert wurden. Die Zensur stellte ein wesentliches Instrument der deutschen Besatzer zur Kontrolle der französischen Theateraufführungen und Filme dar, doch nach welchen inhaltlichen Kriterien richtete sich die deutsche Zensur und inwiefern existierten hier offizielle Richtlinien? Die Propaganda Abteilung erhielt ihre Weisungen vom RMVP in Berlin. Dieses bestimmte beispielsweise im Juli 1941, daß sämtliche französischen Filme fortan auch daraufhin geprüft werden sollten, ob sie für die Jugend freigegeben werden könnten ${ }^{455}$. Welche Filme nach Meinung des RMVP oder des Referats Film jugendfrei waren, geht aus den Akten nicht hervor ${ }^{456}$. Ebenso verhält es sich mit den übrigen Grundsätzen zur Zensur, die nur sehr allgemein formuliert waren. Die engeren Kriterien müssen vorwiegend aus den getroffenen Zensurentscheiden hergeleitet werden ${ }^{457}$.

Ein wesentliches Merkmal der deutschen Zensur war ihre Beschränkung auf den politischen Bereich. In einem Bericht zu den Ergebnissen der Arbeitstagung der Kulturreferenten der Propaganda Staffeln Frankreich vom 24. Mai 1941 heißt es, die Zensur solle nur prüfen, ob Werke politisch für die Interessen der Besatzungsmacht unbedenklich seien. Künstlerisch sollten die deutschen Funktionsträger keinen Einfluß nehmen: „Die Propaganda Staffeln sind nicht dazu da, dem französischen Kulturleben deutsche Moral- und künstlerische Wertmaßstäbe zu vermitteln “458. Obgleich die deutschen Zensoren weder künstlerische noch moralische Aspekte zu berücksichtigen hatten, fühlten sie sich offenbar dennoch dazu bemüßigt. So betonten die Referenten in ihren Zensurberichten zu französischen Filmen oder Theateraufführungen häufig, diese seien „künstlerisch nicht wertvoll“ oder „moralisch zweifelhaft" ${ }^{* 459}$. Verboten wurden sie deswegen aber nicht. Die Filmprüf-

Vorstellungen, weil ein Skandal um dieses Werk entstanden war. Siehe AN, AJ40 10024a, Prop.St., Gr.Kult.Th., Baumann, Aktennotiz vom 2. 5. 1941.

455 Mit dieser neuen Weisung kehrte Diedrich von einer Reise aus Berlin zurück. BAMA, RW35 222, Prop. Abt., Ref.Film, Tätigkeitsbericht, 25. 7.-31. 7. 1941.

456 Auf die Zensurkriterien in der Frage jugendfreier Filme soll im folgenden nicht näher eingegangen werden, da diese für eine Darstellung der Grundsätze der deutschen Zensur nicht von grundlegender Bedeutung sind.

457 Allerdings waren diese durchaus auch widersprüchlich. In manchen Fällen wird nur schwer zu klären sein, ob es sich um Ausnahmen gehandelt hat, oder ob aus dieser Entscheidung auf ein allgemeines Zensurkriterium geschlossen werden kann. Ferner läßt sich bedingt durch die Quellenlage nur ein Teil aller Zensurvorgänge nachvollziehen. In den Akten des Theaterreferats werden die Entscheidungen der Vorzensur nur selten näher erläutert, auch sind die zensierten Manuskripte der Stücke nicht überliefert. In den Tätigkeitsberichten des Referats Film lassen sich nur zu einem kleinen Teil der französischen Filmproduktion Sonderberichte der Filmprüfstelle finden, die für das RMVP in Berlin angefertigt wurden.

458 AN, AJ40 1001-7, Ergebnisse der Arbeitstagung der Kulturreferenten, 24. 5. 1941. 459 Ibid. Tätigkeitsberichte, 30. 10. 1942; 30. 12. 1942; 30. 3. 1943; BA-MA, RW35 224, Filmprüfstelle, Bericht Nr. 10 über das Ergebnis der am 2.12. 1941 erfolgten Prüfung 
stelle vermerkte im Oktober 1940 zu den Filmen, die vor der Besatzungszeit gedreht wurden, die französische Produktion habe sich schon seit Jahren auf abschüssiger Bahn bewegt: „Mord, Totschlag, düsteres Milieu möglichst noch mit Dirnen und Zuhältern charakterisieren die besichtigten Filme ${ }^{460}$. Auch die zur Besatzungszeit gedrehten Filme entsprachen inhaltlich häufig nicht den Vorstellungen der deutschen Zensoren. In der Beurteilung zum Film „Le Pavillon brûle" von Jacques de Baroncelli heißt es:

Bei einiger Mühe und zeitgemäßer Behandlung des Stoffes wäre ein prächtiger verwendbarer Film zu schaffen gewesen. Pflichtbewußtsein, allerdings nicht nur aus Geschäftsinteresse, aufopfernde Pionierarbeit, Kameradschaft, stilles Heldentum, fern der Zivilisation und Kultur und vieles andere wäre aus dem Stoff herauszuholen gewesen, um endlich eine gewisse Gesinnungsänderung der franz. Produktion zu beweisen. Nichts von alledem ist klar herauszuhören ${ }^{461}$.

„Le Pavillon brûle" wurde wie alle anderen französischen Filme und Theaterstücke, deren Qualität oder Inhalt in den Augen der Besatzer nicht befriedigend waren, nicht verboten. Der Fall des Filmes "L'Irrésistible Rebelle“ von Bernard Rolland ist hier als Ausnahme zu sehen. Auf Antrag des COIC war dieser durch die Filmprüfstelle wegen Mangel an Qualität verboten worden. Aufgrund finanzieller Verpflichtungen der Produktionsfirma wurde er schließlich wieder auf Antrag des COIC zugelassen. Allerdings durften nicht mehr als 10 Kopien gezogen und verliehen werden. Auch die Beschränkung der Kopienanzahl war also ein Mittel der Zensur, mit dem die Filmprüfstelle einen Film mitunter bedingt zulassen konnte. Dies war der Fall bei „L'Irrésistible Rebelle“. Gegen den Film bestanden keine militärischen und politischen Bedenken und die Filmprüfstelle betonte, es sei nicht ihre Aufgabe, sogenannte Qualitätszensur zu Gunsten der Franzosen zu betreiben ${ }^{462}$. Die nach Meinung der deutschen Zensoren zum Teil angeblich künstlerisch minderwertige französische Produktion kam der Politik der Besatzungsmacht insofern entgegen, als dies im Sinne des langfristigen deutschen Zieles einer Zerstörung der kulturellen Ausstrahlungskraft Frankreichs lag. Vor diesem Hintergrund ist es nicht erstaunlich, daß sich die deutsche Zensur ausschließlich nach politischen Grundsätzen richten sollte.

des franz. Filmes „Le Pavillon brûle“ Fpf. Nr. 5658; Bericht Nr. 16 über das Ergebnis der am 16. 12. 1941 erfolgten Prüfung des franz. Filmes „La Maison des sept jeunes filles“, Fpf.Nr. 6798. Die Zensurberichte der Filmprüfstelle geben je nach künstlerischer, moralischer und politischer Beurteilung der jeweiligen Filme Empfehlungen für deren Eignung für den Export. Hierbei konnte auch die Qualität ein Kriterium sein; einige Filme wurden als minderwertig eingestuft und deshalb zum Export nicht empfohlen. 460 AN, AJ40 1001, Prop.Abt., Tätigkeitsbericht, IV. Film, 7. 10.-13. 10. 1940.

461 BA-MA, RW35 224, Filmprüfstelle, Bericht Nr. 10 über das Ergebnis der am 2. 12. 1941 erfolgten Prüfung des franz. Filmes „Le Pavillon brûle“ Fpf. Nr. 5658.

462 BA-MA, RW35 227, Bericht Nr. 45 über das Ergebnis der am 31.7. 1942 erfolgten Prüfung des französischen Spielfilms „L'Irrésistible Rebelle“, Fpf. Nr. 6279. Der Film wurde am 31.7.1942 „bedingt“ zugelassen. 
Im Sinne der nationalsozialistischen Rassenideologie waren die Besatzer davon überzeugt, jedes Land, also auch Frankreich, habe seine eigene, originäre Kultur. Der französischen Seite gegenüber wurde diese Einstellung als angeblicher Respekt gegenüber der französischen künstlerischen Freiheit dargestellt. Ziel der milden deutschen Kulturpolitik sei die Bewahrung der Originalität der französischen Kultur. In einem Schreiben im Mai 1941 an de Brinon konstatiert Lucht zur Begründung der rein politischen und nicht künstlerischen deutschen Zensur: „Chaque peuple a ses propres conceptions artistiques et culturelles, et c'est pour la sauvegarde de l'originalité du pays que l'Autorité Occupante laisse aux artistes créateurs français leur liberté" ${ }^{\prime \prime 63}$. Die Argumentation der Propaganda Abteilung war damit der Haltung der Deutschen Botschaft ähnlich, die grundsätzlich vorgab, sie setze sich für die Bewahrung der französischen Kultur ein. Unterschiedliche kulturpolitische Linien lassen sich hier nicht ausmachen. Lucht verschweigt in seinem obigen Schreiben jedoch, daß die deutsche Kultur in den Augen der Besatzer langfristig einen sogenannten geistigen Sieg über Frankreich erringen sollte. Die deutsche Zensur, die künstlerische Freiräume ließ, war also nicht etwa Ausdruck einer wirklichen Toleranz der Besatzungsmacht. Vielmehr verbarg sich dahinter ein pragmatisches Kalkül, d.h. das kurzfristige Ziel einer Aufrechterhaltung des französischen Kulturlebens zur Erhaltung der öffentlichen Ruhe und Ordnung. Langfristiges Ziel blieb für die deutschen Dienststellen die Zerstörung der kulturellen Ausstrahlungskraft Frankreichs. An der Qualität französischer Filme und Theaterstücke waren die deutschen Zensoren also nicht interessiert. Die Beschränkung auf eine politische Zensur macht ferner deutlich, daß die Besatzer die französische Aktivität in Film und Theater inhaltlich nicht etwa nach moralischen und künstlerischen Vorstellungen des Nationalsozialismus ausrichten wollten.

Alle Filme und Theaterstücke, die sich innerhalb des von den Besatzern erlaubten politischen Rahmens bewegten, sollten also angeblich künstlerisch frei gestaltet werden können. Wie sah nun dieser von der Zensur gesteckte politische Rahmen, der sich nach den Interessen der Besatzungsmacht richtete, aus? Die Richtlinien für die Kulturarbeit der Staffeln und Außenstellen vom 20. Mai 1943 nennen als Aufgabe der Zensur den „Schutz der deutschen militärischen und kulturpolitischen Hoheitsrechte “464. Ein wesentliches Interesse der Besatzer bestand in der Aufrechterhaltung der öffentlichen Ruhe und Ordnung. Kulturelle Veranstaltungen sollten hierzu beitragen, obwohl sie grundsätzlich auch die Gefahr von Unruhen bargen. Das Theaterreferat betonte im Juni 1943, wie wichtig gerade hier die Nachzensur sei: „Da Men-

463 CDJC, IV 12, Prop.St., Gr.Kult., Lucht an de Brinon, DGTO, frz. Übersetzung, 6. 5. 1941; dieser Brief war eine abschlägige Antwort auf die Bitte de Brinons, die Propaganda Staffel möge die Aufführung des Stückes „La Machine à écrire" von Jean Cocteau im Théâtre Hébertot verbieten.

464 AN, AJ40 1001-7, Prop.Abt., Gr.Kult.Th., Geheim, Richtlinien für die Kulturarbeit der Staffeln und Außenstellen, 20. 5. 1943. 
schenansammlungen wie Theateraufführungen, Konzerte von sich aus die Gelegenheit zu Demonstrationen und agitatorischen Kundgebungen einschließen, übernimmt der kontrollierende Referent zugleich eine wichtige politische (sicherheitsmäßige) Funktion" ${ }^{465}$. Es ist nur schwer vorstellbar, daß die Anwesenheit eines einzelnen Theaterreferenten spontane Demonstrationen des Publikums wirklich verhinderte, selbst wenn dieser die Vorstellungen in Uniform besuchte. Immerhin befand sich der Zuschauerraum im Dunkeln, was die vermeintliche Furcht der Zuschauer vor dem anwesenden Theaterreferenten zusätzlich vermindert haben dürfte. Die genannte politische Bedeutung der im Theater anwesenden deutschen Zensoren wird hier weit überschätzt, zumal diese nur einen geringen Teil aller Aufführungen an Pariser Theatern besuchen konnten. Gleichwohl wird deutlich, daß die Besatzungsmacht vor allem Protestkundgebungen des Publikums bei öffentlichen Veranstaltungen befürchtete. In der Hauptsache sollte nicht die Nachzensur, sondern schon die Vorzensur zur Vermeidung solcher Vorkommnisse beitragen. Inhaltlich wurde dabei vor allem auf folgenden Grundsatz geachtet: „Ausschaltung jeder politischen Polemik auf der Bühne, die geneigt ist, Mißverständnisse aufkommen oder Ausdeutung entstehen zu lassen, die Spannungen zwischen dem deutschen und französischen Volk bereiten “466. Dies bedeutete konkret, daß nicht nur Werke verboten wurden, die beispielsweise Angriffe auf Deutschland beinhalteten, sondern auch solche, die zu offensichtlich für die deutsche Besatzungsmacht Stellung bezogen. Immerhin hätten diese lautstarke Äußerungen gegen Deutschland im Publikum hervorrufen können. Die Besatzer machten sich offenbar keine Illusionen über ihre mangelnde Beliebtheit in der französischen Bevölkerung. Deshalb verbot die Vorzensur beispielsweise "Ville ouverte" von Jacques und Louis Heraut im November $1942^{467}$. In dem Stück wird eine Stadt von Feinden und Hochwasser bedroht und nur dadurch gerettet, daß sich die junge Generation der Einwohner schließlich mit den Feinden verbündet und gemeinsam einen Damm errichtet. Befreundete Nachbarn, die auf einer Insel wohnen, werden nicht zu Hilfe geholt. Für Theaterreferent Frank war die Interpretation des Werkes eindeutig, die Parallele übermäßig deutlich gezeichnet. Es handelte sich um Deutschland und Frankreich, die benachbarten Inselbewohner waren die Engländer, das Hochwasser der sogenannte Bolschewismus. Zur Wirkung des Werkes meinte er: „Es ist die Frage, ob das an sich wirklich red-

465 Ibid. Aktennotiz für den Herrn Kommandeur, 12. 6. 1943.

466 Ibid. Tätigkeitsbericht der Gruppe IV: Kultur, Arbeitsgebiet Theater (undatiert). Dem Inhalt nach wurde der Bericht im Oktober 1940 verfaßt. Die Zensoren verpflichteten übrigens die Regisseure durch Hinterlegung eines Belegexemplars zur "wortgetreuen Wiedergabe " des Werkes.

467 Bereits im Sommer 1941 war ein Stück, das den gleichen Titel und einen ähnlichen Inhalt, allerdings einen anderen Autor besaß, beim Theaterreferat zur Zensur eingereicht worden. Auch zu diesem Zeitpunkt war die Aufführung verboten worden; siehe AN, AJ40 1001-7, Prop.Abt., Gr.Kult.Th., Aktennotiz z.Hd. des Gruppenleiters, 9. 11. 1942. 
liche Stück durch seine etwas plumpe Art nicht mehr verdirbt als gut macht. Jedenfalls wäre es nicht ausgeschlossen, daß es zu Manifestationen kommt" 468 .

Stücke, die zu sehr für die Besatzungsmacht Stellung bezogen, liefen also Gefahr, durch die Zensur verboten zu werden. Allzu positive und selbstverständlich auch negative Stellungnahmen zur aktuellen politischen Situation bargen in sich eine Gefahr für die öffentliche Ruhe und Ordnung. Die Zensur verbot deswegen Anspielungen auf die deutsch-französischen Beziehungen und die Situation, in der sich Frankreich befand. Für dieses Zensurkriterium lassen sich etliche Belege finden. So wurden im Bereich des Theaters sogenannte Militärschwänke verboten ${ }^{469}$. Auf eine Anfrage des COIC im März 1941, ob jeder Film mit Aufnahmen von französischen und deutschen Soldaten verboten sei, antwortete die Filmprüfstelle mit ja: „Es wurde nahegelegt, überhaupt die Herstellung derartiger Filme zu unterlassen und zunächst einmal Filme anderen Sujets herzustellen" 470 . Wegen des militärischen Milieus ließ die Zensur im Juni 1941 den Film „Feu“ (Jacques de Baroncelli, 1937) nicht $\mathrm{zu}^{471}$. „Enfant de Troupe“ erhielt ebenfalls kein Zensurvisum, „da im gegenwärtigen Zeitpunkt Filme, die geeignet sind, das Interesse für das französische Militär zu wecken, nicht als zeitgemäß betrachtet werden können“472. Die geschickte Formulierung „nicht zeitgemäß“ findet sich häufig in den Begründungen der Zensurentscheide. Gemeint ist hier freilich, daß in Anbetracht der deutschen Besatzung und der politischen Lage in Frankreich das jeweilige Sujet die deutschen Interessen hätte gefährden können. Unter der Prämisse, Unruhen und Demonstrationen in französischen Filmtheatern vermeiden zu wollen, waren auch die von den Verleihfirmen Tobis und Ufa/ ACE vertriebenen deutschen Filme von der Zensur nicht ausgenommen. Die Filmprüfstelle untersuchte sie auf ihre sogenannte politische Verträglichkeit für Frankreich ${ }^{473}$.

Die Zensoren reagierten auf Filme oder Theaterstücke, die auf die aktuelle Situation Frankreichs anspielten, generell negativ. So verbot das Theaterreferat im März 1944 beispielsweise in der Vorzensur das vom Thêâtre du Gymnase zur Zensur eingereichte Stück „Sauvegarde“ von einem Autor, dessen Namen das Referat nur mit Magui angab. Es behandelte das Thema der Kriegsgefangenen nach Meinung des deutschen Zensors in sehr schlechter Art und Weise: „Da es das Elend der französischen Kriegsgefangenen in aufdringlicher Form darstellt, eignet es sich wenig für eine Serie von Aufführun-

468 Ibid. Frank bat Lucht um Entscheidung über dieses Stück.

469 Ibid. Tätigkeitsbericht, 30. 9. 1942.

470 BA-MA, RW35 220, Prop.Abt., Ref. Film, Tätigkeitsbericht 5. 3.-12. 3. 1941, Ausführungen zu Besprechungen mit Ploquin und de Carmoy.

471 BA-MA, RW35 221, Tätigkeitsbericht, 19. 6.-24. 6. 1941.

472 BA-MA, RW35 223, Tätigkeitsbericht, 29. 8.-5. 9. 1941.

473 Zur Auswahl der in Frankreich gezeigten deutschen Filme siehe Kapitel III. 2.1. dieser Arbeit. 
gen in einem Boulevardtheater “474. Ein anderes Stück dagegen, das von der Aufführung eines Theaterstückes in einem Kriegsgefangenenlager handelte, hatte das Theaterreferat im Mai 1942 zugelassen ${ }^{475}$. Offenbar behandelte dieses Theaterstück das Thema der Kriegsgefangenen in so positiver Art und Weise, daß sich die Zensoren entschlossen hatten, dessen Aufführung trotz der Anspielung auf die aktuelle politische Situation zu erlauben. Außerdem beeinflußten auch die sich verschärfende Besatzungspolitik und die veränderte Weltkriegslage die oben genannten Entscheidungen. Beide Aspekte waren allgemein nicht ohne Bedeutung für die Zensurentscheide.

So stellte das Theaterreferat die Aufführungen des von der Comédie-Française bereits vorbereiteten Stückes "L'Aiglon" von Rostand, das von Napoléons Sohn (Herzog von Reichstadt) handelt, im Dezember 1941 auf unbestimmte Zeit zurück: „bis die allgemeine Lage Gewähr dafür bietet, daß es nicht zu Manifestationen kommt, die das vaterländisch hochgestimmte und mitreißende Stück zu Zeiten politischer Anspannung auszulösen geeignet

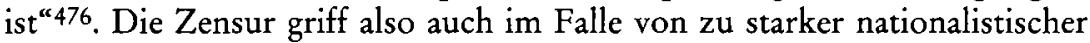
Tendenzen in französischen Theaterstücken und Filmen ein. Aus diesem Grunde verbot die Filmprüfstelle etliche ältere Kolonialfilme ${ }^{477}$. Ferner betraf die Zensur auch Dialogstellen, die vom Publikum im Sinne eines Widerstandes gegen die Besatzer hätten gedeutet werden können. Ein Beispiel hierfür ist die Prüfung des Filmes "Madame sans gêne“ von Roger Richebé im September 1941. Der Film handelt von einer Wäscherin, gespielt von Arletty, die sich durch ihre Heirat mit „Maréchal Lefèvre“ und mit Hilfe ihrer lockeren Art erfolgreich in ein politisches Intrigenspiel um Napoleon einmischt. Die erste Szene des Filmes, die gänzlich herausgeschnitten werden mußte, spielt 1792 in einem Jakobinerclub während der Französischen Revolution. Die Filmprüfstelle nahm an dem folgenden Ausspruch von Robespierre Anstoß: „Citoyens, le peuple n'est jamais vaincu, s'il lui reste la volonté de vaincre [...] la victoire est aux acharnés" 478 . Dennoch bestand für diesen Film zumindest in bezug auf nationalistische Tendenzen ein relativ großer Spielraum. Allein der Stoff des Filmes - die Französische Revolution und die Persönlich-

474 AN, AJ40 1001-7, Prop.Abt., Gr.Kult.Th., Bericht über den Monat März 1944, 31. 3. 1944 .

475 Ibid. Prop.St., Tätigkeitsbericht, 29. 5. 1942.

476 Ibid. Tätigkeitsbericht, 27. 12. 1941; siehe dazu ausführlich JOUBERT, La ComédieFrançaise, S. 161-165.

477 BA-MA, RW35 227, Prop.Abt., Filmprüfstelle, Tätigkeitsbericht, 8.11.-14. 11. 1942; im besetzten Gebiet waren bis zu dem Zeitpunkt etwa 290 französische Kolonialfilme von der Filmprïfstelle erfaßt worden, etwa 60 wurden an das OKW abgegeben und 100 an das Reichsfilmarchiv in Berlin gesandt. An die 110 Kolonialfilme erhielt das Kolonialpolitische Amt in Berlin.

478 BA-MA, RW35 223, Ref.Film, Bericht über das Ergebnis der am 1. 9. 1941 erfolgten Filmprüfung des Filmes „Madame sans gêne“ Fpf.Nr. 4853. Siehe die ungekürzte Version des Filmes unter FDI, VDP 4757. Als Vorlage für diesen Film diente ein Theaterstück von André Sardou, das am 25. 10. 1893 in Paris uraufgeführt wurde. 
keit Bonapartes - ist sehr nationalistisch geprägt. Ähnlich verhält es sich mit dem Film „Pontcarral colonel d'empire" von Jean Delannoy, den die Filmprüfstelle im November 1942 mit Schnitten zuließ ${ }^{479}$. Unter anderem wurde hier eine Szene herausgeschnitten, in welcher die Trikolore zu sehen war ${ }^{480}$. François Garçons Analyse von 285 französischen Spielfilmen aus den Jahren 1936-1944 hat unter anderem ergeben, daß die französische Flagge, die vor der Okkupation als häufiges Motiv in Filmen zu sehen war, in den französischen Filmen der Besatzungszeit fast völlig fehlt ${ }^{481}$. Der Grund hierfür wird wohl entweder in der deutschen Zensur bzw. auch in einer Selbstzensur der Künstler liegen. Obwohl die Zensoren aus „Pontcarral colonel d'empire“ einige nationalistische Szenen herausschneiden ließen, ist der Film dennoch zu den patriotisch geprägten Filmen der Besatzungszeit zu zählen. In bezug auf den Nationalismus in französischen Filmen bestand zumindest ein gewisser Spielraum. In anderen Punkten war die Zensur strenger. Die Werke von Angehörigen der sogenannten Feindstaaten und politischen Gegnern waren auf Bühne und Leinwand ebenso verboten wie die Arbeiten von jüdischen Autoren oder Freimaurern. Im September 1942 berichtete die Gruppe Kultur, sie habe an dem Grundsatz festgehalten, Stücke von Angehörigen der Feindstaaten zu verbieten: „Diese Praxis erstreckt sich auch auf die Werke toter Autoren, sofern das dargestellte Milieu geeignet ist, unnötige Sympathien für das betreffende Land zu schaffen. Aus diesem Grunde wurde u. a. auch eine Dramatisierung des Tolstoi-Romans ,Anna Karenina“ abgelehnt"482. Das Theaterreferat fürchtete, im Publikum könnten Sympathien für die Feinde des nationalsozialistischen Deutschland entstehen. Ausnahmen von diesem Verbot bildeten auch im besetzten Frankreich die wenigen Werke von Autoren aus diesen Ländern, die in Deutschland nicht verboten waren. Hierzu gehörten beispielsweise Stücke von William Shakespeare ${ }^{483}$ und George Bernard Shaw ${ }^{484}$. Im Januar 1942 lautete eine Anweisung des RMVP an das Theater-

479 Ibid. RW35 227, Filmprüfstelle, Tätigkeitsbericht, 21. 11.-28. 11. 1942.

480 GarÇON, De Blum, S. 107.

481 Ibid. S. 106-108.

482 AN, AJ40 1001-7, Prop.Abt., Gr.Kult.Th., Tätigkeitsbericht, 30. 9. 1942.

483 Auch in Deutschland waren Shakespeares Werke nicht verboten. Reichsdramaturg Dr. Rainer Schlösser, schrieb 1938: „Wenn Shakespeare mit so offenen Armen in Deutschland empfangen wurde, dann deshalb, weil gar nicht daran zu zweifeln ist, daß ihn Blutsbande mit uns verbinden. Mit anderen Worten: Wir erkennen in dem universalen dramatischen Schaffen von Shakespeare das gleiche dramatische Grundelement des Nordischen, auf welches wir die Höchstwerte unseres eigenen Volkes zurückzuführen gelernt haben " (Rainer SCHLÖssER, Der deutsche Shakespeare, in: ShakespeareJahrbuch, hg. v. Wolfgang KELLER, Bd. 74, Weimar 1938, S. 23-24, zit. n. WULF, Theater und Film, S. 206). Zu den Werken Shakespeares auf deutschen Bühnen siehe auch DREWINIAK, Das Theater, S. 245-254.

484 AN, AJ40 1001-7, Prop.St., Gr.Kult.Th., Tätigkeitsbericht vom 12. 9.-19. 9. 1941: „In der Comédie des Champs-Elysées (Theatre d'Essai) wurde Bernard Shaws, Candida" als erstes Stück herausgebracht"; siehe auch ibid. Tätigkeitsbericht über den Monat April 1942: „[...] auch Bernard Shaw bekommt kräftige Wahrheiten zu hören. Das 
referat: „An sich ist nur Shaw erlaubt, jedoch wird gegen einen gelegentlichen Wilde kein Einwand erhoben, da er als Ire betrachtet werden kann" 485 .

Die Pariser Theaterdirektoren reichten von vornherein kaum Stücke bei der Zensur ein, die von amerikanischen, englischen oder russischen Autoren stammten. In den Akten des Referats läßt sich jedoch ein Beispiel finden, wo dies der Fall war. Das Stück „Mon Bébé“" von Maurice Hennequin, die französische Übertragung eines amerikanischen Lustspiels, wurde im Oktober 1942 von Direktor Léon Volterra am Théâtre de Paris herausgebracht. In Unkenntnis der amerikanischen Vorlage war das Stück von der deutschen Zensur nicht verboten worden. Erst ein Artikel des Kritikers Henri-René Lenormand in La Gerbe vom 22. Oktober 1942 deckte den Ursprung von „Mon bébé" auf ${ }^{486}$. Der Artikel Lenormands, der laut Frank im Pariser Theaterleben Aufsehen erregte, war freilich für das Theaterreferat relativ peinlich. Ein Theaterdirektor hatte die deutsche Zensur hintergehen können und ein Pariser Kritiker machte die Öffentlichkeit darauf aufmerksam. Diese Angelegenheit war für die Zensoren doppelt unangenehm, da auch der Artikel Lenormands der obligatorischen Pressevorzensur durch das Theaterreferat entgangen war. Man erwog hierfür zeitweise sogar eine Bestrafung des Blattes ${ }^{487}$. In einer Aktennotiz vom 26. Oktober 1942 heißt es, Volterra habe das Stück sofort absetzen müssen und sei nicht mit einer Geldstrafe belegt worden, da ihm ohnehin 400000 Francs Verlust entstanden seien. Ferner habe er das Referat nicht absichtlich hintergehen wollen, sondern sei selbst nicht über den Ursprung des Stückes informiert gewesen ${ }^{488}$. Besonders betonte das Referat ferner die abschreckende Wirkung des Zensurverbotes: „Es ist festgestellt worden, daß sich das Verbot des Stückes schnell herumgesprochen und seine Wirkung auf die übrigen Theater nicht verfehlt hat" ${ }^{\text {"489. }}$. Es war für die Theaterdirektoren also durchaus möglich, die deutsche Zensur zu hintergehen. In dem obigen Fall kann die Reaktion des Theaterreferats als relativ moderat betrachtet werden, da außer dem Verbot des Stückes dem Theater kein weiterer Schaden entstand. Angesichts der finanziellen Verluste die ein solches Verbot jedoch nach sich zog, dürfte ein Großteil der Pariser Theaterdirektoren von vornherein solch ein Risiko bewußt vermieden haben. Zumindest findet sich in den Akten des Theaterreferats kein weiterer Fall eines derartigen Versto-

Theater Pigalle bringt von ihm, On ne peut jamais dire in einer flotten, spritzigen Aufführung, ohne die überholte Problematik plausibel machen zu können“. Auf deutschen Bühnen waren Stücke von Shaw bis zur Schließung der Theater im Sommer 1944 zu sehen, wobei sich ihre Anzahl während der Zeit des Krieges immer mehr verringert hatte. Siehe dazu DREWNIAK, Das Theater, S. 255-259.

485 AN, AJ40 1002-2, RMVP, Lang an Prop.St.Paris, Telegramm, Meldung Nr. 90, 17. 1. 1942. Im Deutschen Reich waren Werke von Wilde bis zum Jahre 1942 erlaubt; siehe bei DREWNIAK, Das Theater, S. 255.

486 AN, AJ40 1001-7, Prop.Abt., Gr.Kult.Th., Tätigkeitsbericht, 30. 10. 1942.

487 Ibid. Aktennotiz für den Gruppenleiter, 2. 11. 1942.

488 Ibid. Aktennotiz für den Herrn Kommandeur, 26. 10. 1942.

489 Ibid. 
ßes gegen die deutschen Zensurbestimmungen. Abgesehen davon, daß auch im Bereich des Filmes literarische Vorlagen, die von Autoren der Feindstaaten stammten, verboten waren, durften grundsätzlich amerikanische oder englische Schauspieler in den Filmen nicht erwähnt werden. Aus dem von der Continental produzierten Film „Le Club des soupirants“ (Maurice Gleize, 1941) mußten die Hersteller beispielsweise eine Szene herausschneiden, in der „für eine amerikanische Schauspielerin Werbung gemacht worden war" ${ }^{490}$. Im Falle des Filmes „Premier bal“ (Christian-Jaque, 1941) wurden zwei Schnitte angeordnet, weil die Schauspieler Carol Lombard und Clark Gable „in propagandistischer Weise hervorgehoben “ 491 worden waren.

Im Zuge der von der Besatzungsmacht verfolgten „Säuberung“ des kulturellen Lebens waren im Bereich des Theaters jüdische Autoren und von Juden angefertigte Übersetzungen verboten. Zum Ausschluß solcher Werke heißt es in den Richtlinien für Kulturreferenten vom 15. Juli 1941: „Die Überwachung des Kunstlebens hat jüdische Elemente als Autoren, als Interpreten sowie auch als Geldgeber auszuschalten. Sie hat zu verhindern, daß sich hinter dem Deckmantel künstlerischer Zielsetzung politische und antideutsche Bestrebungen sammeln" 492 . Anti-deutsche Aussagen vermuteten die Zensoren vor allem aber bei französischen Autoren, denen sie politische Gegnerschaft vorwarfen. Doch wurde die Zensur hier weniger strikt als im Bereich des Ausschlusses der Werke jüdischer und feindstaatlicher Autoren gehandhabt, denn die Zensurentscheide in diesem Bereich waren relativ widersprüchlich ${ }^{493}$. So waren die Werke von Jean Giraudoux, der während des Krieges verantwortlich für die französische Propaganda gewesen war, zu Anfang der Besatzungszeit verboten. Im Jahre 1943 aber wurde die Aufführung seines Stückes "Sodome et Gomorrhe" nicht nur erlaubt, sondern in einem Bericht des Theaterreferats vom März 1944 sogar als Zeichen dafür gesehen, daß sich der Pariser Theaterbetrieb trotz materieller Schwierigkeiten auf „bemerkenswerter Höhe " 494 befindet. Zudem schrieb Giraudoux das Drehbuch zu „La Duchesse de Langeais“ (1941) von Jacques de Baroncelli mit Edwige Feuillère. Vorlage war ein Roman Honoré de Balzacs. 495

Im Oktober 1941 führte das Théâtre de L'CEuvre Paul Claudels "L'Annonce faite à Marie" auf. Theaterreferent Frank schrieb in seinem Bericht: „ein Stück, das in seinem legendär-naiven, starke dichterische Werte

490 BA-MA, RW35 223, Prop.Abt., Ref. Film, Tätigkeitsbericht, 12. 9.-19. 9. 1941

491 Ibid. Bericht über das Ergebnis der am 9. 9. 1941 erfolgten Filmprüfung des Filmes „Premier bal“ Fpf.Nr. 4968.

492 AN, AJ40 1001-7, Richtlinien für die Kulturreferenten, 15. 7. 1941.

493 ADDED, Le Théâtre, S. 100.

494 AN, AJ40 1001-7, Prop.Abt., Gr.Kult.Th., Bericht über den Monat März 1944.

495 Siehe FDI, VDP 848; siehe auch Alain DUNEAU, Giraudoux sous l'occupation: L'écrivain, son double, son refus, in: Actes du Colloque de Reims, S. 62; Duneau gibt an, Giraudoux habe während der Okkupation die Drehbücher zu zwei Filmen verfaßt, wobei er jedoch deren Titel nicht nennt. 
aufweisenden Eigenstil eine künstlerisch bedeutsame Wiedergabe findet “496. Zur Aufführung von Claudels „Le Soulier de satin“ im Dezember 1943 an der Comédie-Française meinte sein Nachfolger Goldmann:

Daß man überhaupt dieses Hauptwerk des als Deutschenhasser bekannten Dichters und Diplomaten zur Aufführung zugelassen hat - die Pariser Zeitung und auch das Reich brachten eine positive Besprechung - wurde verschiedentlich als Zeichen der Überlegenheit und Großzügigkeit der überwachenden Zensur angesehen. Andere Stücke von Claudel ("L'Otage“", "L'Échange" und "Le pain dur"), die von kleineren Theatern eingereicht waren, wurden abgelehnt ${ }^{497}$.

Die Zensurentscheide durch die unterschiedlichen Theaterreferenten liefern hier ein widersprüchliches Bild, was nur zum Teil auf die persönliche Meinung der verschiedenen Referenten zurückgeführt werden kann. So waren zusätzlich die sich verändernde Weltkriegslage und somit die veränderte Stimmungslage und politische Situation in Frankreich für die Handhabung der Zensur mit von Bedeutung. Für den Bereich des Theaters lassen sich etliche Belege für eine Verschärfung der Zensur finden. In einem Tätigkeitsbericht vom Dezember 1942 klagte Theaterreferent Frank, nur wenige deutsche Theaterstücke würden in den Pariser Spielplan aufgenommen, da man lediglich auf eine Kollaborationsbereitschaft der Franzosen vertraut habe. Durch eine verschärfte Handhabung der Zensur solle deswegen ein stärkerer Druck auf die Theaterdirektoren ausgeübt werden: „Stücke, die auch nur entfernt eine gewisse Sympathie mit den Feindstaaten ahnen lassen, verfallen dem Verbot $^{\text {“498 }}$. Vor allem seit Ende des Jahres 1942 läßt sich eine Verschärfung der deutschen Theaterzensur ausmachen, während diese immer deutlicher als Druckmittel zur Durchsetzung der Ziele deutscher Kulturpropaganda benutzt wurde. Ein Jahr später, im Dezember des Jahres 1943, berichtete das Theaterreferat: „Eine neu einsetzende starke Shakespeare-Welle wurde gestoppt durch die Auflage an die Theater, zunächst ein deutsches Stück zu spielen"499. Die Zensur verschärfte sich um die Jahreswende 1942/43 im Zeichen der sich verändernden Weltkriegslage besonders in bezug auf russische Autoren ${ }^{500}$. Während in bezug auf englische und russische Autoren eine Ver-

496 AN, AJ40 1001-7, Prop.Abt., Gr.Kult.Th., Tätigkeitsbericht, 10. 10.-31. 10. 1941. 497 Ibid. Bericht über den Monat Dezember 1943. Jean-Louis Barrault inszenierte „Le Soulier de satin", dessen Aufführung fünf Stunden dauerte; in der Nachzensur ließ das Theaterreferat einige Dialoge des Stückes streichen; siehe JouberT, La Comédie-Française, S. 157-159.

498 AN, AJ40 1001-7, Prop.Abt., Gr. Kult.Th., Tätigkeitsbericht, 30. 12. 1942.

499 AN, AJ40 1001-7, Prop.Abt., Gr.Kult.Th., Bericht über den Monat Dezember 1943. Eine zunehmende Verschärfung der Zensur zeigt auch folgendes Beispiel: Theaterdirektor Raymond Raynal wollte Ende 1943 am Théâtre Jeune Colombier Shakespeares "Sommernachtstraum“ inszenieren, was das Theaterreferat nicht gestattete. Es nahm sogar seinen Kompromißvorschlag, erst den Sommernachtstraum und danach ein deutsches Stück zu spielen, nicht an; AN, AJ40 1002-4b, Briefe von Raymond Raynal an Lucht vom 23. 11. und 4. 12. 1943.

500 AN, AJ40 1001-7, Prop.Abt., Gr. Kult.Th., Tätigkeitsbericht, 29. 1. 1943. 
schärfung der Zensur zu beobachten ist, wurde der Ausschluß jüdischer Autoren von vornherein strikt verfolgt. Allein im Bereich politischer Anspielungen französischer Autoren erfolgte keine Verschärfung der Zensur.

Im Bereich des Filmes ist, was die Filmproduktionen der Besatzungszeit anbelangt, keine Verschärfung der Zensur erkennbar. Ein Grund hierfür dürfte eine verstärkte Selbstzensur der Produzenten gewesen sein. Das finanzielle Risiko, wenn beispielsweise ein Filmvorhaben abgelehnt worden wäre, weil der Stoff auf einem russischen Roman beruhte, war zumindest relativ groß. Ein Theaterdirektor, der das Textbuch eines Stückes bei der Vorzensur einreichte, hatte dagegen in der Regel noch nicht in seine Aufführung investiert. Zudem liefert die Quellenlage nur wenig Informationen über die Zensurtätigkeit der Untergruppe Filmherstellung und -verleih des Referats Film. Der fertig produzierte Film, der schließlich von der Filmprüfstelle zensiert wurde, entsprach in der Regel bereits den deutschen Zensurbestimmungen.

Anders verhält es sich mit der Zensur älterer französischer Filme, die mehr und mehr durch eine von deutscher Seite betriebene sogenannte Marktbereinigung vor allem den deutschen Filmen Platz machen sollten. Mit Hilfe der Zensur sollte damit auch im Bereich des Filmes das Ziel deutscher Kulturpropaganda durchgesetzt werden. Hinzu kamen hier noch wirtschaftliche Interessen der deutschen Filmindustrie. Amerikanische und englische Filme wurden zu Beginn der Besatzungszeit ebenso wie französische anti-deutsche Filme verboten. Bereits Mitte Oktober 1940 waren 200 Filme, darunter auch 14 deutsche, vom französischen Markt zurückgezogen worden ${ }^{501}$. Die Besatzungsmacht beschlagnahmte die Filmrollen und sandte sie, vor allem dann, wenn es sich um sogenannte Hetzfilme handelte, an das Reichsfilmarchiv nach Berlin. Es kam dabei auch zu Unstimmigkeiten zwischen der Abwehrleitstelle und dem Referat Film über die Zuständigkeit, doch fiel die Prüfung dieser Filme offiziell in den Aufgabenbereich des Referats ${ }^{502}$. Die Besatzer versuchten sogar eine Zurückziehung amerikanischer Filme aus dem unbesetzten Gebiet zu bewirken; sie stießen damit bei der Regierung in Vichy jedoch auf Widerstand. Erst am 15. Oktober 1942, kurz vor der Besetzung ganz Frankreichs, gab die französische Regierung Anweisung, sämtliche amerikanischen Filme in der unbesetzten Zone zu verbieten ${ }^{503}$. Das Verbot von Filmen der Feindstaaten und von anti-deutschen Produktionen wurde offiziell zur Wahrung der politischen Interessen der Besatzungsmacht durchgeführt. Unter die Marktbereinigung fielen aber auch ältere französische Filme, welche die Zensoren zunächst noch einzeln verboten hatten. $\mathrm{Zu} \mathrm{Be}-$ ginn der Besatzungszeit wurden Filme mit jüdischen Darstellern nicht grundsätzlich verboten. Im Sinne einer Aufrechterhaltung des kulturellen Lebens ließen die Zensoren zunächst einen Großteil der Filme auf dem

501 Bertin-Maghit, Le Cinéma sous l'Occupation, S. 92.

502 BA-MA, RW35 222, Prop.Abt., Ref.Film, Tätigkeitsbericht, 10. 7.-17. 7. 1941.

503 BA-MA, RW35 227, Filmprüfstelle, Tätigkeitsbericht, 13. 9-19. 9. 1942. 
Markt, um die französischen Filmtheater mit einer genügenden Anzahl an Filmen zu versorgen. Es gab noch keine neueren französischen Produktionen und die neueren deutschen Filme waren noch nicht französisch synchronisiert. So bestand die Filmprüfstelle lediglich darauf, daß die Namen jüdischer Schauspieler von Werbeplakaten und aus dem Vor- und Abspann der Filme verschwanden. Teilweise ließen die Zensoren Szenen herausschneiden, in denen jüdische Schauspieler zu sehen waren.

Im März 1941 berichtete das Referat Film, es habe die Angelegenheit der Marktbereinigung geprüft. Die Zurückziehung älterer französischer Filme sei „im Interesse der Förderung des Absatzes deutscher Filme, sowie neuerer französischer Filme" 504 unbedingt notwendig. Hinter dieser Politik standen wirtschaftliche und propagandistische Interessen und vor allem sollte damit der Absatz deutscher Filme in Frankreich gefördert werden. Dies entsprach dem Ziel deutscher Kulturpropaganda und kam den wirtschaftlichen Interessen der deutschen Verleihfirmen Tobis und ACE entgegen. Ferner lag die Marktbereinigung auch im Interesse der deutschen Continental, die einen Teil der neueren französischen Filme produzierte. Nach einer Verordnung des MBF über die Regelung und Bereinigung des Filmmarktes vom 25. Mai 1941 wurden schließlich alle französischen Filme, deren Uraufführung vor dem 1. Oktober 1937 gelegen hatte, verboten. Allerdings gab es einige Ausnahmen. So bestanden beispielsweise noch finanzielle Forderungen der deutschen Agfa aus dem Verkauf von Filmmaterial an die französische Firma SIRIUS aus der Vorkriegszeit. Aus diesem Grunde erwog das Referat Film im Oktober 1941 „zur Unterstützung der Einbringung der Forderungen im deutschen Interesse" 505 den Verleih von drei älteren Filmen der SIRIUS, die vor dem 1. Oktober 1937 uraufgeführt worden waren. Im Februar 1942 berichtete das Referat Film dem RMVP, daß die Zensur bisher im besetzten Gebiet etwa 2800 amerikanische und englische Filme vom französischen Markt zurückgezogen hatte, ebenso 530 französische, 100 deutsche und 400 Filme der übrigen europäischen Produktionen. Es handelte sich um Filme, an denen jüdische Filmschaffende beteiligt waren, oder die "gegen Deutschland in verletzender Weise in Erscheinung getreten waren" 506 . Ferner hatte die Filmprüfstelle 300 weitere französische Filme aufgrund der Verordnung vom Mai 1941 zur Bereinigung des Filmmarktes verboten. Ausnahmsweise waren noch 80 dieser Filme verlängert worden. Weiter heißt es in dem Bericht an das RMVP, auf dem französischen Filmmarkt seien nun noch insgesamt 374 französische Spielfilme; diese Zahl schloß Filme, welche die ACE und Tobis verliehen, mit ein. An deutschen Filmen befanden sich demnach 125 Produk-

504 BA-MA, RW35 220, Ref.Film, Tätigkeitsbericht, 5. 3.-12. 3.1941.

505 BA-MA, RW35 224, Tätigkeitsbericht, 10.10.-17.10. 1941; Bericht zu einer Besprechung von Diedrich mit Rouvre von der Sirius und dem Pariser Vertreter der Agfa. 506 BA-MA, RW35 225, Gr.Film, Tätigkeitsbericht, 20. 2.-27. 2. 1942; die Übersicht zur Marktbereinigung wurde erst auf Anfragen des RMVP vom 7.1. und 12.2. 1942 nach Berlin geschickt. 
tionen auf dem französischen Markt; hinzu kamen 3 italienische und 15 aus übrigen Ländern ${ }^{507}$. Bis zum Beginn der nächsten Saison plante die Filmprüfstelle weitere 130 ältere französische Produktionen zurückziehen, in denen jüdische Schauspieler in kleineren Rollen, jüdische Techniker und andere jüdische Filmschaffende mitwirkten. An neueren Produktionen kämen 2 deutsche, 27 italienische und 41 französische Spielfilme in Kürze auf den Markt. Der Filmmarkt der nächsten Saison, so das Referat, gestalte sich folgendermaßen: 285 französische Filme, 127 deutsche Filme, 30 italienische Filme, 12 Filme der übrigen Produktion ${ }^{508}$. Diese Aufstellungen machen deutlich, wie stark gerade die Marktbereinigung das Verhältnis von französischen und deutschen Filmen auf dem französischen Markt beeinflußte. Ziel war es, dieses Verhältnis so weit als möglich zugunsten der deutschen Filme zu ändern und ihren Absatz zu fördern. Wenn den Filmtheaterbesitzern weniger französische Filme zur Verfügung standen, dann mußten sie notgedrungen verstärkt auf deutsche Filme zurückgreifen.

Ein Protestschreiben der Filmherstellungs- und Verleihunternehmen vom 30. März 1942 an Ploquin, den Leiter des COIC, hatte die Zurückziehung von älteren Filmen mit jüdischen Darstellern in kleineren Rollen, oder etwa mit jüdischen Technikern zum Inhalt. In der deutschen Übersetzung dieses Schreibens heißt es: „Wir wollen an eine solche Maßnahme, die ohne Grund die ganze französische Industrie ruinieren würde, nicht glauben" 509 . Zu wenig Filme blieben für den französischen Markt übrig und gerade die kleineren Kinos müßten dann schließen. Ferner sei das Verbot unsinnig, da die Besatzer zu Beginn der Okkupation angeordnet hätten, alle jüdischen Namen, die im Vorspann und der Reklame auftauchten, zu entfernen. Die Filme seien anschließend genehmigt worden. Ferner habe eine Abtretung der von jüdischen Produzenten hergestellten oder verliehenen Filme an Arier - gegen eine Bezahlung - stattgefunden. Die Zurückziehung dieser Filme schade also den französischen Verleihfirmen finanziell. Man sehe den Grund dieser Maßnahme nicht ein. In dem Schreiben wird ferner erklärt: „Außerdem achtet der Zuschauer heute sowenig als gestern auf die ,Rasse von manchen Schauspielern in kleinen Rollen, wie diese auch früher den Produzenten unbekannt

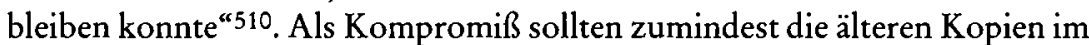
Umlauf bleiben, wenn schon keine neuen genehmigt würden. Dieses Protestschreiben legte Referatsleiter Diedrich zwar dem Kommandeur vor, doch blieb es ohne Erfolg. Diedrich war der Meinung, die Unterzeichner des Briefes hätten „die neue Zeit“ nicht begriffen. Ferner beklagte er sich, „daß seitens des COIC nichts geschieht, um die französischen Filmkreise zur Er-

507 Ibid.

508 Ibid.

509 BA-MA, RW35 225, Prop.Abt., Gr.Film, Tätigkeitsbericht, 4. 4.-11. 4. 1942.Von 40 französischen Firmen gezeichnetes Protestschreiben, an Raoul Ploquin, COIC, vom 30. 3. 1942, deutsche Übersetzung.

510 Ibid. 
kenntnis der antisemitischen Grundeinstellung Europas und dementsprechender Ausrichtung auch des französischen Filmwesens zu erziehen und die Dinge immer wieder unter dem Gesichtspunkt demokratischer materialistischer Auffassung betrachtet werden" 511 . Die Versorgung des französischen Marktes war nach Ansicht Diedrichs nicht gefährdet. Ferner sei die deutsche Seite ohnehin sehr großzügig gewesen, denn wenn alle Filme mit jüdischen Filmschaffenden verboten worden wären, dann hätten 90 Prozent des heutigen französischen Filmbestandes aus dem Verkehr gezogen werden müssen ${ }^{512}$. Diedrich gibt in seinen Ausführungen an, diese Maßnahme richte sich vor allem gegen jüdische Künstler. Allerdings wird in den Berichten des Referats Film mehrfach deutlich, daß die "Sicherung des Absatzes deutscher Filme und neuerer französischer Filme ${ }^{\text {} 513}$ im Vordergrund stand. Zum Teil schob das Referat Film hier rasseideologische Motive vor, hinter denen sich auch deutsche wirtschaftliche wie propagandistische Ziele verbargen.

Anfang Oktober 1942 notierte die Filmprüfstelle, sie wolle bis Ende Dezember einen weiteren großen Teil der älteren französischen Filme vom Markt zurückziehen ${ }^{514}$. Im Januar 1943 berichtete sie, auf dem französischen Markt stünden nun 321 französische Spielfilme 175 deutschen Produktionen gegenüber: „Dieses Angebot deutscher Filme in einem besetzten bzw. unter deutschem Einfluß stehenden Gebiet ist einmalig. Den deutschen Verleihunternehmungen wurde nahegelegt, diese Lage zu Gunsten der Unterbringung deutscher Filme bestmöglichst auszunutzen " 515 . Im März 1943 waren laut Filmprüfstelle 193 deutsche und 433 französische Spielfilme auf dem französischen Markt. Sie betonte, daß dieses für den deutschen Film günstige Verhältnis allein aufgrund der Verordnung des MBF zur Marktbereinigung erreicht werden konnte ${ }^{516}$. Mit Hilfe der Zensur ist hier die deutsche Filmexportpolitik nach Frankreich gleichsam flankiert worden. Die deutschen Verleihfirmen in Frankreich verfolgten nicht nur wirtschaftliche Interessen, sondern standen mit ihrer Aufgabe der Verbreitung von deutschen Filmen in Frankreich auch im Dienste deutscher Kulturpropaganda.

In bezug auf ältere Filme ist eine Verschärfung der Zensur im Laufe der Besatzungszeit festzustellen. Gleichwohl gab es auch hier Ausnahmen, wie

511 Ibid. Prop.Abt., Gr.Film, Tätigkeitsbericht, 4. 4.-11. 4. 1942.

512 Ibid.

513 Siehe beispielsweise BA-MA, RW35 225, Prop.Abt., Gr.Film, Tätigkeitsbericht, 18. 4.-25. 4. 1942; Bericht über eine Besprechung vom 16. 4. 1942 zwischen Diedrich und Vertretern der Tobis und ACE: „Bei dieser Gelegenheit wurde auch die Frage der weiteren Bereinigung des französischen Filmmarktes von alten Filmen erörtert, die zur Sicherung des Absatzes und der Verbreitung deutscher Filme auch in der Zukunft einerseits und im Interesse des Absatzes und der Verbreitung neuer französischer Filme erforderlich ist". Siehe auch BA-MA, RW35 226, Prop.Abt., Gr. Film, Tätigkeitsbericht, 15. 5.-23. 5. 1942.

514 BA-MA, RW35 227, Filmprüfstelle, Tätigkeitsbericht, 27.9.-3.10.1942.

515 Ibid. Tätigkeitsbericht, 16. 1.-23. 1. 1943.

516 Ibid. Tätigkeitsbericht, 20. 3.-27. 3. 1943. 
das Beispiel des Filmes "Education de prince“ (1938) von Maurice Donnay zeigt. Die Liebesgeschichte eines jungen Fürsten mit einer Pariserin wurde am 2. August 1941 unbefristet zugelassen, nachdem allein die Namen zweier jüdischer Schauspieler herausgeschnitten worden waren. Die Filmprüfstelle verbot den Film am 10. Juni 1942 aufgrund von deren Mitwirkung. Doch nur fünf Tage später traf Diedrich die Entscheidung, den Film bis zum 30. April 1943 erneut zuzulassen, weil es sich hier um eine besonders teure Produktion handelte und der Film erst vier Monate vor Kriegsbeginn in die Kinos gekommen war; er hatte sich also keineswegs amortisieren können. Allerdings mußten nun einige Szenen herausgeschnitten werden ${ }^{517}$. In einem Brief an die Verleihfirma des Filmes, Pathé Consortium Cinéma, schrieb der Leiter der Filmprüfstelle am 4. November 1942: „Auf Grund Ihrer Intervention habe ich mich bereit gefunden nach Durchführung gewisser Schnitte eine weitere Auswertung des Filmes zu genehmigen, jedoch nicht über den 30. 4.43 [hinaus] “518. Er betonte, er könne angesichts der Regelung des $\mathrm{MBF}$ für Filme mit jüdischen Darstellern von diesem Grundsatz nicht abweichen. Gleichwohl wurde der Film am 28. April 1943 erneut verlängert, am 19. April 1944 verboten und schließlich am 24. Juni wieder zugelassen. 519 Dieses Beispiel zeigt, daß zwar eine Verschärfung der Zensur in bezug auf die Filme mit jüdischen Darstellern ab Frühjahr/Sommer $1942 \mathrm{zu}$ erkennen ist, offenbar konnte aber in Einzelfällen von diesem Grundsatz abgewichen werden, falls es vom wirtschaftlichen Standpunkt aus notwendig erschien. Im Sinne der Aufrechterhaltung des kulturellen Lebens hatten die Besatzer auch ein Interesse an einer finanziell gesunden französischen Filmproduktion. Ähnlich wie im Bereich des Theaters versuchte die Besatzungsmacht im Bereich des Filmes durch eine verschärfte Zensur deutsche Filme in französische Filmtheater zu bringen. Diese Bemühungen waren im Bereich des Filmes massiver. Anders als beim Theater waren im Bereich des Filmes auch die wirtschaftlichen Interessen deutscher Verleihfirmen ein Motiv für diese Verschärfung der Zensur, die zudem dem Ziel deutscher Kulturpropaganda diente. Insbesondere bei den Maßnahmen zur Marktbereinigung wurden zum Teil rasseideologische Gründe nur vorgeschoben, während sich dahinter auch wirtschaftliche und kulturpropagandistische Motive verbargen.

Diesen Zielen folgte neben der Kontrolle und „Säuberung“ des französischen Kulturlebens auch die Zensur der Film- und Theaterkritiken. Die sogenannte künstlerische Freiheit der Feuilletonschreiber war eingeschränkt durch die obligatorisch guten Kritiken, die zu deutschen Filmen, Theaterstücken und Gastspielen erscheinen sollten ${ }^{520}$. Die französische Presse

517 AN, AJ40 1005-2, Prop.Abt., Ref.Film, Filmprüfstelle, Dossier „Education de Prince“.

518 Ibid.

519 Ibid.

520 AN, AJ40 1001-7, Aktennotiz für die kulturpolitische Pressekonferenz 10.3. 1943, 8.3.1943. 
wurde generell streng von der Besatzungsmacht kontrolliert ${ }^{521}$. Im Kulturbereich mußte sie jüdische und angeblich freimaurerische Künstler ebenso totschweigen wie Angehörige der Feindstaaten. Dies traf auch auf französische Künstler zu, die emigriert waren oder sich als deutschfeindlich gezeigt hatten. Zwei Listen mit verbotenen Namen wurden an die Presse gegeben. Die sogenannte Liste der nichtjüdischen Filmschaffenden enthielt insgesamt 65 Personen, die mit Bezeichnungen wie „Hetzfilmmitwirkende“, „Freimaurer", „Kommunist" oder "gegen Deutschland tätig“, belegt wurden ${ }^{522}$. Darunter waren - mit dem Zusatz „Emigrantin“ versehen - Lilian Harvey und Marlene Dietrich; Erich von Stroheim erhielt die Bemerkung „politisch gegen das Reich", Fred Astaire "Amerikaner, deutschfeindlicher Jude“, Michèle Morgan "wirkt in Amerika in einem Hetzfilm mit" und Charles Boyer erhielt den Zusatz „im Radio gegen Deutschland gewirkt"523. Eine zweite Liste der in Frankreich tätig gewesenen jüdischen Filmschaffenden enthielt Namen wie Kurt Gerron, Max Ophüls und Robert Siodmak; insgesamt waren es 222 Personen ${ }^{524}$. Grundsätzlich durfte die Presse keine englischen oder amerikanischen Schauspieler nennen. Dies war laut Filmprüfstelle eine Bedingung zur Zurückdrängung des amerikanischen Filmes in Europa und in Frankreich. Ferner sollten französische Filmschaffende wie Michèle Morgan, Jean Gabin, René Clair oder Julien Duvivier, die unter Vertrag mit amerikanischen Filmfirmen standen, in der Öffentlichkeit totgeschwiegen werden ${ }^{525}$. Im Bereich des Theaters entstanden zwischen der Gruppe Kultur und der Gruppe Presse der Staffel Kompetenzstreitigkeiten über die Ausübung der Pressezensur, die im Falle der Theaterkritiken in den Händen der Gruppe Kultur lag. Im August 1941 beschwerte sich die Gruppe Presse über Verzögerungen der Zensur der Kulturartikel. Diese verlören dadurch an Aktualität, weshalb die Zeitungen sie nicht mehr veröffentlichten ${ }^{526}$. Offenbar war die Gruppe Kultur mit der Menge an Arbeit überfordert, blieb jedoch zunächst dafür noch zuständig. Im April 1942 warf sie der Gruppe Presse vor, nicht alle Kulturartikel an die Gruppe Kultur weiterzugeben und stattdessen selbst Kulturartikel zu zensieren ${ }^{527}$. Zudem vernachlässigte die Presse zeitweise die Einreichung gerade der Kulturartikel528. Weil die Gruppe Kultur schließlich die anfallende Arbeit doch nicht mehr bewältigen konnte, wurde die Pressevorzensur für Kulturartikel im März 1943 abgeschafft und durch

521 MiCHEL, Paris allemand, S. 322-330.

522 BA-MA, RW35 223, Tätigkeitsbericht, 5. 9.-12. 9. 1941, Liste der nichtjüdischen Filmschaffenden.

523 Ibid.

524 Ibid. Liste der in Frankreich tätig gewesenen jüdischen Filmschaffenden. Beide Listen wurden regelmäßig kontrolliert und ergänzt.

525 Ibid. Tätigkeitsbericht, 5. 9.-12. 9. 1941.

526 AN, AJ40 1001-7, Prop.St., Gruppe Presse an Gruppe Kultur, 13. 8. 1941.

527 Ibid. Prop.St., Gr.Kult.Th., Lucht, Notiz an Gruppe Presse z.Hd. des Gruppenleiters, 24. 4. 1942.

528 Ibid. Bericht über den Monat April 1942. 
eine vierzehntätige sogenannte kulturpolitische Pressekonferenz ersetzt, was jedoch keine Lockerung der Zensur bedeuten sollte. In den Richtlinien für die Kulturarbeit der Staffeln und Außenstellen vom 20. Mai 1943 heißt es, die Nachzensur für Presseartikel werde beibehalten, Verstöße seien „im Rahmen des Möglichen rücksichtslos zu ahnden"529. Mit der Einführung der kulturpolitischen Pressekonferenz sollte vor allen Dingen eine Entlastung der zuständigen Referate erreicht werden. Außerdem erschien es der Besatzungsmacht nicht als zu risikoreich, hier auf eine Vorzensur zu verzichten. Sie verließ sich offenbar auf die kollaborierende Presse. Durch den Wegfall der Vorzensur übertrug die Propaganda Staffel bzw. Abteilung die Verantwortung auf die französischen Zeitungen, die sich nach den in der sogenannten kulturpolitischen Pressekonferenz ausgegebenen Grundsätzen zu richten hatten ${ }^{530}$. Abgesehen von der deutschen Zensur, wurde die französische kulturelle Aktivität auch durch eine französische Zensur kontrolliert und eingeschränkt. Hierbei kam es teilweise auch zu Unstimmigkeiten zwischen den deutschen und französischen Zensoren.

\subsection{Zur französischen Zensur}

Für die Behandlung von Theaterfragen gab es keinen Vertreter der französischen Regierung in Paris, während im Bereich des Filmes mit dem Regierungsbeauftragten de Carmoy und später Galey ein solcher Funktionsträger in der Hauptstadt präsent war ${ }^{531}$. Hauptsächlich liegt die Ursache hierfür in einem größeren Interesse, das die Vichy-Regierung der Kulturpolitik dem Bereich des Filmes als dem des Theaters entgegenbrachte ${ }^{532}$. Ferner war das Theaterleben weit mehr auf Paris konzentriert als die Filmproduktion und im besetzten Gebiet unterlag sie gänzlich der Kontrolle der Besatzungsmacht. Doch selbst in der unbesetzten Zone verfolgte das Vichy-Regime keine klar umrissene und konsequente Theaterpolitik im Sinne der bereits genannten nationalen Erneuerung ${ }^{533}$. Die Theaterzensur war in Frankreich im Jahre 1906 abgeschafft worden und erst unter der Vichy-Regierung wurde sie gleichsam wiederbelebt. Doch war die dem Informationsministerium angeschlossene Direction de la censure nur für den Süden Frankreichs zuständig und auch dort soll ihre Arbeit im Bereich des Theaters nicht sehr effizient

529 Ibid. Geheim, Richtlinien für die Kulturarbeit der Staffeln und Außenstellen, 20. 5. 1943.

530 Ibid. Prop.St., Bericht über den Monat April 1942; Ibid. Aktennotiz für die kulturpolitische Pressekonferenz 10.3.1943, 8. 3. 1943.

531 Im Oktober 1941 wurde Galey, der bisherige Chef du service du cinéma, als Nachfolger De Carmoys, zum Commissaire général du gouvernement pour le cinéma“; BAMA, RW35 224, Prop.Abt., Ref.Film, Tätigkeitsbericht, 17.10.-14. 10. 1941.

532 ADDED, Le Théâtre, S. 29-94; BerTIN-MAGHit, Le Cinéma sous l'Occupation, S. 49-119, 134-152.

533 Siehe hierzu bei ADDED, Le Théâtre, das Kapitel „Ả la recherche de la politique théâtrale de Vichy“, S. 30-54. 
gewesen $\operatorname{sein}^{534}$. Abgesehen davon, war es theoretisch dem französischen Staat möglich, ein Stück dann zu verbieten, wenn es die bonnes mours, die guten Sitten, verletzte oder die öffentliche Ordnung gefährdete ${ }^{535}$. Allein auf dieser Grundlage gab es in Paris Ansätze zu einer Zensur Vichys, da auf Veranlassung de Brinons einige Male Theaterstücke nach ihrer Premiere von der Polizeipräfektur verboten wurden.

Wie problematisch diese französische Nachzensur sein konnte und wie die deutschen Zensoren darauf reagierten, zeigt die Aufführung des Stückes „La Machine à écrire" von Jean Cocteau im Théâtre Hébertot im April 1941. Das Stück, das bereits vor dem Kriege in Paris ohne Probleme aufgeführt worden war, verursachte nun einen Theaterskandal. Es verarbeitete den gleichen Stoff wie Clouzots Film „Le Corbeau“: In einer französischen Kleinstadt tauchen anonyme Briefe auf, welche die angesehenen Bürger der Stadt in Zweifel ziehen. Die Briefe selbst sowie die Suche nach deren Urheber tauchen das Stück in ein Klima von Denunziation und falschen Verdächtigungen ${ }^{536}$. Es handelte sich also um einen Stoff, der während der Besatzungszeit durchaus einen realen Bezug hatte, wenn man an die anonymen Briefe denkt, mit denen jüdische Mitbürger denunziert wurden. Hinzu kam die Thematisierung von Abtreibung und Selbstmord, was freilich nicht in die von Vichy propagierten Vorstellungen von famille, travail, patrie paßte. In einem Bericht des Theaterreferats vom April/Mai 1941 heißt es, de Brinon habe vor dem Verbot des Stückes vom Autor Streichungen und Änderungen der Szenen verlangt, welche nach dessen Meinung den guten Geschmack des Publikums verletzten; Cocteau habe diese vorgenommen. Trotzdem habe de Brinon das Stück durch die Polizei verbieten lassen, und zwar ohne die Propaganda Abteilung davon zu unterrichten. Das Polizeiverbot entbehre jeder Rechtslage. Sowohl aus Prestigegründen als auch aus rein juristischen Gründen hätte die deutsche Seite deswegen gegen diese Maßnahme einschreiten müssen. Ferner schrieb das Referat: „In der Aufführung hat das Publikum keinerlei Protestkundgebungen gemacht, die beiden ersten Akte wurden sogar mit starkem

534 Die Direction de la censure, die dem Informationsministerium Vichys angeschlossen war, hatte eine für die Theaterzensur zuständige Unterabteilung „livres et spectacles“. Bis zum Ende der Besatzung war sie nur für den südlichen Teil Frankreichs zuständig. Nach Added fehlte jener Theaterzensur Vichys eine klare Linie; die Zensurverbote seien sehr widersprüchlich und die Arbeit der Abteilung relativ ineffizient gewesen. Hauptsächlich habe sich die dramatische Produktion Frankreichs ohnehin auf Paris konzentriert; ADDED, Le Théâtre, S. 42; zur Zensur Vichys siehe insbesondere S. 37-45.

535 CDJC, IV 12, Prop.St., Gr.Kult., Lucht an de Brinon, DGTO, frz. Übersetzung, 6. 5. 1941. In diesem Schreiben weist Lucht de Brinon ausdrücklich auf diese Regelung hin.

536 Siehe auch die Einleitung dieser Arbeit. 
Beifall aufgenommen"537. Im Einvernehmen mit der Deutschen Botschaft wurde das Verbot wieder aufgehoben.

Die deutschen Behörden fühlten sich also durch de Brinon übergangen und vor allem deshalb mußte das Verbot rückgängig gemacht werden. Die Besatzungsmacht demonstrierte so ihre alleinige Zuständigkeit im Bereich der Theaterzensur. Auch war das Theaterreferat der Meinung, das Stück verstoße weder gegen die guten Sitten noch gefährde es die öffentliche Ordnung. Erst nach Verhandlungen zwischen de Brinon und Lucht wurde „La Machine à écrire" schließlich im Juni 1941 wieder verboten ${ }^{538}$. Die Gründe de Brinons für das Verbot des Stückes sind nicht mehr eindeutig zu bestimmen. Abgesehen von inhaltlichen Motiven, ist es laut Added auch denkbar, daß sich diese Maßnahme vor allem gegen die Person des Autors richtete. Cocteau war in den Augen der Kollaborateure ein für die angebliche Dekadenz der Troisième République typischer Autor ${ }^{539}$. Die Propaganda Staffel führte das Verbot auch auf einen Einfluß von deutscher Seite zurück. Inhaltlich war „La Machine à écrire" von der deutschen Vorzensur als politisch unbedenklich eingestuft worden. Theaterreferent Baumann konstatierte lediglich, das Stück trage dekadente Züge, die nach seiner Meinung jedoch nahezu alle Stücke der Pariser Spielpläne kennzeichnete. Laut Baumann hatte de Brinon das Stück auf Anregung von Susanne Abetz verboten. Die Frau des Botschafters sei der Ansicht, „daß das neue Frankreich gegen dekadente Erscheinungen sich nunmehr auflehne und es den französischen Zuschauer kränken müsse, wenn in Paris noch Stücke gespielt werden, die im unbesetzten Gebiet nicht mehr erwünscht seien “540. Abetz selbst soll dem Stück während der Premiere dagegen Beifall gezollt haben. Die Propaganda Staffel zeigte sich über die von ihr vermutete Einmischung der Botschaft in das französische Theaterleben empört. Gegenüber Generalkonsul Schleier betonte sie, daß die deutsche Zensur allein die politische Tendenz der Theaterstücke prüfen solle:

Die französische Lebensart hat eine Fülle von Theaterstücken herausgebracht, die sich mit den Zerfallserscheinungen des französischen Volkes decken. Es ist uns bisher nicht zur Aufgabe gemacht worden, nach deutschen Maßstäben das sittliche Leben Frankreichs auszurichten ${ }^{541}$.

537 AN, AJ40 1001-7, Prop.St., Gr.Kult.Th., Tätigkeitsbericht, 27. 4.-5. 5. 1941; siehe auch den Tätigkeitsbericht vom 13.6.1941.

538 Ibid. Baumann, Tätigkeitsbericht, 13. 6. 1941. De Brinon versuchte zunächst erfolglos, Nutzen aus den Kompetenzstreitigkeiten der deutschen Dienststellen zu ziehen. Er wandte sich mit einem Brief an Epting, um sein Verbot durchzusetzen. Epting leitete den Brief an die Propaganda Staffel weiter und so war es schließlich Lucht, der de Brinon abschlägig antwortete; CDJC, IV 12, Prop.St., Gr.Kult., Lucht an de Brinon, DGTO, frz. Übersetzung, 6. 5. 1941.

539 ADDED, Le Théâtre, S. 43.

540 AN, AJ40 1002-4a, Prop.St., Gr.Kult.Th., Baumann, Aktennotiz, 2. 5. 1941.

541 Ibid. 
Zudem war die rechtliche Grundlage für die Maßnahme de Brinons problematisch, da das Stück nach Ansicht der Propaganda Staffel weder die bonnes moeurs verletzte noch die öffentliche Ordnung gefährdete ${ }^{542}$. Abgesehen davon, daß ihre Dienststelle bei dem Verbot übergangen worden war, gab es für die Propaganda Staffel noch einen weiteren Grund, gegen die Maßnahme de Brinons Stellung zu beziehen. Die finanziellen Einbußen waren für ein Theater nicht unerheblich, wenn eine Aufführung erst nach der Premiere verboten wurde. Dies lag keineswegs im Sinne einer von den Besatzern befürworteten kurzfristigen Aufrechterhaltung des Theaterbetriebes. Aus diesem Grunde wurde auf deutscher Seite die Notwendigkeit einer französischen Vorzensur moralischer und künstlerischer Art eingesehen. So schrieb Theaterreferent Baumann: „Es muß grundsätzlich überlegt werden, ob zur moralischen Ausrichtung des Theaterlebens eine französische Zensurstelle eingerichtet werden kann" 543 . Nur dadurch sei der Ruin der betreffenden Theater zu vermeiden. Allein durch de Brinons Verbot hatte das Theater laut Baummann einen Verlust von 400000 Francs erlitten. Dem Skandal um „La Machine à écrire“ folgte also die Diskussion um eine französische Vorzensur. Der Theaterdirektorenverband hatte vorher bereits eine offizielle französische Zensur im besetzten Gebiet gefordert und meinte nun: „C'est la seule manière de concilier les exigences morales de ces tristes jours avec les intérêts légitimes d'un directeur qui risque de voir son spectacle arrêté après qu'il en a fait tout le travail et engagé toutes les dépenses" 544 . Lucht betonte in einer Besprechung mit dem Comité de direction des ADTP, bestehend aus Gaston Baty, Pierre Renoir und Charles Dullin, daß auch ihm an der Bestellung eines für das Theater zuständigen Regierungsbeauftragten von Vichy in Paris gelegen sei. Das Comité sollte de Brinon den Vorschlag vortragen ${ }^{545}$. Obwohl sich die Propaganda Staffel und die französische Berufsorganisation in dieser Frage einig waren, gab es bis zum Ende der Besatzungszeit in Paris keinen für Theaterangelegenheiten zuständigen Beauftragten der französischen Regierung. Der Grund hierfür dürfte das letztlich doch zu geringe propagandistische Interesse des Vichy-Regimes am Theater gewesen sein. Dem ADTP gelang es nach dem Vorfall um Cocteaus Stück lediglich, mit dem Sécrétariat général des Beaux-Arts eine inoffizielle Vorzensur zu vereinbaren. Die Theaterdirektoren konnten ihre Manuskripte freiwillig beim ADTP einreichen, bevor sie diese beim Theaterreferat vorlegten. Added hat hierzu konstatiert,

542 CDJC, IV 12, Prop.St., Gr.Kult., Lucht an de Brinon, frz. Übersetzung, 6. 5. 1941. Dieser Meinung war freilich auch der Theaterdirektor Jacques Hébertot, der sich in einem Schreiben an Lucht über das Vorgehen de Brinons beschwerte; siehe AN, AJ40 1002-4a, „Rapport“, Hébertot an Lucht, Prop.Abt., Gr.Kult, 1. 5. 1941.

543 AN, AJ40 1002-4a, Prop.St., Gr.Kult.Th., Baumann, Aktennotiz, 2. 5. 1941; auch CDJC, IV 12, Prop.St., Gr.Kult., Lucht an de Brinon, frz. Übersetzung, 6. 5. 1941. 544 AN, AJ40 1004-1, ADTP, Comité de direction an Jacques Hébertot, 1. 5. 1941. 545 AN, AJ40 1001-7, Prop.St., Gr.Kult.Th., Aktennotiz, Besprechung des Gruppenleiters Kultur mit den Theaterdirektoren Baty, Renoir, Dullin. 
diese censure douce ${ }^{546}$ scheine nicht funktioniert zu haben. Seit Juni 1942 mußten offiziell alle Manuskripte über das COES beim Theaterreferat eingereicht werden ${ }^{547}$. Grundsätzlich kam es während der Besatzungszeit nur mehr punktuell zu Verboten von Theaterstücken durch die Polizeipräfektur, wogegen die Propaganda Staffel in der Regel auch nicht mehr einschritt. Im Oktober 1941 verbot die französische Polizeipräfektur ein zweites Stück von Cocteau, „Les Parents terribles“, das im Thêatre du Gymnase gespielt wurde. Vor den Aufführungen kam es zu öffentlichen Protesten im Theater, woraufhin die Besitzerin des Theaters, Alice Cocéa, sich bei der Gruppe Kultur beschwerte. Diese verwies sie einfach an die französische Polizei ${ }^{548}$. „La Parisienne" drohte im November 1942 ein Verbot, weil Vichy an dem Titel Anstoß nahm. Bei dem Stück handelte es sich um eine Liebesgeschichte zwischen Ehemann, Ehefrau und deren Liebhaber. Die französische Regierung war der Ansicht, der Titel vermittle den Eindruck, Pariser Frauen verhielten sich im allgemeinen unmoralisch. Deshalb mußte "La Parisienne" in "Clothilde de Mesnil" umbenannt werden ${ }^{549}$.

Die deutsche Zensur überließ es also der französischen Seite, bei Theaterstücken über die Einhaltung der sogenannten guten Sitten zu wachen. Die Besatzungsmacht befürwortete eine französische Vorzensur, damit den Theaterdirektoren durch nachträgliche Verbote kein finanzieller Schaden entstand. Die Vichy-Regierung zeigte hier letztlich jedoch nur wenig Interesse, da bis zum Ende der Besatzung kein offizieller Regierungsbeauftragter in Paris für diese Aufgabe abgestellt wurde. Gleichwohl übte der COES, über den schließlich die Manuskripte eingereicht wurden, hier eine gewisse Kontrolle aus. Das Verhältnis von deutscher und französischer Zensur kann im Bereich des Theaters - von dem Skandal um „La Machine à écrire“ einmal abgesehen - als relativ konfliktfrei bezeichnet werden. Ganz anders war dies im Bereich des Filmes.

Hier gab es im Laufe der Besatzungszeit weit mehr Streitpunkte zwischen der Filmprüfstelle und der für die Filmzensur zuständigen Commission de censure $^{550}$ in Vichy. Dazu hat Bertin-Maghit bemerkt, die Geschichte der 546 ADDED, Le Thêâtre, S. 44.

547 AN, AJ40 1001-7, Prop.St., Gr.Kult.Th., Frank, Tätigkeitsbericht vom 1.-30.6. 1942.

548 Ibid. Tätigkeitsbericht, 10.-31. 10. 1941; zu diesem Fall siehe auch die Tätigkeitsberichte des Theaterreferats vom 20.12. 1941 und 27. 12. 1941 sowie die Aktennotiz vom 5. 1. 1942. Die französische Polizei verbot ferner 1942 „Kiddou“ von Guy Rotter und "Andromaque“ von Jean Racine im Théâtre Eduard VII. nach einer Inszenierung von Jean Marais im Juni 1944 (Ibid. Bericht über den Monat Juni 1944).

549 Ibid. Tätigkeitsbericht, 30.11. 1941.

550 Siehe dazu BerTIN-MAGHIT, Le Cinéma sous l'Occupation, S. 92; die Zensurkommission mit Sitz in Vichy unterstand dem Generalsekretariat für Information und Propaganda; ihre neun Mitglieder entschieden über drei verschiedene Arten von Zensurvisa: „visa de production“, „visa d'exploitation“", „visa d'exportation“. Um ein „visa de production" zu erhalten, mußte unter anderem auch eine „synopsis“ des Filmes vorgelegt werden. Auch dann, wenn ein Film in der besetzten Zone zur Herstellung zugelas- 
Filmzensur während der Okkupation sei das Resultat eines ständigen Kräftemessens gewesen „entre le gouvernement de Vichy et les autorités d'occupation, entre les pouvoirs publics français et les associations, les autorités religieuses, les individus qui entendent exercer des pressions moralisatrices" ${ }^{* 51 .}$ An der Prüfung der Filme bestand also auf deutscher wie auch auf französischer Seite ein weit größeres Interesse als an der Theaterzensur. Zu Beginn der Besatzungszeit waren die Kompetenzen der deutschen und französischen Zensur sauber getrennt; die deutsche beschränkte sich auf das besetzte, die französische auf das unbesetzte Gebiet. Ab Februar 1941 wurde jedoch der französische Filmmarkt einheitlich. Filme, die in der ZO gedreht worden waren, konnten in die ZNO eingeführt werden und umgekehrt. Es ist bereits erwähnt worden, daß die Vichy-Regierung auf der Verwaltungseinheit des französischen Territoriums bestanden hatte. Auch der Filmmarkt sollte also trotz der unterschiedlichen Zonen eine Einheit bilden. Während die Besatzungsmacht forderte, die Zensurentscheide der Filmprüfstelle müßten im unbesetzten Gebiet ohne weiteres anerkannt werden, war sie ihrerseits jedoch nicht dazu bereit, die Entscheidungen der französischen Kommission im besetzten Gebiet gelten zu lassen ${ }^{552}$. Die Weigerung, Filme aus der ZNO ohne weiteres in der ZO zuzulassen, nutzte das Referat Film auch als Druckmittel, um eine Konzentration der Filmproduktion in Paris zu erreichen; dort war sie unter deutscher Kontrolle. Aus wirtschaftlichen Gründen waren die Produzenten freilich daran interessiert, ihre Filme auch im besetzten Gebiet verleihen zu können. Indem dies bei einer Herstellung im unbesetzten Gebiet erschwert wurde, hofften die Besatzer, die Produktionsfirmen nach Paris zu ziehen ${ }^{553}$. Die Vichy-Regierung bestand hingegen auch weiterhin auf der alleinigen Kontrolle über die Filmzensur im unbesetzten Gebiet. Erst im September 1942, also kurz vor der Besatzung ganz Frankreichs, erkannte sie die bisher erfolgten Zensurentscheide der Filmprüfstelle auch für das unbesetzte Gebiet an ${ }^{554}$.

Ein weiterer Streitpunkt war die unbeschränkte Einfuhr deutscher Filme in das unbesetzte Gebiet. Der Wunsch der französischen Stellen, die deutschen Filme vorher ansehen zu können - also nicht einmal zu zensieren - und daraufhin ein französisches Zensurvisum auszustellen, wurde von deutscher Seite zurückgewiesen. Die Besatzungsmacht sah darin einen Versuch, die Einfuhr deutscher Filme in das unbesetzte Gebiet zu erschweren ${ }^{555}$. Im März

sen worden war, konnte die Zensurkommission in Vichy durchaus das Visum zum Verleih des Filmes später verweigern.

551 Ibid. S. 91.

552 Ibid. S. 93.

553 BA-MA, RW35 221, Prop.Abt., Ref.Film, Tätigkeitsbericht, 12. 6.-18. 6. 1941.

554 BA-MA, RW35 227, Filmprüfstelle, Tätigkeitsbericht, 13. 9.-19. 9. 1942.

555 BA-MA, RW 35 220, Ref.Film, Tätigkeitsbericht 5. 3.-12. 3. 1941, 12. 3. 1941, Ausführungen zu Besprechungen Diedrichs mit Ploquin (COIC) und de Carmoy (Service du cinéma). 
1941 schlug die französische Seite zur Bereinigung dieser Unstimmigkeiten die Errichtung einer gemeinsamen deutsch-französischen Zensurkommission vor, was Referatsleiter Diedrich zu diesem Zeitpunkt ablehnte. Er zog die Bestellung eines Zensurbeauftragten Vichys bei der Filmprüfstelle vor, doch kam es hier zu keiner Einigung 556 . Erst im Juli 1942 ergriff die deutsche Seite selbst die Initiative zu einer deutsch-französischen Zensurkommission, die ihren Sitz in Paris bei der Filmprüfstelle haben sollte; nun ging aber die Vichy-Regierung auf diesen Vorschlag nicht ein. Der Regierungsbeauftragte Louis Emile Galey setzte sich stattdessen dafür ein, die französische Zensurkommission von Vichy nach Paris zu verlegen und bei seiner Dienststelle, dem Service du cinéma, eine Zensurabteilung einzurichten. Galeys Initiative hatte im Juli 1942 Erfolg. Er setzte ferner eine französische Vorzensur aller Filmvorhaben und fertigen Filme für das gesamte französische Gebiet durch ${ }^{557}$. Mit seiner Initiative hatte Galey nicht nur die Interessen der französischen Zensur sichern wollen, sondern er erhoffte sich durch diesen Umzug auch eine Minderung der stark moralisierenden Einflüsse der offiziellen Zensoren in Vichy558.

Die Konflikte zwischen deutscher und französischer Zensur entsprangen in vielen Fällen wirtschaftlichen Motiven. Im unbesetzten Gebiet verfolgte die Vichy-Regierung eine relativ strenge moralische Zensur. Im Juli 1941 bemerkte das Referat Film, die Filmzensurstelle in Vichy habe etliche französische Filme verboten, „die im besetzten Gebiet Frankreichs deswegen zugelassen worden waren, weil eine kulturelle Zensur der Filme nicht durchzuführen war “559. Probleme entstanden dagegen vor allem dann, wenn die Entscheidungen der Commission de censure die Interessen der Besatzungsmacht berührten. So verbot Vichy im Mai 1941 ausgerechnet die Herstellung des von der deutschen Continental produzierten Films "Le Club des soupirants“ in Marseille, weil es diesen für unmoralisch erachtete und der Meinung war, er liefere einen schlechten Eindruck von der französischen Gesellschaft ${ }^{560}$. Diedrich verlangte eine Zurücknahme des Verbotes, die wenig später auch erfolgte. Gegenüber der französischen Zensurstelle betonte er, „daß deutscherseits allein beurteilt werden könne, was unmoralisch sei, und ein Eingreifen seitens der französischen Regierung in die Frage der Herstellung eines deutschen Unternehmens nicht zugelassen werde" 561 . Die Filmprüfstelle übte in der Regel keine moralische Zensur aus und war im Mai 1941 auch nicht für das unbesetzte Gebiet zuständig. Wenn allerdings wie hier deutsche wirtschaftliche Interessen mit im Spiel waren, ging das Referat Film entschie-

556 Ibid. siehe auch Tätigkeitsbericht, 27. 3.-3. 4. 1941.

557 BA-MA, RW35 226, Gr.Film, Tätigkeitsbericht, 20. 6.-26. 6. 1942 und 18. 7.-24. 7. 1942; siehe auch BERTIN-MAGHIT, Le Cinéma sous l'Occupation, S. $100 \mathrm{f}$.

558 Ibid. S. 102.

559 BA-MA, RW35 222, Prop. Abt., Ref.Film, Tätigkeitsbericht, 25. 7.-31. 7. 1941.

560 BA-MA, RW35 221, Tätigkeitsbericht, 1.5.-7.5.1941.

561 Ibid. 
den gegen Zensurverbote der Commission de censure vor. Doch auch bei französischen Filmen, die für das besetze Gebiet zugelassen werden sollten, wurden Versuche der Vichy-Regierung, eine moralische oder künstlerische Zensur auszuüben, bis zur Einigung im Juli 1942 abgeschmettert. Beispielsweise bat im Februar 1941 Galey, der sich generell für eine gute Qualität der französischen Filme einsetzte, die Filmprüfstelle, den Film "Pension Jonas“ von Pierre Caron nicht zuzulassen. Galey begründete diese Bitte damit, daß er den Film für mißlungen halte. Seiner Meinung nach sollte mit diesem Verbot gegenüber den französischen Produktionsfirmen signalisiert werden, „daß auch die deutschen Behörden nicht geneigt sind, eine oberflächliche Arbeit anzuerkennen" 562 . Die Filmprüfstelle genehmigte den Film dennoch und betonte, ihr stehe eine Zensur hinsichtlich der Qualität der französischen Produktionen nicht zu. Zudem müßten dann auch andere nicht gelungene Filme verboten werden. Ähnlich wie im Bereich des Theaters waren die deutschen Dienststellen grundsätzlich an der Förderung qualitativ guter französischer Produktionen nicht interessiert. Ferner bestand die Besatzungsmacht zumindest bis zum Sommer 1942 im Bereich des Filmes weit mehr als im Bereich des Theaters auf die alleinige Zuständigkeit für die Zensur im besetzten Gebiet. Doch auch nach der Einigung auf eine französische Vorzensur war jene offenbar dann machtlos, wenn es sich um von der Continental produzierte Filme handelte.

Die unterschiedlich stark ausgeprägten Interessen im Bereich von Film und Theater zeigt das Beispiel des Stoffes von „La Machine à écrire“, das im Falle des Theaterstückes in einem Verbot geendet hatte. Clouzots „Le Corbeau", der im September 1943 in Paris uraufgeführt wurde, verarbeitete inhaltlich den gleichen Stoff. Ebenso wie das Theaterstück beanstandeten die französischen Zensoren den Film aus moralischen Gründen, weil er als Angriff auf Frankreich und auf den französischen Patriotismus galt. Doch Galey versuchte vergeblich, den Leiter der Continental, Greven, dazu zu bringen, den Film zumindest nicht zu exportieren ${ }^{563}$. Evelyn Ehrlich konstatiert zur Rezeption des Filmes während der Okkupation: "That the leftists in the Résistance should ally themselves with Vichy and the Church in condemnation of Le Corbeau is one of the many paradoxes of the occupation" 564 . Als eine Produktion der deutschen Continental wurde der Film aber freilich nicht verboten. Die Tatsache, daß deutsches Kapital mit französischer Filmproduktion verwoben war, führte dazu, daß die deutsche Filmzensur weit mehr als im Bereich des Theaters auf ihrer alleinigen Zuständigkeit bestand. Während den französischen Behörden eine Theaterzensur zugestanden wurde, die zwar nicht institutionalisiert war, aber trotzdem im besetzten Paris über die Einhaltung der guten Sitten und der öffentlichen Ordnung wachen

562 BA-MA, RW35 225, Gr.Film, Tätigkeitsbericht, 30. 1.-6. 2.1942.

563 EHRlich, Cinema of Paradox, S. 177.

564 Ibid. S. 178. 
konnte, war das bei der Filmzensur zumindest bis zum Sommer 1942 nicht der Fall.

Im März 1942 berichtete die Filmprüfstelle, Polizeipräfekturen und Bürgermeister hätten verschiedentlich Filme für Jugendliche verboten, die von der deutschen Zensur zugelassen worden waren. Diese Verbote waren auf eine Druckschrift der katholischen Kirche zurückzuführen, welche die Bürgermeister darauf hingewiesen hatte, „daß sie nach verschiedenen Gesetzen Filme verbieten könnten, die nach ihrer Ansicht gegen die öffentliche Ordnung oder die guten Sitten verstoßen"565. Die Filmprüfstelle betonte, daß dies nur für das unbesetzte Gebiet galt. Ausschließlich der MBF war mit der Verordnung über die Zulassung von Filmen zur öffentlichen Vorführung vom 9. September $1940 \mathrm{im}$ besetzten Gebiet zuständig. Von der Filmprüfstelle bereits zugelassene Filme durften nicht durch französische Staatsorgane wie Präfekturen und Bürgermeister nochmals zensiert werden. Nach Ansicht der Filmprüfstelle sollte die deutsche Seite deswegen sofort scharf protestieren und einschreiten ${ }^{566}$. Diese strikte Reaktion der Filmprüfstelle hatte ihren Ursprung in vorangegangenen Streitigkeiten mit der inoffiziellen Zensur der katholischen Kirche. Die Centrale catholique du cinéma et de la radio (CCCR) hatte Beurteilungen zu Filmen, welche die Noten von eins bis sechs erhielten, an Kirchentüren geheftet ${ }^{567}$. Im August 1941 berichtete das Referat Film, "Jud Süß" habe die Note „4 bis" erhalten, was soviel heiße wie "trotz schlechter Teile unschädlich bei vorheriger Warnung"568. In Paris brachte die CCCR statt der Beurteilungen durch Noten auch einfache Stellungnahmen an den Eingängen der Kirchen an. Der Kommentar zu „Jud Süß" lautete, „pas pour les jeunes filles“ 569 . Die Filmprüfstelle bezeichnete die Streitigkeiten zwischen deutscher und katholischer Zensur als „Kulturkampf ${ }^{\prime 570}$. Im September 1942 entschied die Filmprüfstelle, eine Zensur der CCCR zu dulden, falls diese in Zukunft ihre Filmbewertung ausschließlich im Sinne einer positiven Empfehlung von Filmen durchführe ${ }^{571}$. Dieser Kompromißvorschlag zeigt, daß es der Filmprüfstelle offenbar nicht gelungen ist, gegen die von der katholischen Kirche ausgeübte Zensur erfolgreich

565 Ibid. Schreiben des Kommandeurs Schmidtke an die Staffeln Angers und Dijon, in: Tätigkeitsbericht Nr. 10, 20. 3. 1942.

566 Ibid. Siehe auch BA-MA, RW35 224, Bericht der Prop.Abt., Ref. Film vom 10.11. 1941 über die „Filmzensur durch katholische Dienststellen“, an MBF, Verwaltungsstab, Abt. Verwaltung, abgedruckt in: Prop. Abt., Ref.Film, Tätigkeitsbericht, 14. 11.-21. 11. 1941.

567 Ibid. Schreiben des Kommandeurs Schmidtke an die Staffeln Angers und Dijon, in: Tätigkeitsbericht Nr. 10, 20. 3. 1942. Siehe auch SicliER, La France de Pétain, S. 445457; Thalmann, La Mise au pas, S. 188-191.

568 BA-MA, RW35 222, Pop.Abt., Ref.Film, Tätigkeitsbericht, 1. 8.-7. 8. 1941.

569 Ibid. Tätigkeitsbericht, 8. 8.-15. 8. 1941.

570 BA-MA, RW35 227, Filmprüfstelle, Tätigkeitsbericht, 13. 9.-19. 9. 1942.

571 Ibid. 
vorzugehen. Allerdings ist es fraglich, wie stark das Publikum tatsächlich von den Beurteilungen an den Kirchentüren beeinflußt wurde ${ }^{572}$.

Ein weiterer Streitpunkt zwischen deutscher und französischer Filmzensur war die unbeschränkte Einfuhr deutscher Filme in die unbesetzte Zone. Im Dezember 1941 verbot die Zensur in Vichy drei deutsche Filme. „Bel ami“" wurde für das unbesetzte Gebiet verboten, weil der Film, der auf einer Novelle von Guy de Maupassant basierte, für den Geschmack der Vichy-Regierung eine zu frivole Darstellung des französischen Verführers lieferte. Für das Gebiet Nordafrikas verbot Vichy den anti-jüdischen Film "Jud Süss" und die anti-englische Produktion „Ohm Krüger“. Die deutsche Zensur reagierte ihrerseits im besetzten Gebiet mit einem Verbot für „La Fille du puisatier" (1940) von Marcel Pagnol und „L'Étrange Suzy“ (Pierre-Jean Ducis, 1941); beide waren im unbesetzten Gebiet produziert worden ${ }^{573}$. Das Referat Film berichtete, die französische Regierung habe es vorher nicht über das Verbot informiert. Das Verhalten gegenüber den deutschen Filmen müsse dazu führen, zukünftig in bezug auf die französischen Wünsche bei der $\mathrm{Zu}-$ lassung und Herstellung französischer Filme Zurückhaltung zu üben ${ }^{574}$. So ließ die Filmprüfstelle „La Venus aveugle“ (1940) von Abel Gance für das besetzte Gebiet nicht zu, obwohl der Zensurentscheid eigentlich positiv ausgefallen war. Zu einer Beendigung der Streitigkeiten um den Film „Bel ami“ kam es erst im Juli 1942 durch den Vorschlag Galeys, die Filmprüfstelle solle eine erneute formelle Zensur durchführen und kleinere Schnitte vornehmen. Im Gegenzug sollten „La Fille du puisatier“ und „L'Étrange Suzy“ für das besetzte Gebiet zugelassen werden ${ }^{575}$. Die Filmprüfstelle nahm den Kompromißvorschlag wenig später $a^{576}$. Angesichts der so unterschiedlich gelagerten Zensur von Besatzungsmacht und Vichy-Regierung stellt sich die Frage, welche Filme und Theaterstücke unter diesen Bedingungen entstanden. Gab es innerhalb des vor allem von der Besatzungsmacht gesteckten Rahmens für die Künstler Möglichkeiten zu politischen Anspielungen in Theaterstücken und Filmen?

\subsection{Zu politischen Anspielungen in Theaterstücken und Filmen}

Die Ausführungen zu deutschen Zensurverboten haben deutlich gemacht, daß französische Theaterstücke und Filme in den Augen der Besatzer mög-

572 BA-MA, RW35 223, Ref.Film, Tätigkeitsbericht, 22. 8.-29. 8. 1941; in diesem Bericht heißt es beispielsweise: „Es zeigt sich jedoch, daß bei der vorgenommenen Zensur mit schlechten Noten die Filmtheater später vollkommen ausverkauft waren".

573 BA-MA, RW35 224, Tätigkeitsbericht, 20. 12. 1941-2. 1. 1942.

574 Ibid.

575 BA-MA, RW35 226, Gr.Film, Tätigkeitsbericht, 3. 7. 1942. Wenig später wurde dieser Vorschlag Galeys verwirklicht; siehe dazu den Tätigkeitsbericht 25.7.31. 7. 1942.

576 Ibid. Gr.Film, Tätigkeitsbericht 25. 7.-31. 7. 1942. 
lichst kein Vehikel politischer Propaganda sein durften. So prüften die Zensoren auch Anspielungen kritisch, die auf eine deutsch-französische Kollaboration abzielten, weil sie negative Reaktionen des Publikums befürchteten. Die Erhaltung der öffentlichen Ruhe und Ordnung war hier für die Besatzungsmacht von primärer Bedeutung. Nach Ende der Besatzungszeit hat sich innerhalb der französischen Öffentlichkeit das Bild eines Theaters der Résistance entwickelt, nach dem einige im besetzten Paris uraufgeführte Theaterstücke als pièces résistantes dem Publikum versteckte politische Anspielungen vermittelt haben sollen. Dies ist bis heute ein umstrittenes Thema ${ }^{577}$. Im Bereich des Filmes ist ebenfalls für einige Filme eine attitude de résistance festgestellt worden ${ }^{578}$. Die Frage nach den pièces résistantes, films résistants oder dem Mythos eines Résistance-Theaters läßt sich letztlich, wie Untersuchungen in diesem Bereich zeigen, nicht eindeutig klären; deshalb wird der Stand der Diskussion sowie die Haltung der deutschen Zensoren hier nur kurz referiert ${ }^{579}$. Ferner ist nach einzelnen politischen Anspielungen auf verbotene oder den Besatzern wenig genehme Sujets in den Filmen und Theaterstücken zu fragen ${ }^{580}$.

577 ADDED, Le Théâtre, S. 254-273.

578 BERTIN-MAGHIT, Le Cinéma sous l'Occupation, S. $144 \mathrm{f}$.

579 Die Sekundärliteratur liefert keine inhaltlichen Analysen zu den Theaterstücken, die unter der deutschen Besatzung in Paris gespielt worden sind. Bisher waren vor allem Werke, die als Résistance-Stücke bezeichnet worden sind, Gegenstand von Analysen. Siehe beispielsweise folgende Studien: FLÜGGE, Verweigerung, zur „Antigone“ von Anouilh; GALSTER, Le Thêâtre, zu „Les Mouches" und „Huis Clos" von Sartre; ADDED, Le Théâtre, S. 254-273 zu allen genannten Stücken; auf S. 262-273 bei Added findet sich ferner eine Analyse zu Claude Vermorels "Jeanne avec nous", das ebenfalls als Résistance-Stück bezeichnet wurde; siehe ferner Volker RolofF, Zur Ambiguität des Mythos in Theaterstücken der Okkupationszeit, in: Wolfgang DrOST u.a. (Hg.), Paris sous l'occupation. Paris unter deutscher Besatzung, Heidelberg 1995, S. 94-106. Die Pariser Spielpläne der Besatzungszeit sind in ihrer Gesamtheit wohl nicht zuletzt auch aufgrund der schwierigen Rekonstruktion von Inszenierungen noch nicht analysiert worden. Anders verhält es sich mit den Filmen der Besatzungszeit. Eine umfassende Analyse hat François Garçon in seiner bereits genannten Studie geliefert, in der er auch Filme der Vorkriegszeit mit untersucht (GARÇON, De Blum).

580 Politische Anspielungen in Theaterstücken und Filmen konnten sich freilich nicht nur auf die Besatzer, sondern auch auf das Vichy-Regime beziehen. So lassen sich beispielsweise unter den Filmen der Okkupation auch solche finden, die von Vichy als Angriff auf die Ideen und Werte der Révolution nationale, sowie auf ihre Vorstellungen von „Familie, Arbeit, Vaterland“, aufgefaßt wurden. Ferner hat Garçons Untersuchung ergeben, daß diese Themen schon in den Filmen der Vorkriegszeit auftauchen und während der Okkupation in stärkerem Umfang weiterhin vorhanden sind. Die Filmproduktion unter deutscher Besatzung war demnach auch Träger der Ideen des Vichy-Regimes (GarÇON, De Blum, S. 196). Für das Theater konstatiert Added, daß die Theaterstücke durchaus von diesen Ideen beeinflußt waren, doch habe das Theater nicht als Vehikel für politische Aussagen im Sinne der Ideologie Vichys gedient (ADDED, Le Théâtre, S. 290). Der Einfluß Vichys auf die Inhalte der Filme und Theaterstücke soll im folgenden jedoch nicht näher erläutert werden. 
Eine Untersuchung der Frage, ob Theaterstücke versteckte, vom Autor beabsichtigte politische Anspielungen enthielten, welche die Zuschauer zudem verstanden, ist aus mehreren Gründen problematisch. So läßt sich die Rezeption der Werke beim Publikum im allgemeinen nur noch schwer nachvollziehen ${ }^{581}$. Auch ist die Intention von Autoren und Regisseuren nicht immer klar zu erkennen. Ein wesentliches Merkmal von Theaterstücken und Filmen ist gerade die Möglichkeit der unterschiedlichen Interpretation. Für das Theater besteht außerdem noch das methodische Problem einer nachträglichen Rekonstruktion der Inszenierung. Die Problematik einer politischen Interpretation der Werke zeigt das Beispiel des Theaterstücks "Antigone" von Jean Anouilh, das im Februar 1944 im Pariser Théâtre de l'Atelier uraufgeführt wurde. Die offizielle Presse legte Anouilhs „Antigone“ kollaborationistisch aus und die Résistance-Presse war gegen das Stück eingestellt. Erst nach der Libération wurde es zu einem Résistance-Stück stilisiert ${ }^{582}$. Jean Davy, der sowohl bei der Uraufführung im Februar 1944 als auch später im befreiten Paris die Rolle des Tyrannen Créon spielte meint hierzu:

Il est évident que lorsque nous jouions la pièce sous l'Occupation, les Allemands voyaient dans le personnage de Créon l'autoritarisme, le tyran, l'homme qui faisait régner l'ordre, qui faisait respecter la loi [...] Et puis les résistants, qu'est ce qu'ils voyaient? Ils voyaient Antigone qui résistait contre le pouvoir, contre l'Occupation en réalité [...] Qu'est ce que c'est Antigone ${ }^{583}$ ?

Das Theaterreferat berichtete allerdings im Mai 1944 von der "Antigone“ Anouilhs im Zusammenhang mit anderen Antigone-Aufführungen: "Als symptomatisch für die den Krieg ablehnende Haltung der Franzosen ist das Auftauchen des Antigone-Stoffes in verschiedener Gestalt"584. Studenten der Sorbonne, so der Referent, hätten als Privataufführung die Antigone des "Sophokles" gespielt. Zudem hatte die Opéra Comique "Antigone“ mit der Musik von Arthur Honegger nach dem Text Jean Cocteaus gezeigt. Anouilh feierte mit seiner „Antigone“ am Thêâtre de l'Atelier große Erfolge und das Thêâtre Charles de Rochefort brachte die "Antigone" von 1588 von Robert Gernier heraus. Das Theaterreferat sah die Antigone-Aufführungen als Ausdruck eines französischen Pazifismus und nahm dies nicht zum Anlaß, durch ein Zensurverbot einzuschreiten.

Problematisch ist auch die Frage, ob die im besetzten Paris uraufgeführten Werke von Sartre als Résistance-Stücke zu sehen sind. Nach den Intentionen des Autors enthielt „Les Mouches“ (1943) einen versteckten Widerstand gegen die Besatzungsmacht. Diese politische Botschaft verstand jedoch nur eine kleine Gruppe von Intellektuellen, die den Text kannte und mit der Philosophie Sartres vertraut war. Sowohl den Pariser Kritikern als auch einem

581 Siehe dazu ADDED, L'Euphorie théâtrale, S. 315-350.

582 FLÜGGE, Verweigerung, S. 271-330.

583 Interview mit dem Schauspieler Jean Davy, 24. 6. 1992, Paris.

584 AN, AJ40 1001-7, Prop.Abt., Gr.Kult.Th., Bericht über den Monat Mai 1944. 
Großteil des Publikums blieb der Widerstand zwischen den Zeilen verschlossen. Ingrid Galster betont in ihrer Analyse des Stückes, allein aufgrund der Intention Sartres sei es als Résistance-Stück zu sehen ${ }^{585}$. Added hat jedoch zu recht mit dem Hinweis auf die Rezeption von "Les Mouches" während der Okkupation betont, daß allein die Absicht Sartres für die Bezeichnung pièce résistante nicht ausreichend sei ${ }^{586}$. Laut Galster ist dagegen „Huis Clos“ (1944) von Sartre nicht mit der Intention eines Widerstandes zwischen den Zeilen verfaßt worden; das Publikum soll aber zur Besatzungszeit gerade dieses Stück als pièce résistante aufgefaßt haben ${ }^{587}$. In den Akten des Theaterreferats heißt es zu „Huis Clos" im Juni und Juli 1944 lediglich, mit der Aufführung des Stückes im Théâtre Vieux Colombier feiere Sartre einen großen literarischen Erfolg ${ }^{588}$. In einem anderen Bericht des Referats wird ebenfalls vor allem betont, Sartres Werk behaupte sich als literarisch wertvoll; ähnlich verhalte es sich mit "Le Malentendu“ von Albert Camus im Théâtre des Mathurins, ein Stück „von tief pessimistischer Grundhaltung “589. Demnach wurde „Huis Clos“ von deutscher Seite nicht im Sinne eines politischen Widerstandes gedeutet und sogar gelobt. Wie Added bemerkt hat, entwickelte sich nach Ende der Besatzungszeit in der französischen Öffentlichkeit ein spezifisches Bild vom Theaterleben der Besatzungszeit. Hier paarten sich Vorstellungen von unbeholfenen deutschen Zensoren, die den versteckten politischen Gehalt der Résistance-Stücke nicht erkannt hatten, mit dem Bild eines subtilen französischen Publikums, das die übermittelten Anspielungen leicht erkannte ${ }^{590}$. Sowohl von Galster als auch von Added ist diese These einer unfähigen deutschen Zensur bereits widerlegt worden ${ }^{591}$. Die Berichte der Theaterreferenten zeigen, daß es sich hier durchaus um Spezialisten ihres Gebietes handelte, die der französischen Sprache mächtig waren. Ferner ist es rückblickend, wie Added zudem bemerkt, wenig einsehbar, wie die Masse des französischen Publikums ein Theaterstück klar als pièce résistante habe einschätzen können, während dies den Besatzern und auch den französischen Kollaborateuren völlig entgangen sein soll ${ }^{592}$.

Als Begründung für die relativ milde Handhabung der Zensur, die teilweise politische Anspielungen zuließ, sind ferner auch persönliche Sympathien der deutschen Referenten angeführt worden. So hat beispielsweise der

585 GalsTER, Le Théâtre, S. 179f., 186-192; siehe auch Ingrid GalSTER, Les Mouches, pièce résistante?, in: Lendemains 42 (1986) S. 43-53.

586 ADDED, Le Théâtre, S. 261. Ebenso kommt er für das Stück "Jeanne avec nous" von Claude Vermorel, das im August 1942 aufgeführt und nach der Libération zum théâtre résistant gezählt wurde, zu dem Schluß, man könne es auf keinen Fall als RésistanceStück bezeichnen (S. 272).

587 GALSTER, Le Théâtre, S. 240, 243.

588 AN, AJ40 1001-7, Prop.Abt., G.Kult.Th., Bericht über den Monat Juni 1944.

589 Ibid. Bericht über den Monat Juli 1944.

590 ADDED, Le Théâtre, S. 255.

591 GALSTER, Le Théâtre, S. 79; ADDED, Le Théâtre, S. 255.

592 Ibid. 
für die Literaturzensur zuständige Gerhard Heller, wie in der Einleitung erwähnt, behauptet, er habe sich für Sartres „Les Mouches“ und Anouilhs "Antigone“ eingesetzt, was jedoch sehr fragwürdig ist ${ }^{593}$. Von den Spekulationen über persönliche Sympathien der zuständigen Referenten einmal abgesehen, kann zumindest gesagt werden, daß diese gerade den literarischen Theaterstücken des Pariser Spielplans relativ positiv gegenüberstanden ${ }^{594}$. Im Gegensatz dazu äußerten sich die Theaterreferenten häufig abschätzig über die zahlreichen Boulevardstücke der Pariser Spielpläne ${ }^{595}$. Aus Prestigegründen begrüßte die Besatzungsmacht, daß im besetzten Paris Stücke von Anouilh, Claudel, Giraudoux, Sartre und Camus gespielt wurden. Wenn dies als ein „Zeichen der Überlegenheit und Großzügigkeit der überwachenden Zensur" 596 gesehen wurde, so paßte es genau in das Bild einer vorgeblich milden Kulturpolitik, welches die Besatzer der Öffentlichkeit vermitteln wollten. Es sollte demonstriert werden, daß trotz der sich verschlechternden materiellen Lage im besetzten Paris die französische Kultur sich auf einem hohen Niveau befinde, weil die Besatzungsmacht so tolerant sei. Das Gros der aufgeführten Werke vermittelte keine Gedanken des Widerstands. So ist das théâtre résistant im besetzten Paris eher als Mythos als eine Realität zu sehen. Obwohl diese Frage umstritten bleibt, lassen sich einige wenige Theaterstücke durchaus als pièces résistantes sehen ${ }^{597}$.

Auch Theaterstücke, die für die Kollaboration Stellung bezogen, prüfte die Besatzungsmacht kritisch. Im September 1942 bezeichnete Theaterreferent Frank die Wiederaufnahme des Stückes „La Captive“ im Théâtre de l'Odéon, das von Charles Méré während des Ersten Weltkriegs geschrieben worden war, als politisch nicht interessant: „Die damals ausgesprochen pazifistische Tendenz wird jetzt collaborationistisch ausgelegt: Zwei Brüder, die unter den Fahnen verschiedener Länder gekämpft haben, finden unter dem

593 GALSTER, Le Théâtre, S. 84f. Laut Erinnerungen von Zeitzeugen soll ferner ein für die Theaterzensur zuständiger Referent gegen den Nationalsozialismus eingestellt gewesen sein und ein Verhältnis mit einer französischen Schauspielerin gehabt haben, womit rückblickend eine in Einzelfällen mildere Zensur begründet worden ist. Genannt wird hier der Name Rademachers, der sich in den Akten des Referats allerdings nicht finden läßt. Jener Referent soll später dann zur Ostfront versetzt worden sein, was beispielsweise auch auf Frank zutrifft, der im Juni 1943 das Theaterreferat verlassen mußte. Zu dieser Version der Begründung einer milden Zensur, siehe GALSTER, Le Théâtre, S. $79 \mathrm{f}$.

594 Dies haben die obigen Zitate zu den Stücken Sartres, Anouilhs und Camus gezeigt. Übrigens erhielt auch „Eyridice“ von Anouilh eine gute Kritik durch den Theaterreferenten; siehe den Tätigkeitsbericht des Theaterreferats vom 27.12. 1941.

595 AN, AJ40 1001-7, Prop.Abt., Gr.Kult.Th., siehe beispielsweise die Tätigkeitsberichte vom 30. 12. 1942, 30. 10. 1942 und den Bericht über den Monat April 1942.

596 Ibid. Bericht über den Monat Dezember 1943; siehe die oben bereits zitierte Beurteilung zu Claudels "Soulier de satin“.

597 Siehe ADDED, Le Thêâtre, das Kapitel „Théâtre résistant“: mythe ou réalité? S. 253273. 
Einfluß ihrer Mutter wieder zueinander"598. Obwohl Frank die Geschichte hier nicht als pazifistisch deutet, war diese Interpretation den Zuschauern rein theoretisch durchaus möglich. Nach Frank war "La Captive“ im Sinne einer deutsch-französischen Kollaboration zu deuten. Ein anderes Stück, "Les Pirates de Paris" von Alain Laubreaux, Kritiker des Je suis Partout, der hier unter dem Pseudonym Michel Daxiat arbeitete, wurde im März 1942 bei der Wiedereröffnung des Theaters Ambigu aufgeführt. Dieses Stück über die sogenannte Affäre Stavisky, das sich über die Politiker der Troisième République mokierte, wurde ausgerechnet zur Zeit des Riom Prozesses gespielt ${ }^{599}$. Vor der Aufführung hatte das Theaterreferat de Brinon um seine Stellungnahme gebeten, weil in dem Werk von Laubreaux auch lebende Personen eine Rolle spielten: „De Brinon erklärte unumwunden seine Zustimmung, und zwar mit dem Hinweis, daß er, während sich vor aller Öffentlichkeit der Prozeß von Riom abspiele, keine Veranlassung sehe, Franzosen, die in jene Schieberaffaire verwickelt waren, zu schonen" 600 . Nach Besuch der Premiere verfaßte Theaterreferent Frank eine vernichtende Kritik zu diesem Stück ${ }^{601}$. Wie die Einnahme-Register des Theaters bei der Société des auteurs et compositeurs d'art dramatique (SACD) zeigen, war das Stück allgemein ein Mißerfolg. Anders als vorgesehen wurde es nur einen Monat lang gespielt ${ }^{602}$. Die wenigen Theaterstücke, die für eine deutsch-französische Kollaboration plädierten oder politische Tendenzen im Sinne der Révolution nationale aufwiesen, waren also relativ erfolglos; zudem prüfte und bewertete die deutsche Zensur sie sehr streng. Auch Theaterstücke mit anti-englischer oder anti-jüdischer Tendenz waren eine Seltenheit ${ }^{603}$.

Im Bereich des Filmes war dies ähnlich. Wie Bertin-Maghit betont hat, waren allein drei Spielfilme der französischen Produktion der Besatzungszeit als Filme der Kollaboration zu sehen ${ }^{604}$. Bei diesen Filmen handelte es sich um „Mermoz" (1943) von Louis Cuny, "Coup de tête" (1943) von René Le Hénaff und „Le Carrefour des enfants perdus“ (1943) von Léo Joannon. Ferner hat die Untersuchung Garçons ergeben, daß die Filme der Okkupation kaum anti-englische oder antisemitische Tendenzen aufwiesen, obwohl dies bei den Filmen der Vorkriegszeit der Fall war. Sujets, die sich gegen Deutsche oder Deutschland richteten, verschwanden ebenfalls mit Beginn der Okkupation aus der Filmproduktion. Stattdessen tauchten aber nicht etwa deutschfreundliche Tendenzen auf605. Das Gros der französischen Filme nahm weder für noch gegen Deutschland Stellung, doch gab es einige, deren

598 AN, AJ40 1001-7, Prop.Abt., Gr.Kult.Th., Tätigkeitsbericht, 30. 9. 1942.

599 ADDED, Le Théâtre, S. 318 f. ThalmanN, La Mise au pas, S. 182.

600 AN, AJ40 1001-7, Prop.St., Gr.Kult.Th., Tätigkeitsbericht, 27. 2. 1942.

601 Ibid. Tärigkeitsbericht, 12. 3. 1942.

602 ADDED, Le Théâtre, S. $318 \mathrm{f}$.

603 Ibid. S. 289.

604 BerTiN-MAGHIT, Le Cinéma sous l'Occupation, S. 145.

605 GARÇON, De Blum, S. 152, 165-184. 
Inhalte als politische Anspielung auf die Situation der Besatzung verstanden worden sind. Ein Beispiel dafür ist "Les Visiteurs du soir" von Marcel Carné aus dem Jahre 1942 mit Arletty und Alain Cuny in den Hauptrollen. Cuny ist nicht der Meinung, daß der Erfolg des Filmes auf einer möglichen Interpretation desselben im Sinne eines Widerstandes gegen die Besatzer gründete:

Je ne crois pas que le succès des „Visiteurs du soir “ était dû au fait que le contenu de ce film aurait pu être un encouragement pour les Français occupés à résister à l'occupant, à l'envahisseur et que donc malgré la puissance du diable dans les "Visiteurs du soir“, le diable et l'enfer étant, si vous voulez donc, symboliquement dans l'esprit des Français mais je ne crois pas que c'est ce qui s'est passé - l'Allemagne Hitlérienne et que bien que les amants qui s'aiment dans les „Visiteurs du soir“ meurent, ils ne meurent que dans leur temporalité, ils ne meurent que dans leur fraction humaine, leur cœur éternel continue à battre, donc la France malgré tout ce qu'elle subit à ce moment là, restera éternelle. On peut dire ça. Je ne crois pas que c'est ce qui s'est passé, non ${ }^{606}$.

Ähnlich wurde der Film „La Main du Diable“ von Maurice Tourneur mit Pierre Fresnay, der 1942 von der Continental gedreht wurde, aufgefaßt $\mathrm{t}^{607}$. Für Anspielungen auf die aktuelle politische Situation lassen sich weitere Beispiele finden, die offenbar nicht von der Zensur verboten wurden. In einer der ersten Szenen des Filmes „Donne-moi tes yeux“ (1943) von Sacha Guitry, besucht der Bildhauer François Bressoles (Guitry) eine Vernissage im Palais de Tokyo. Eine Sonderausstellung zeigt dort zudem Bilder von Cézanne, Courbet, Renoir und Daumier. Bressoles zeigt sie einem Freund:

Bressoles: Ils sont d'une espèce particulière, parce que tous les chefs d'œuvre que tu regardes en ce moment [...] ont été faits en 1871 [...] Voilà ce que faisaient les hommes de génie à l'heure ou nous venions de perdre la guerre [...] Eh bien, dis moi, quelle impression as-tu en regardant ces merveilles?

Freund: L'impression que ce que l'on perdait d'un côté, on le regagnait de l'autre.

Bressoles: Voilà, et entre nous on a le droit de considérer [...] que des œuvres pareilles ça tient lieu de la victoire [...]

Freund: 1943, ça continue.

Bressoles: Oui, oui la France continue ${ }^{608}$.

Guitry macht hier sehr deutliche Anspielungen auf die Lage Frankreichs; eine französische militärische Niederlage sei 1871 durch die wunderbaren Werke der Maler mit künstlerischen Siegen einhergegangen und auch im Jahre 1943 dürfe dies nicht anders sein. Das Argument, die Franzosen hätten bei einer militärischen Niederlage wenigstens im kulturellen Bereich nicht geschlagen geben müssen, ist auch nach der Besatzungszeit zu einer Rechtfertigung der Künstler, die auch im besetzten Paris weiterhin aktiv waren, angeführt worden. In dem genannten Film Guitrys finden sich abgesehen vom obigen Dialog noch weitere Szenen, die auf den Alltag im besetzten Paris an-

606 Interview mit Alain Cuny, 30. 4. 1992; siehe dazu auch EHrLICH, Cinema of Paradox, S. 53.

607 Ibid. S. 52.

608 Siehe FDI, VDP847. 
spielen ${ }^{609}$. Die Darstellung französischer Genies ist in den zur Zeit der Besatzung gedrehten Filmen kein Einzelfall. Die Untersuchung Garçons hat ergeben, daß die Filme der Okkupation häufig auf berühmte französische Persönlichkeiten Bezug nehmen ${ }^{610}$. „La Symphonie fantastique“ (1941) von Christian-Jacque, ein Continental-Film, feiert den Komponisten Berlioz. Goebbels war darüber empört, daß diese "nationale Fanfare erster Klasse"611 ausgerechnet von der Continental hergestellt worden war.

Trotz dieser Ansicht von Goebbels bestand ein relativ großer Spielraum für nationalistisch geprägte französische Filmproduktionen. Nationalistische Filme, beispielsweise zu französischer Literatur, Musik und Kunst, zur nationalen Luftfahrt und zu Bonaparte hatten in der Filmproduktion der Okkupation ihren Platz ${ }^{612}$. Hierbei haben die Produzenten offenbar durch eine Selbstzensur zum Teil solche Themen modifiziert dargestellt. So findet man Bonaparte, der in Filmen vor 1940 ganz klar als Symbol des Kriegsherrn erschien $^{613}$, während der Besatzungszeit in privatisierter Form wieder. Garçon konstatiert hierzu: „Rendu à la vie civile, le Napoléon de l'Occupation est ainsi éclairé sous l'angle de la vie quotidienne, entouré de femmes lascives; c'est un portrait de l'Empereur qui rejoint le cliché du Français séducteur irrésistible"614. Ein Wandel läßt sich auch für die Darstellung des 14. Juli als Nationalfeiertag feststellen. Dieses Sujet, das vor 1940 noch auf der Leinwand zu sehen war, fehlt in den Filmen der Okkupation fast völlig615. Die deutschen Zensoren haben durchaus erkannt, ob ein Film eine stark nationalistische Tendenz enthielt. So notierte die Filmprüfstelle im September 1941 zu dem Film „La Romance de Paris“ von Jean Boyer, einem Gesangsfilm mit Pariser Lokalkolorit mit dem bekannten Sänger Charles Trenet, folgendes:

Der Film versucht für Paris, sein Nachtleben, seine Frauen, seine Mode usw. Propaganda zu machen, demgemäß sind auch die Lieder [...] größtenteils als Pariser Lieder gedichtet und komponiert. Der amerikanische Einfluß ist hierbei, wie bei den meisten Liedern von Trenet, unverkennbar. [...] Der Film ist politisch unbedenklich. Selbst die erwähnte Werbung für das traditionelle Paris der Revuen usw. dürfte kaum unverträglich sein. Bedenklich dagegen erscheint der Film für Luxemburg, Elsaß, Lothringen,

609 Beispielsweise verpaßt Bressoles in einer anderen Szene die letzte Metro und begegnet auf dem Heimweg im Dunkeln einem Fremden, den er bittet, ihn mit der Taschenlampe zu begleiten. Bressoles fragt den Fremden, was er von den Geschehnissen heutzutage halte, worauf jener kaum reagiert. Stattdessen bietet ihm der Fremde Zucker für 200 Francs pro Kilo an (FDI, VDP 847).

610 GARÇON, De Blum, S. 104-133.

611 LOCHNER, Goebbels Tagebücher, S. 201, Eintragung vom 15. Mai 1942.

612 Garçon, De Blum, S. 104-133.

613 Ibid. S. 112.

614 Ibid. S. 115; diesem Bild entspricht beispielsweise die Darstellung Bonapartes in „Madame sans gêne“ (FDI, VDP 4757).

615 GARÇON, De Blum, S. $109 \mathrm{f}$. 
Protektorat und das Generalgouvernement, woselbst eine derartige Werbung für die franz. Hauptstadt unerwünscht sein dürfte $\mathrm{e}^{616}$.

Der Film, der nach Meinung der Filmprüfstelle Propaganda für Paris machte und zudem noch amerikanische Einflüsse aufwies, wurde als „politisch unbedenklich“617 eingestuft. Ferner heißt es zu Guitrys „Le Destin fabuleux de Désirée Clary“ (1941): „Nach der politischen Seite engagiert Guitry Frankreich und die Franzosen ohne das deutsche Volk oder die Besatzungsarmee anzufechten" 618 . England spiele in der Handlung des Filmes eine unsympathische Rolle. Nach Meinung der Filmprüfstelle entsprach dies der aktuellen Position Englands.

Sowohl Aspekte des französischen Nationalismus als auch politische Anspielungen auf die Situation der Besatzung lassen sich also in den Filmen und Theaterstücken der Besatzungszeit finden. Die deutschen Zensoren beurteilten die während der Okkupation uraufgeführten anspruchsvollen Werke von Sartre und Anouilh positiv. Sie sollten der Öffentlichkeit vermitteln, wie intakt das französische Kulturleben unter einer besonders milden Kulturpolitik der Besatzungsmacht sei. Die wenigen Theaterstücke und Filme, die für eine Kollaboration Stellung bezogen, prüften und kritisierten die Zensoren dagegen relativ streng, weil sie Proteste und Unruhen im Publikum befürchteten. In den Ausführungen zur Zensur ist deutlich geworden, daß sich jene nach allgemein formulierten Grundsätzen richtete, die mehr oder weniger flexibel ausgelegt werden konnten. Die Handhabung der Zensurgrundsätze war neben der Weltkriegslage und der Stimmungslage in der französischen Bevölkerung auch davon abhängig, welche allgemeinen kulturpolitischen Ziele in der jeweiligen Situation von den Besatzern als primär wichtig angesehen wurden. Besonders zu Beginn der Besatzungszeit stand das kurzfristige kulturpolitische Ziel der Wiederbelebung und Aufrechterhaltung des französischen kulturellen Lebens im Vordergrund. Etwa seit Beginn des Jahres 1941 rückte das Ziel der Errichtung einer „kulturellen Hegemonie“ Deutschlands mehr und mehr in den Vordergrund; die deutsche Zensur, die nun im Dienste deutscher Kulturpropaganda stand, verschärfte sich. Trotzdem lassen sich bis zum Ende der Besatzungszeit fortwährend noch Belege für eine relativ milde Handhabung der Zensur aufgrund des erstgenannten Zieles finden. Die Erhaltung der öffentlichen Ruhe und Ordnung im besetzten Paris sollte durch ein blühendes kulturelles Leben unterstützt werden. Die Propaganda Abteilung war somit an einer finanziell gesunden französischen Filmindustrie sowie an florierenden Theatern interessiert. Unter dieser

616 BA-MA, RW35 223, Prop.Abt., Ref.Film, Bericht über das Ergebnis der am 26. 9. 1941 erfolgten Filmprüfung des Filmes „La Romance de Paris“ Fpf.Nr. 5154; siehe auch Film unter VDP 275.

617 Ibid.

618 BA-MA, RW35 226, Gr.Film, Bericht Nr. 42 über das Ergebnis der am 6. 7. 1942 erfolgten Prüfung des neuhergestellten franz. Spielfilmes „Le destin fabuleux de Désirée Clary“ Fpf. Nr. 6626. 
Prämisse konnten Zensurgrundsätze flexibel gehandhabt werden. Besonders gilt dies für den Bereich des Filmes, wo generell wirtschaftliche Interessen eine weit größere Rolle als beim Theater spielen.

Dies ist auch mit ein Grund dafür, daß die Prüfung und Zulassung der Filme weit mehr als die Theaterzensur Objekt der Streitigkeiten zwischen deutscher und französischer Zensur war. Außerdem sah sowohl die deutsche als auch die französische Seite im Film, der ein zahlenmäßig größeres Publikum als das Theater erreicht, ein wertvolles Propagandainstrument. Im Gegensatz zur rein politischen Zensur der Besatzungsmacht, verfolgte die $\mathrm{V}_{\mathrm{l}}$ chy-Regierung nach Möglichkeit eine moralische und künstlerische Zensur der französischen Filme im Sinne der Werte der Révolution nationale. Die deutsche Zensur verbot hingegen Anspielungen auf die aktuelle politische $\mathrm{Si}$ tuation der Besatzung in Frankreich, zu starke Tendenzen von französischem Nationalismus und direkte Angriffe gegen Deutschland; dazu gehörte alles, was von den Zensoren als Widerstand gegen die Besatzungsmacht aufgefaßt wurde. Die Zensoren prüften ferner auch die wenigen Werke mit kollaborationistischer Tendenz eingehend und verboten diese, wenn sie Protestreaktionen des Publikums befürchteten. Aus demselben Grunde wurden auch deutsche Filme auf ihre sogenannte politische Verträglichkeit für Frankreich hin geprüft.

In den Augen der Besatzungsmacht sollten die französischen Theaterstücke und die französische Produktion von Spielfilmen grundsätzlich kein Instrument für eine politische Propaganda sein. Die Besatzer wollten diese nicht im Sinne nationalsozialistischer Vorstellungen von Kultur oder antijüdischer, anti-britischer oder anti-bolschewistischer Ideen beeinflussen. Gleichwohl schloß die deutsche Zensur Werke von jüdischen Autoren oder von Freimaurern ebenso aus wie Werke politischer Gegner oder von Angehörigen der sogenannten Feindstaaten. Hier ist eine fortwährende Verschärfung der Zensur im Rahmen der „Säuberung“ des Kulturlebens etwa seit Beginn des Jahres 1942 zu beobachten. Dagegen waren während der gesamten Zeit der Besatzung in Theaterstücken und Filmen auch politische Anspielungen, nationalistische Tendenzen und Themen, die als politischer Widerstand hätten aufgefaßt werden können, möglich.

Die Besatzungsmacht setzte die Verschärfung der Zensur auch als Druckmittel zur Durchsetzung deutscher Kulturpropaganda in Frankreich ein. Die verstärkte Zurückziehung älterer französischer Filme, diente auch dem Absatz deutscher Filme. Gerade hier verbanden sich rasseideologische und ökonomische Interessen mit den Zielen deutscher Kulturpropaganda. Auch im Bereich des Theaters setzten die Zensoren die französischen Theaterdirektoren unter Druck, indem sie verlangten, daß etwa vor der Aufführung eines Stückes von Shakespeare ein deutsches Stück gespielt werden mußte. Während die Zensur ein wesentliches Kontrollinstrument des französischen kulturellen Lebens darstellte, ging die deutsche Kulturpropaganda einen Schritt weiter. Die deutschen Dienststellen versuchten, Spielpläne und Filmpro- 
gramme dahingehend zu beeinflussen und zu lenken, daß deutsche Werke darin ihren festen Platz erhielten und die französischen zurückdrängten. Dem militärischen Sieg über Frankreich - und über ganz Europa - sollte ein geistiger Sieg folgen. Die Kulturpropaganda sollte hier eine Waffe sein, in einem sogenannten Kampf der Kulturen. 